\title{
KÁRIN SANTANA DE CARVALHO
}

\section{ALTERAÇÕES NA GLIA OBSERVADAS EM REGIÕES ENCEFÁLICAS ENVOLVIDAS NO CONTROLE RESPIRATÓRIO EM UM MODELO ANIMAL DA DOENÇA DE PARKINSON}

Dissertação apresentada ao Programa de Pós-Graduação em Farmacologia do Instituto de Ciências Biomédicas da Universidade de São Paulo, para obtenção do Título de Mestre em Ciências. 


\section{KÁRIN SANTANA DE CARVALHO}

\section{ALTERAÇÕES NA GLIA OBSERVADAS EM REGIÕES ENCEFÁLICAS ENVOLVIDAS NO CONTROLE RESPIRATÓRIO EM UM MODELO ANIMAL DA DOENÇA DE PARKINSON}

Dissertação apresentada ao Programa de Pós-Graduação em Farmacologia do Instituto de Ciências Biomédicas da Universidade de São Paulo, para obtenção do Título de Mestre em Ciências.

Área de concentração: Farmacologia

Orientadora: Profa. Dra. Ana Carolina Takakura

Versão corrigida. A versão original eletrônica, encontra-se disponível tanto na Biblioteca do ICB quanto na Biblioteca Digital de Teses e Dissertações da USP (BDTD). 


\section{CATALOGAÇÃO NA PUBLICAÇÃO (CIP) \\ Serviço de Biblioteca e informação Biomédica do Instituto de Ciências Biomédicas da Universidade de São Paulo}

Ficha Catalográfica elaborada pelo(a) autor(a)

Carvalho, Kárin Santana de

Alterações na glia observadas em regiões encefálicas envolvidas no controle respiratório em um modelo animal da doença de Parkinson / Kárin Santana de Carvalho; orientador Profa. Dra. Ana Carolina Takakura; coorientador Prof. Dr. Thiago Moreira. -- São Paulo, 2017.

$87 \mathrm{p}$.

Dissertação (Mestrado) ) -- Universidade de São Paulo, Instituto de Ciências Biomédicas.

1. Doença de Parkinson. 2. 6-OHDA. 3. Astrócitos. 4. Microglia. 5. Respiração. I. Takakura, Profa. Dra. Ana Carolina, orientador. II. Moreira, Prof. Dr. Thiago, coorientador. III. Título. 


\section{UNIVERSIDADE DE SÃO PAULO INSTITUTO DE CIÊNCIAS BIOMÉDICAS}

Candidata: Kárin Santana de Carvalho

Titulo da Dissertação: Alterações na glia observadas em regiões encefálicas envolvidas no controle respiratório em um modelo animal da doença de Parkinson.

Orientador: Profa. Dra. Ana Carolina Takakura.

A Comissão Julgadora dos trabalhos de Defesa da Dissertação de Mestrado, em sessão publica realizada a , considerou a candidata:

( ) Aprovada ( ) Reprovada

Examinador(a):

Assinatura:

Nome:

Instituição:

Examinador(a):

Assinatura:

Nome:

Instituição:

Examinador(a):

Assinatura:

Nome:

Instituição:

Presidente: Assinatura:

Nome:

Instituição: 


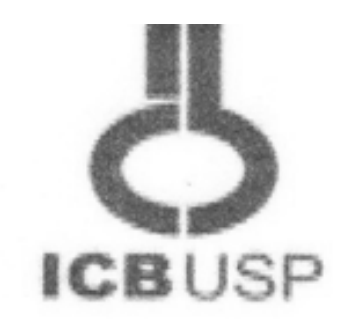

Cidade Universitária "Armando de Salles Oliveira", Butantă, Săo Paulo, SP. Av. Professor Lineu Prestes, 2415 - ICB III - 05508000 Comissăo de Ética no Uso de Animais - Telefone (11) 3091-7733 - e-mail: cep@icb.usp.br

Decl. CEUA.047/2015

\author{
D E C L A R A Ç Ã 0
}

Em adendo ao Certificado 104/14/CEUA, datado de 06/10/2014, e por solicitação da Profa. Dra. Ana Carolina Takakura, responsável pela linha de Pesquisa, autorizo a inclusão da aluna Kárin Santana de Carvalho ao Projeto de Pesquisa "Análise da ativação seletiva de neurônios bulbares em modelo experimental para Doença de Parkinson: um estudo temporal dos possiveis mecanismos para restauração da função respiratória", uma vez que se trata de utilização da mesma espécie animal e de métodos experimentais similares ao Projeto.

São Paulo, 19 de junho de 2015.

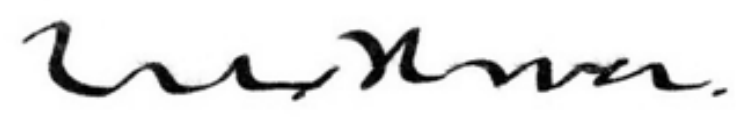

Prof. Dr. Wothan Tavares de Lima

Coordenador da CEUA-ICB/USP 


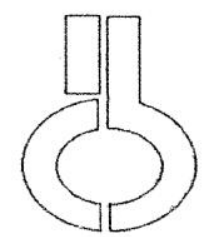

\section{CERTIFICADO}

Certificamos que o protocolo registrado sob $n^{\circ} 104$ nas fls. 23 do livro 03 para uso de animais em experimentação, sob a responsabilidade do Prof(a) Dr(a) Ana Carolina Thomaz Takakura, Coordenador (a) da Linha de pesquisa "Análise da ativação seletiva de neurônios bulbares em modelo experimental para Doença de Parkinson: um estudo temporal dos possíveis mecanismos para restauração da função respiratória" do qual participam o(s) aluno(s) Silvio de Araújo Fernandes Junior, Credenciado PG Thiago S. Moreira está de acordo com os Princípios Éticos de Experimentação Animal adotado pela Soçiedade Brasileira de Ciência de Animais de Laboratório (SBCAL) e foi aprovado pela COMISSÃO DE ÉTICA NO USO DE ANIMAIS (CEUA) em 06.10.2014, com validade de 4 anos.

São Paulo, 07 de outubro de 2014.

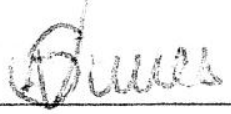

Prof. Dr. ANDERSON DE SÁ NUNES Vice- Coordenador- CEUA- ICB/USP

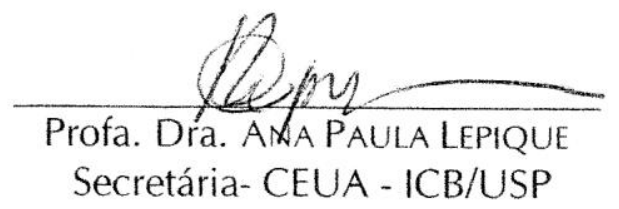


Ao meu filho José Lucas. Meu presente de Deus, que me ensinou $o$ significado do amor incondicional, me motivou e me deu forças pra lutar e seguir em frente. 


\section{AGRADECIMENTOS}

Agradeço a minha orientadora Profa. Dra. Ana Carolina Takakura que se fez presente em cada etapa para realização deste trabalho, partilhou comigo suas idéias, conhecimentos e experiências. Agradeço pelo apoio incondicional prestado e pela forma extraordinária que me conduziu até este momento. Suas críticas construtivas, conversas, paciência foram fundamentais ao longo deste percurso. Com todo meu respeito, carinho e admiração, serei eternamente grata.

Ao Prof. Dr. Thiago dos Santos Moreira, meu coorientador por ter me aceitado inicialmente como orientanda e gentilmente permitiu minha mudança para o Departamento de Farmacologia. Permaneceu ao meu lado durante todo este período. Agradeço imensamente pela oportunidade, atenção, ensinamentos e confiança.

Ao meu marido José Leandro que suportou minhas crises, angustias, medos, sempre me apoiando, me incentivando, reestabelecendo meu equilíbrio em momentos difíceis e que me ama acima de tudo. Por ser meu companheiro de vida. Obrigada meu amor. Você é essencial em minha vida. "Amus".

Agradeço também ao meu filho José Lucas, por existir.

As minhas meninas Nana e Lila, que amo imensuravelmente, por me apoiarem sempre, por estarem do meu lado sempre. Ao meu afilhado Pedro e ao meu primo Caio que também são meus filhos de coração, pelo amor, admiração e respeito que me motivam para ser cada vez melhor.

Aos meus pais de coração, que também são meus tios Marcelo e Ediglei, meus exemplos de família, integridade, meus alicerces, que me apoiam em todos os momentos da minha vida. $O$ amor que nos une também me fortalece, em cada amanhecer.

Aos meus pais Leandro e Sandra por terem priorizado minha educação e meus estudos, fundamentais para esta trajetória. Pelo carinho, incentivo e cumplicidade. 
Sou grata aos meus irmãos Eduardo e Alessandra e ao meu cunhado Bomfim, meus sobrinhos amados Leandrinho, Lari e Manu que aquecem meu coração, me enchem de amor e fazem seguir em frente.

Sou grata a minha família (Marão, Refugiados, do Dinheiro e dos Bonitos), pelas brincadeiras, conversas e alegrias diárias. Em especial aos meus avós: Mário, Dulcélia e Edith que são minhas riquezas, fizeram parte da minha criação e educação. Por serem meus exemplos de fé, luta e vitórias.

Gratidão também a minha madrinha Celina, fundamental na minha vida, seu amor, seus conselhos e orações iluminaram minhas escolhas. Sempre me acolhe e me fortalece. Obrigada por tudo.

A minha querida amiga Cláudia Marie Araki que sempre foi o meu exemplo, minha inspiração e minha grande incentivadora. Por acreditar em mim e ser essencial na minha formação. "Quero ser igual a você quando eu crescer".

Aos amigos do laboratório, pelos ensinamentos, amizade e momentos incríveis que vivemos juntos. Ainda, os amigos do nosso corredor, da copa e dos Departamento de Farmacologia e Departamento de Fisiologia e Biofísica.

Grata aos professores, técnicos e funcionários do Departamento de Farmacologia. Em especial: Fabiane, Mônica, Camila e Manoel.

Ao Prof. Dr. Luiz Roberto Giorgetti de Britto, que gentilmente cedeu o seu laboratório e disponibilizou equipamentos fundamentais para a realização deste projeto.

Agradeço as funcionárias da biblioteca, em especial Tereza e Renata pela ajuda fundamental para finalização deste trabalho, por serem tão solicitas, gentis e esclarecedoras.

Aos animais, utilizados na execução deste trabalho.

Grata à Universidade de São Paulo, ao Instituto de Ciências Biomédicas e ao Departamento de Farmacologia por cederem o espaço para que este trabalho fosse realizado.

E a Deus que permitiu e abençoou tudo isso. 
Grata em especial à Coordenação de Aperfeiçoamento de Pessoal de Nível Superior (CAPES), pela bolsa concedida ao longo desses dois anos, fornecendo assim, o suporte financeiro que viabilizou a execução deste trabalho (Número USP 9415833). 
"A felicidade às vezes é uma bênção, mas geralmente é uma conquista." Paulo Coelho 


\section{RESUMO}

CARVALHO, K. S. Alterações na glia observadas em regiões encefálicas envolvidas no controle respiratório em um modelo animal da doença de Parkinson. 2017. 87 f. Dissertação (Mestrado em Farmacologia) - Instituto de Ciências Biomédicas, Universidade de São Paulo, São Paulo, 2017.

O decurso da doença de Parkinson (DP) é acompanhado por um declínio da capacidade respiratória, responsável por morbidades e mortalidade desses pacientes. Estudo utilizando um modelo de DP induzido pela injeção de 6hidroxidopamina (6-OHDA) no estriado de ratos mostrou alterações respiratórias em repouso e prejuízo na resposta respiratória em condições hipercápnicas a partir do $40^{\circ}$ dia após a lesão. Após tratamento imunoistoquímico, observou-se redução no número de neurônios envolvidos no controle neural da respiração. Contudo, não seria possível desprezar o comportamento das células gliais nessas regiões. Assim, este estudo objetivou avaliar temporalmente alterações gliais de grupamentos neurais como núcleo retrotrapezóide (RTN), núcleo do trato solitário (NTS), complexo pré-Bötzinger (preBotC) e grupamento respiratório ventrolateral rostral (rVRG) que estão envolvidos no controle da atividade respiratória e correlacionar com alterações ventilatórias utilizando o mesmo modelo experimental de DP. Ratos Wistar (250-300g) receberam a injeção de 6-OHDA $(24 \mu \mathrm{g} / \mu \mathrm{l})$ ou veículo bilateralmente no estriado e tiveram avaliados os parâmetros respiratórios um dia antes e 30, 40 ou 60 dias após a injeção. Tratamento imunoistoquímico para tirosina-hidroxilase (TH) na região da substância negra (SN) mostrou redução maior que $70 \%$ dos neurônios dopaminérgicos da SN em animais que receberam a injeção de 6-OHDA. Também se observou uma redução na densidade da imunorreatividade para proteína ácida fibrilar glial (GFAP) em astrócitos no rVRG de 14,7\% no grupo de 30 dias e essa redução permaneceu durante todo período analisado (40 dias: $42,7 \%$ e 60 dias: 60,8\%). A partir de 40 dias, observou-se redução de $40,80 \%$ no RTN permanecendo até 60 dias (62,92\%). A partir de 60 dias a redução tornou-se significante nas demais regiões (NTSc: $47,98 \%$, NTSi: $45,67 \%$ e preBotC: $51,1 \%$ ). Ainda, observamos o aumento da proteína ligante de actina cruzada (IBA) em microglias na região do RTN, principal região envolvida na quimiorrecepção central aos 30 dias $(25,25 \%)$ e 40 dias $(20,50 \%)$. Nossos dados sugerem que a redução astrocitária pode estar contribuindo para as alterações respiratórias basais e induzidas por hipercapnia observadas neste modelo experimental e ainda, a presença de neuroinflamação no RTN pode estar contribuindo para a perda neural nesta região.

Palavras-chaves: Doença de Parkinson. 6-OHDA. Astrócitos. Microglia. Bulbo, Respiração. 


\begin{abstract}
CARVALHO, K. S. Glial changes observed in medullary regions involved in the control of breathing in an animal model of Parkinson's disease. 2017. 87 p. Master thesis (Pharmacology) - Instituto de Ciências Biomédicas, Universidade de São Paulo, São Paulo, 2017.

The development of Parkinson's disease (PD) is characterized by a decline in respiratory capacity, responsible for morbidity and mortality in these patients. A study using a model of PD induced by the injection of 6-hydroxydopamine (6-OHDA) in the striatum of rats showed respiratory changes at rest and induced by hypercapnia from the 40th day after the injury. After immunohistochemical treatment, a reduction in the number of neurons involved in the neural control of breathing was observed. However, it is important to investigate the role of glial cells in these regions. The aim of this study was to evaluate temporally glial changes in important regions that control breathing as retrotrapezoid nucleus (RTN), nucleus of the solitary tract (NTS), pre-Bötzinger complex (preBotC) and rostral ventral respiratory group (rVRG) and correlate those glial with ventilatory changes using the same experimental model of PD. Wistar rats $(250-300 \mathrm{~g})$ received the injection of 6-OHDA $(24 \mu \mathrm{g} / \mu \mathrm{l})$ or vehicle bilaterally into the striatum and had respiratory parameters assessed one day before and 30,40 or 60 days after the injection. Immunohistochemical treatment for tyrosine hydroxylase $(\mathrm{TH})$ in the substantia nigra region showed more than $70 \%$ of reduction of the dopaminergic neurons of SN in animals that received the 6-OHDA injection. A reduction in the immunoreactivity density for glial fibrillary acidic protein (GFAP) in astrocytes in the rVRG of $14.7 \%$ was also observed in the 30 day group and this reduction remained throughout the analyzed period (40 days: $42.7 \%$ and 60 days: $60.8 \%$ ). At 40 days, a reduction of $40.80 \%$ in the RTN was observed, remaining up to 60 days $(62.92 \%)$. At 60 days, the reduction became significant in the other regions analyzed (commissural NTS: $47.98 \%$, intermediate NTS: $45.67 \%$ and preBotC: $51.1 \%)$. We also observed the increase of the lonized calcium binding adaptor molecule 1 (IBA1) in microglia in the region of the RTN, the main region involved in central chemoreception at 30 days $(25.25 \%)$ and 40 days $(20.50 \%)$. Our data suggest that the reduction of astrocytes may be contributing to the resting and hypercapnic respiratory changes observed in this experimental model and also the presence of neuroinflammation in the RTN may contribute to the neuronal loss in this region.
\end{abstract}

Keywords: Parkinson's disease. 6-OHDA. Astrocytes. Microglia. Medulla Oblongata. Breathing. 


\section{LISTA DE ILUSTRAÇÕES}

Figura 1 - Fotomicrografia de um corte sagital de encéfalo de rato com representação esquemática da localização da coluna respiratória dorsal (CRD) e ventral (CRV)..... 23

Figura 2 - Efeitos da injeção bilateral de veículo ou 6-OHDA (24 $\mu \mathrm{g} / \mu \mathrm{l})$ no CPu. ....27

Figura 3 - Redução de neurônios Phox2b do RTN e NTS .28

Figura 4 - Redução na densidade de receptores NK1 no preBotC e rVRG 29

Figura 5 - Efeito da injeção bilateral de 6-OHDA no CPu sobre neurônios dopaminérgicos da SN.

Figura 6 - Efeitos da injeção bilateral de 6-OHDA no CPu na respiração basal de ratos não anestesiados 46

Figura 7 - Efeitos da injeção bilateral de 6-OHDA no CPu nas respostas respiratórias produzidas por hipercapnia em ratos não anestesiados. 48

Figura 8 - Efeito da injeção bilateral de 6-OHDA no CPu sobre a expressão de GFAP no NTSc

Figura 9 - Efeito da injeção bilateral de 6-OHDA no CPu sobre a expressão de GFAP no NTSi 51

Figura 10 - Efeito da injeção bilateral de 6-OHDA no CPu sobre a expressão de GFAP no $r V R G$ 52

Figura 11 - Efeito da injeção bilateral de 6-OHDA no CPu sobre a expressão de GFAP no preBotC 53

Figura 12 - Efeito da injeção bilateral de 6-OHDA no CPu sobre a expressão de GFAP no RTN.

Figura 13 - Correlação entre as alterações de freqüência respiratória basais e induzidas por hipercapnia e o total de GFAP nas regiões envolvidas no controle neural da respiração

Figura 14 - Efeito da injeção bilateral de 6-OHDA no CPu sobre a expressão de IBA no NTSc.

Figura 15 - Efeito da injeção bilateral de 6-OHDA no CPu sobre a expressão de IBA no NTSi.

Figura 16 - Efeito da injeção bilateral de 6-OHDA no CPu sobre a expressão de IBA no rVRG.

Figura 17 - Efeito da injeção bilateral de 6-OHDA no CPu sobre a expressão de IBA no preBotC

Figura 18 - Efeito da injeção bilateral de 6-OHDA no CPu sobre a expressão de IBA no RTN. 


\section{LISTA DE TABELAS}

Tabela 1 - Resumo dos resultados obtidos. .64 


\section{LISTA DE ABREVIATURAS}

6-OHDA - 6-hidroxidopamina

$A B N$ - academia brasileira de neurologia

Amb - núcleo ambíguos

AOS - apnéia obstrutiva do sono

$A P$ - área postrema

ATP - trifosfato de adenosina

BotC - complexo de Bötzinger

$\mathrm{Ca}^{2+}$ - cálcio

CC - canal central

CEUA - Comissão de Ética no Uso de Animais

ChAT - colina acetiltransferase

$\mathrm{CO}_{2}$ - dióxido de carbono

CONCEA - Conselho Nacional de Experimentação Animal

CPu - núcleos Caudado e Putâmen

$\mathrm{CRD}$ - coluna respiratória dorsal

CRV- colua respiratória dorsal

cVRG - porção caudal do grupamento respiratório ventrolateral

DP - doença de Parkinson

ELA - esclerose lateral amiotrófica

fR - frequência respiratória

GFAP - proteína glial fribrilar ácida

Gr - núcleo grácil

i.p - intraperitonealmente

IBA - proteína ligante de actina cruzada

Iba1 - lonized calcium binding adaptor molecule 1

ICB - Instituto de Ciências Biomédicas

LRN - núcleo reticular lateral

MPTP - 1-metil-4-fenil-1,2,3,6-tetrahidropiridina

$\mathrm{N}_{2}$ - nitrogênio

NK1 - neurocinina 1

NTS - núcleo do trato solitário

NTSc - núcleo do trato solitário porção comissural 
NTSi - núcleo do trato solitário porção intermediária

$\mathrm{O}_{2}$ - oxigênio

PAG - substância cinzenta periaquedutal

PBS - solução salina tamponada com fosfato

$\mathrm{pCO}_{2}$ - pressão parcial de $\mathrm{CO}_{2}$

PreBotC - complexo de pré-Bötzinger

py - trato piramidal

RTN - núcleo retrotrapezóide

rVRG - porção rostral do grupamento respiratório ventrolateral

$\mathrm{SN}$ - substância negra

SNC - sistema nervoso central

SNc - substância negra compacta

$\mathrm{SNr}$ - substância negra reticular

sol - trato solitário

$\mathrm{TH}$ - tirosina hidroxilase

USP - Universidade de São Paulo

VE - ventilação

VII - núcleo motor do facial

VT - volume corrente

VTA - área tegmental ventral

WHO - world health organization 


\section{SUMÁRIO}

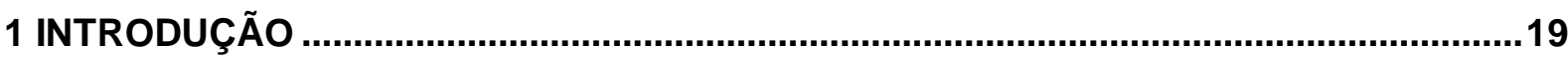

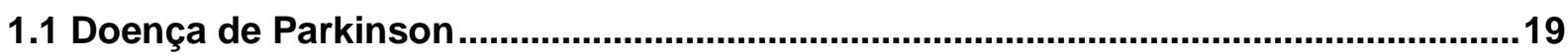

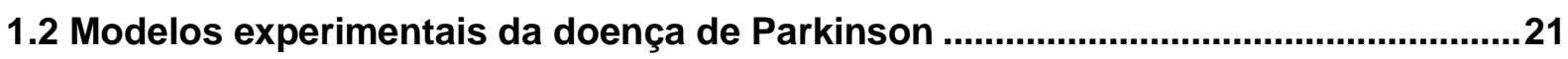

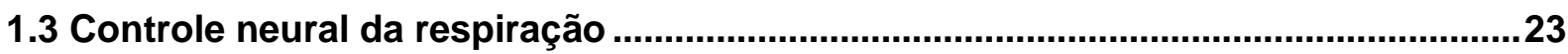

1.4 Alterações neuroanatômicas em regiões encefálicas envolvidas no controle

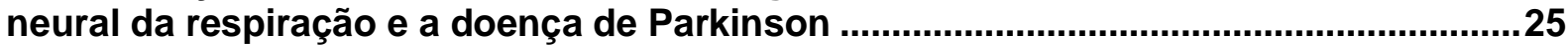

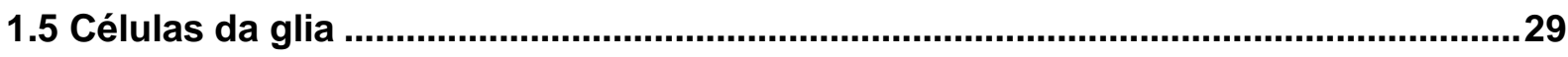

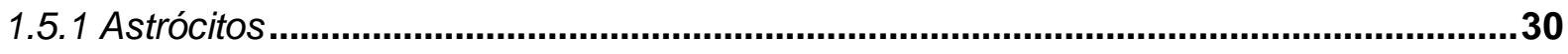

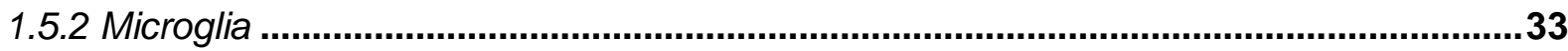

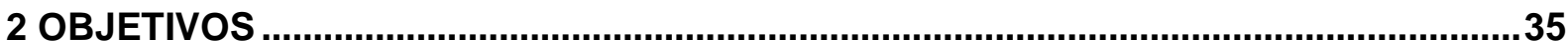

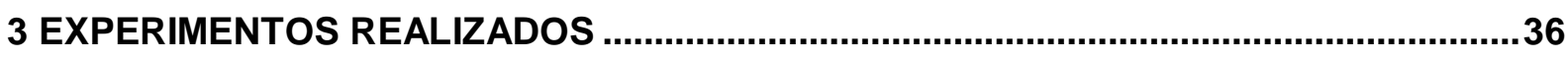

3.1 Avaliação temporal de alterações gliais em áreas encefálicas envolvidas no controle neural da respiração, no modelo de DP induzida pela injeção de 6-OHDA no $\mathrm{CPu}$

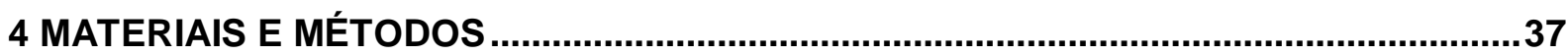

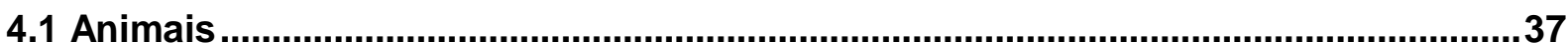

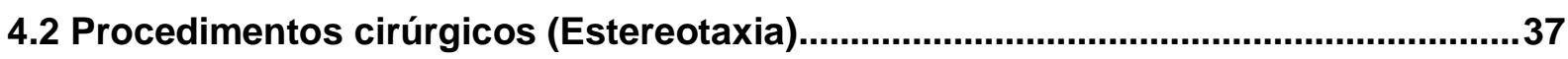

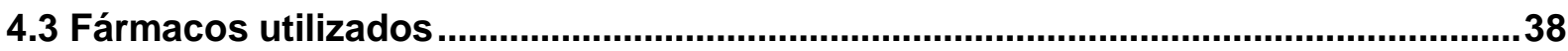

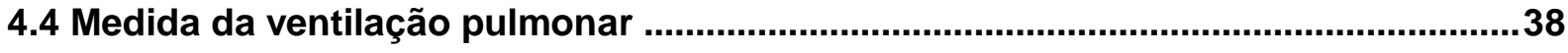

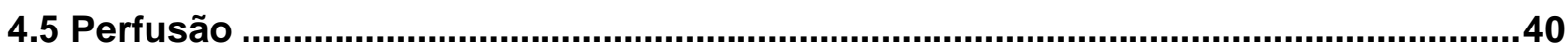

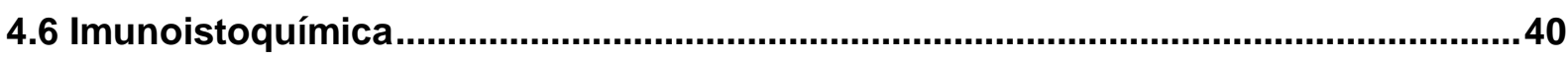

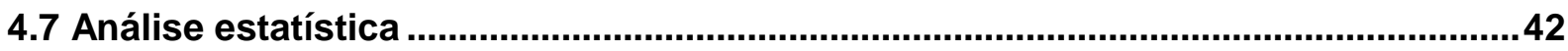

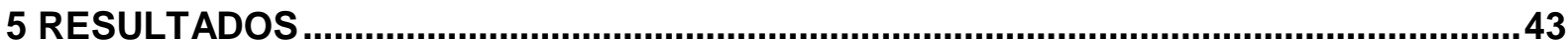

5.1 Efeito da injeção bilateral de 6-OHDA no CPu sobre neurônios dopaminérgicos da SN

5.2 Efeitos da injeção bilateral de 6-OHDA no $\mathrm{CPu}$ na respiração basal de ratos não

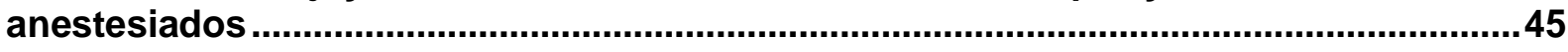

5.3 Efeitos da injeção bilateral de 6-OHDA no CPu nas respostas respiratórias produzidas por hipercapnia em ratos não anestesiados ...............................................47 
5.4 Efeito da injeção bilateral de 6-OHDA no CPu sobre a expressão de GFAP nas regiões envolvidas no controle neural da respiração

5.5 Correlação entre as alterações de freqüência respiratória basais e induzidas por hipercapnia e o total de GFAP nas regiões envolvidas no controle neural da respiração .55

5.6 Efeito da injeção bilateral de 6-OHDA no CPu sobre a expressão de IBA nas regiões envolvidas no controle neural da respiração

5.7 Correlação entre as alterações de freqüência respiratória basais e induzidas por hipercapnia e o total de IBA nas regiões envolvidas no controle neural da respiração

6 DISCUSSÃO .64

6.1 Alterações neuronais e funcionais respiratórias encontradas no modelo animal de DP 64

6.2 Alterações astrocitárias observadas em regiões encefálicas envolvidas no controle respiratório em um modelo animal de DP

6.3 Alterações microgliais observadas em regiões encefálicas envolvidas no controle respiratório em um modelo animal de DP. 69

6.4 Limitações das técnicas .70

7 CONCLUSÃO. .73

REFERÊNCIAS .74 


\section{INTRODUÇÃO}

\subsection{Doença de Parkinson}

Em 1817, o médico James Parkinson descreveu os sintomas de uma paralisia agitante em seu trabalho intitulado "An essay on the shaking palsy" como uma afecção neurológica caracterizada por tremores e rigidez dos movimentos (revisado por BLUM et al., 2001; PARKINSON, 1817). Atualmente, o conjunto de desordens por ele descrito é conhecido como a doença de Parkinson (DP).

A DP é uma doença neurodegenerativa idiopática, crônica e progressiva resultante da perda de neurônios ventrolaterais da substância negra (SN) em sua porção compacta (SNc) ao nível do mesencéfalo, com subseqüente disfunção dopaminérgica na via nigroestrial. Associados à perda neuronal, ocorrem formações de precipitados protéicos intracitoplasmáticos constituídos por proteínas que são chamados de corpos de Lewy, usados atualmente como marcador neuropatológico da DP (SPILLANTINI et al., 1998; TRETIAKOFF, 1919).

A dopamina é um importante neurotransmissor na via nigroestrial, modula o controle do movimento, aprendizado, humor, emoções, cognição, sono e memória (SOUZA et al., 2011). Sua síntese é dada a partir da hidroxilação e descarboxilação do aminoácido L-tirosina por meio da enzima tirosina-hidroxilase $(\mathrm{TH}$; presente apenas em células catecolaminérgicas), o produto desta reação é a L-Dopa. Esta é a primeira catecolamina produzida pela cadeia de síntese das catecolaminas e posteriormente ela é convertida, pela ação da enzima dopa descarboxilase, à dopamina (CHENG et al., 1997; ERRCHIDI et al., 1991).

O equilíbrio da neurotransmissão dopaminérgica é capaz de coordenar impulsos nervosos, promovendo a harmonia motora. Porém, com o prejuízo desta via na DP, o equilíbrio se perde e após redução de cerca de $60 \%$ dos neurônios nigrais e aproximadamente redução de $80 \%$ dos níveis dopaminérgicos no estriado, manifestam-se os sintomas motores (OBESO et al., 2000; SCHULZ; FALKENBURGER, 2004).

Os sintomas iniciais da DP são bradicinesia (lentidão dos movimentos voluntários ou dificuldades em iniciar os movimentos) ou acinesia (falta de movimentos), tremores de repouso, rigidez muscular, alterações da marcha, 
instabilidade postural com quedas frequentes e falta de expressão facial (AGID, 1991).

As anormalidades celulares e teciduais no desenvolvimento da DP geram alterações neuroquímicas e perturbam diversas regiões encefálicas, criando, por sua vez, circuitos neurais prejudicados (MARTENS; LEWIS, 2017), isto implica no aparecimento de sintomas não motores como depressão, apresentada em cerca de $40 \%$ dos pacientes, ansiedade, comprometimento da memória, lentidão dos pensamentos, demora em responder algumas perguntas, desconexão com o ambiente, demência e distúrbios do sono, podendo apresentar-se antes, concomitantemente ou após os sintomas motores (CUMMINGS, 1992; PALMERI et al., 2017; SOUZA et al., 2011)

Sabe-se que, cronicamente, problemas respiratórios surgem, sendo estes os principais responsáveis por mortalidade e morbidade desses pacientes. Obstrução de vias aéreas superiores, diminuição da complacência da caixa torácica e discinesias musculares podem causar dispneia, hipoventilação e atelectasias, facilitando assim um quadro de pneumonia causada por aspiração (WERMUTH et al., 1995). Ainda, dentre os problemas respiratórios podemos apontar a pausa temporária da atividade respiratória a qual pode evoluir ou não para uma parada respiratória definitiva (NASHEF et al., 1996; NOGUES et al., 2002) e a apneia obstrutiva do sono (AOS) que tem sido apontada como principal causa de óbito entre os pacientes portadores da DP (MEHANNA; JANKOVIC, 2010).

Apesar dos inúmeros progressos obtidos na pesquisa da DP, a sua etiopatogenia ainda permanece obscura, apenas cerca de $5 \%$ tem natureza hereditária, comumente relacionada aos casos precoces. Os casos esporádicos atingem cerca de $1 \%$ da população mundial acima de 50 anos, passando para $2 \%$ após 65 anos de idade. Tem distribuição universal, afeta diferentes classes socioeconômicas, grupos étnicos, discreta preponderância masculina e é considerada a segunda doença neurodegenerativa mais comum, depois da doença de Alzheimer (BARBOSA et al., 2006; HUGHES et al., 1993; STEIDL et al., 2007).

No Brasil, segundo a Academia Brasileira de Neurologia (ABN), estima-se que 200 mil pessoas sofram com a DP (dados de 2014). Pesquisas realizadas com populações distintas em todo o mundo afirmam que o número de casos varia entre 
50 a 260 casos a cada 100.000 pessoas. Considera-se delicada a exatidão desses números devido ao critério diagnóstico, distribuição etária das populações, histórico do paciente e a exclusão de outras doenças neurológicas (BARBOSA et al., 2006; HASSE et al., 2008; MELO et al., 2007).

Com o aumento da expectativa de vida e o envelhecimento populacional, é notório o crescente número de casos nos últimos anos, fomentando incapacidade, queda de qualidade de vida e devido à falta de tratamento curativo, gera altos gastos econômicos. Mais de 6 milhões de pessoas morrem por ano em consequência de desordens neurológicas, sendo consideradas uma das maiores ameaças à saúde pública no mundo (WHO, 2007).

\subsection{Modelos experimentais da doença de Parkinson}

Os avanços na neurociência proporcionaram uma maior compreensão da DP. Inquestionavelmente, o desenvolvimento e a utilização de modelos animais forneceram informações valiosas, permitindo estudos acerca da sua patogênese, mecanismos envolvidos na sua progressão, assim como alterações neuroanatômicas e fisiológicas a ela associada.

Atualmente, existem diversos modelos que promovem experimentalmente a degeneração dos neurônios dopaminérgicos da SNc, mimetizando o que ocorre na DP. Os mais freqüentes na literatura são as contaminantes da heroína sintética como a 1-metil-4-fenil-1,2,3,6-tetrahidropiridina (MPTP), as análogas da dopamina como a 6-hidroxidopamina (6-OHDA) e a toxina ambiental conhecida como Rotenona. Todos os modelos animais demonstram ativação de microglia na SN após a injeção local e um paralelismo entre a progressão da lesão e a ativação glial (PURISAI et al., 2007; SMEYNE et al., 2005).

A MPTP é uma substância lipossolúvel, portanto cruza a barreira hematoencefálica e penetra em neurônios dopaminérgicos, bem como nas células gliais. Uma vez dentro da célula, desencadeia disfunção mitocondrial e estresse oxidativo. Por sofrer facilmente oxidação, promove degeneração neural subseqüente a uma elevada toxicidade, representando um risco inclusive para o próprio pesquisador (KUMAR et al., 2009; MCDOWELL; CHESSELET, 2012). 
A 6-OHDA é uma neurotoxina que possui uma estrutura análoga à das catecolaminas. Dentro dos neurônios é acumulada como um falso neurotransmissor. Sendo um composto muito eletroativo, a 6-OHDA é rapidamente oxidada, levando à produção de vários compostos neurotóxicos que irão ser responsáveis pela degradação neuronal progressiva (BOVÉ et al., 2005; SCHWARTING; HUSTON, 1996). A administração sistêmica de 6-OHDA não é capaz de produzir destruição dos neurônios do mesencéfalo, já que esse composto é incapaz de atravessar a barreira hematoencefálica (BOVÉ et al., 2005) porém, quando injetada diretamente nas estruturas encefálicas de interesse é capaz de destruir seletivamente neurônios catecolaminérgicos, levando a uma depleção de dopamina, noradrenalina e adrenalina nas regiões encefálicas que apresentam imunorreatividade para a enzima TH (SCHWARTING; HUSTON, 1996).

A injeção de 6-OHDA no estriado, na porção centro-lateral dos núcleos Caudado e Putâmen ( $\mathrm{CPu}$ ) é o modelo que mais se aproxima do quadro encontrado em humanos (TILLERSON et al., 2002), principalmente se a lesão for bilateral (revisado por DEUMENS et al., 2002). De acordo com a literatura, a máxima neurodegeneração observada quando aplicada nesta região ocorre aproximadamente vinte dias após a injeção (PRZEDBORSKI et al., 1995).

Outras regiões encefálicas como, por exemplo, a própria $\mathrm{SNc}$ ou o feixe prosencefálico podem ser escolhidas para a realização da injeção de 6-OHDA com o mesmo objetivo de promover a lesão dos neurônios dopaminérgicos da SNc. Entretanto, esses dois sítios levam a uma rápida e agressiva degeneração desses neurônios, com elevada taxa de mortalidade dos animais (FAULL; LAVERTY, 1969; ZUCH et al., 2000). O presente estudo utilizou a 6-OHDA, injetando-a bilateralmente no CPu a fim de promover uma lesão retrógrada gradativa e temporal dos neurônios dopaminérgicos da região da SNc, visando uma maior aproximação ao padrão clássico da DP.

Existem evidências crescentes de que o contato com agentes tóxicos ambientais pode estar associado a um risco aumentado de desenvolver a DP (BROWN et al., 2006; TANNER et al, 2011; WANG et al, 2011). A administração de um exemplo de pesticida conhecido como rotenona em ratos demonstrou promover lesões da via nigroestriatal e o acúmulo de a-sinucleina (CANNON et al., 2009). 
Alguns estudos examinaram a capacidade desse composto de imitar aspectos da doença e diversos sintomas não motores passaram a ser estudados com sucesso neste modelo (MCDOWELL; CHESSELET, 2012). No entanto, a falta de especificidade da toxina e alta variabilidade dos seus efeitos ainda são obstáculos enfrentados pelos pesquisadores (ZHU et al., 2004).

Além dos modelos induzidos por toxinas, existem os modelos geneticamente modificados de DP que incluem, entre outros, animais que superexpressam $\alpha$ sinucleina ou Knockouts dos genes relevantes para a doença como Park1 ou Park4 (MAGEN; CHESSELET, 2010). Entretanto, ainda são recentes os estudos que utilizam estes modelos para avaliar sintomas não motores (BAPTISTA et al., 2013).

\subsection{Controle neural da respiração}

O controle da respiração é realizado por uma rede neural que contém coluna respiratória dorsal (CRD) e coluna respiratória ventral (CRV) (Figura 1). A primeira se localiza no núcleo do trato solitário (NTS). Nessa região, existem diferentes grupos de neurônios com atividade inspiratória, pós-inspiratória ou expiratória, exercendo uma atividade modulatória sobre a respiração (SUBRAMANIAN et al., 2007).

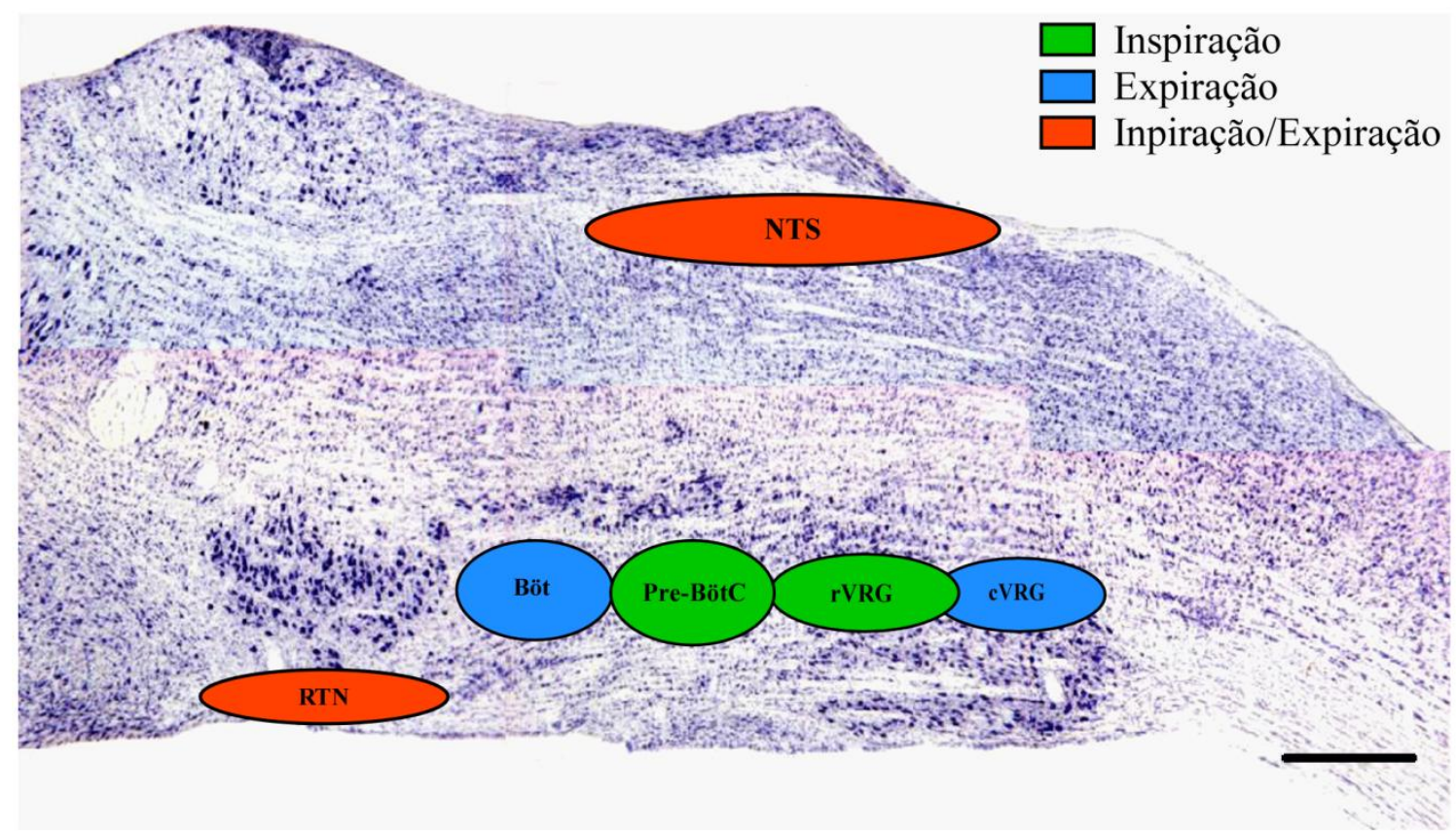

Figura 1 - Fotomicrografia de um corte sagital de encéfalo de rato com representação esquemática da localização da coluna respiratória dorsal (CRD) e ventral (CRV). Abreviações: Böt: complexo Bötzinger; Pre-Böt: complexo pré-Bötzinger; rVRG: porção rostral do grupamento respiratório ventrolateral; cVRG: porção caudal do grupamento respiratório ventrolateral; RTN: núcleo 
retrotrapezóide, compondo a CRV e NTS: núcleo do trato solitário, compondo a CRD. Escala: $1 \mathrm{~mm}$ (Rosin et al., 2006, modificada).

A CRV se localiza na superfície ventrolateral do bulbo e é comumente descrita na literatura no sentido rostro-caudal, composta por grupamentos neurais funcionalmente distintos:

i. Complexo de Bötzinger (BotC) neurônios inibitórios envolvidos na atividade expiratória basal, sendo predominantemente glicinérgicos. Conectam-se com outros neurônios da coluna respiratória em sua porção mais caudal (SMITH et al., 2009; SMITH et al., 2013).

ii. Complexo de pré-Bötzinger (preBotC), grupo de neurônios considerados essenciais para a geração da atividade inspiratória, predominantemente glutamatérgicos e expressam receptores para substancia $P$ de neurocinina 1 (NK1) (CONNELY et al., 1992; STORNETTA et al.,2003; TAN et al., 2010).

iii. Porção rostral do grupamento respiratório ventrolateral (rVRG), neurônios que participam da atividade inspiratória, sendo considerados neurônios pré-motores inspiratórios (BIANCHI et al., 1995; EZURE, 1990; EZURE et al., 2003; SMITH et al., 1991; SMITH et al., 2007).

iv. Porção caudal do grupamento respiratório ventrolateral (cVRG), neurônios que participam da expiração ativa, sendo considerados neurônios pré-motores expiratórios (BIANCHI et al., 1995; EZURE, 1990; EZURE et al., 2003; SMITH et al., 1991; SMITH et al., 2007).

Recentemente adicionado à CRV em sua porção mais rostral encontra-se o núcleo retrotrapezóide (RTN), composto por neurônios glutamatérgicos e que expressam o fator de transcrição Phox2b, além de não apresentarem marcação para $\mathrm{TH}\left(\mathrm{TH}^{-}\right)$e colina acetiltransferase (ChAT') (KANG et al., 2007; TAKAKURA et al., 2006; TAKAKURA et al., 2008; TAKAKURA et al., 2014).

O RTN está localizado estrategicamente na superfície ventrolateral do bulbo, abaixo do núcleo motor do facial. É composto por neurônios responsáveis por detectar rapidamente alterações da pressão parcial de dióxido de carbono $\left(\mathrm{pCO}_{2}\right.$ hipercapnia) e queda de $\mathrm{pH}$, in vivo e in vitro (SMITH et al., 2013; TAKAKURA et al., 2006), sendo descritos como neurônios que contêm os quimiorreceptores centrais (CONNELLY, et al., 1989, SMITH, et al., 2009, STORNETTA, et al., 2006, 
TAKAKURA, et al., 2008). Nessas condições são ativados e estimulam um aumento rápido da atividade respiratória para reestabelecer a homeostase (GUYENET et al., 2005; MULKEY et al., 2007; NATTIE; LI, 2002; STORNETTA et al., 2006).

Coletivamente, a atividade respiratória basal é gerada por estes grupamentos neurais que, por meio de conexões recíprocas e inibitórias, coordenam a atividade de neurônios motores inspiratórios e expiratórios (RICHTER, 1982; RICHTER; SPYER, 2001; SMITH et al., 2007). No entanto, pouco se sabe a respeito das alterações do controle da respiração frente às doenças neurodegenerativas, apesar de observarmos que ocorre um declínio significativo da capacidade respiratória, com o progredir dessas patologias, incluindo na DP.

\subsection{Alterações neuroanatômicas em regiões encefálicas envolvidas no controle neural da respiração e a doença de Parkinson}

O decurso da DP é acompanhado por um declínio da capacidade respiratória. Dentre as alterações funcionais encontradas, destacam-se a obstrução das vias aéreas superiores, diminuição da complacência da caixa torácica e discinesias musculares (WERMUTH et al., 1995). Alguns estudos postulam que pacientes com DP podem ter mais dificuldade para realizar atividades motoras repetitivas por causa da bradicinesia e rigidez muscular, sugerindo inclusive que a atividade dos músculos respiratórios pode estar igualmente comprometida (BROWN, 1994; TZELEPIS et al., 1988). As infecções pulmonares costumam ser recorrentes, consequência desta mecânica prejudicada, fomentando inúmeras morbidades (SHILL; STACY, 1998).

O aparecimento da AOS é apontada como principal causa de morte destes pacientes. Entretanto, até o momento, sua patofisiologia é desconhecida apesar de alguns trabalhos especularem que ocorre uma degeneração em neurônios responsáveis por comandar a atividade respiratória (GILMAN et al., 2003). Sabe-se que a diminuição de neurônios quimiossensíveis em importantes regiões do controle neural da respiração, como RTN, altera o padrão respiratório (TAKAKURA et al., 2014) o que desperta atenção acerca de degenerações em grupamentos neurais que comandam a respiração em pacientes com DP.

Estudos fornecem indícios de que as patologias neurodegenerativas podem afetar diferentes componentes do controle da respiração como: receptores sensoriais, vias aferentes, inter-neurônios da região do tronco encefálico e neurônios 
pré-motores, neurônios motores e junções neuromusculares (FELDMAN, 1986; FELDMAN; ELLENBERGER, 1988; NOGUES et al., 2002; RICHTER; SPYER, 2001).

Um dos estudos pioneiros realizado em 2003 por Benarroch e colaboradores apresenta evidências de neurodegeneração no preBotC, em que ao analisarem encéfalos pós mortem de pacientes com DP observaram uma intensa redução de densidade de receptores NK1 nesta região, comparados com indivíduos sem a patologia. Outro estudo realizado por Seccombe e colaboradores em 2011 mostrou por meio de estudos clínicos funcionais que o grau de fraqueza em músculos ventilatórios encontrados em pacientes com DP seria insuficiente para justificar uma restrição importante na atividade respiratória. Ainda, que estes pacientes apresentavam um déficit de $47 \%$ na resposta à hipercapnia, mas não em condições de hipóxia, sugerindo uma alteração no controle neural da respiração (SECCOMBE et al., 2011).

Estudos realizados em nosso laboratório com modelo de DP induzido pela injeção de 6-OHDA no CPu demonstraram alterações respiratórias basais a partir do $40^{\circ}$ dia após a lesão e esse efeito durou pelo menos até o $60^{\circ}$ dia (Figura 2, TUPPY et al., 2015). Além disso, esse mesmo estudo mostrou que a resposta respiratória induzida por hipercapnia também está reduzida 40 e 50 dias após a lesão (Figura 2, TUPPY et al., 2015). 


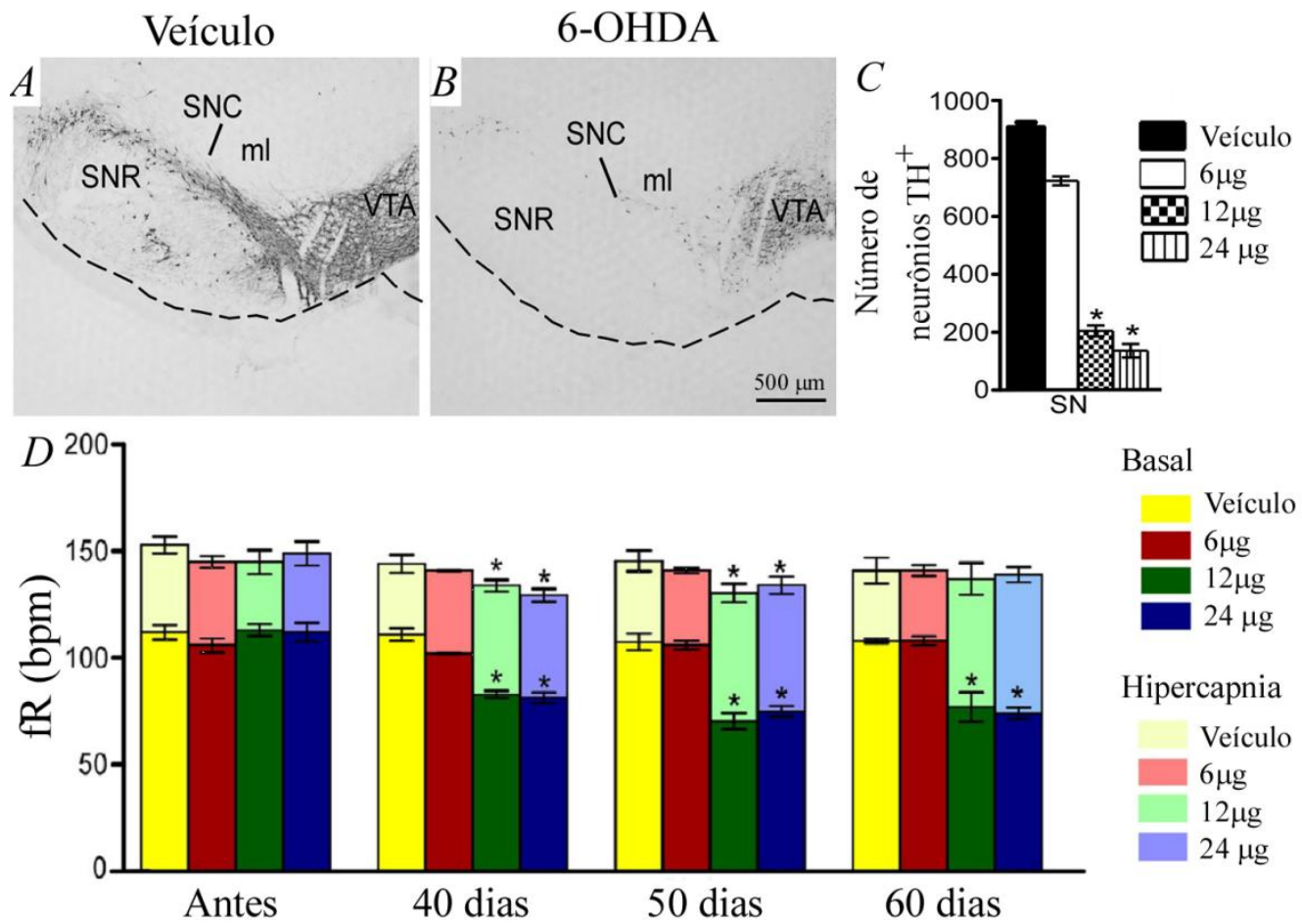

Figura 2 - Efeitos da injeção bilateral de veículo ou 6-OHDA (24 $\mu \mathrm{g} / \mu \mathrm{l})$ no CPu. A e B) Fotomicrografia mostrando a imunorreatividade de neurônios catecolaminérgicos da SNc; C) Número de neurônios imunorreativos para Tirosina-Hidroxilase $\left(\mathrm{TH}^{+}\right)$na SNc com diferentes doses de 6-OHDA. D) Efeitos da injeção bilateral de 6-OHDA ou veículo no CPu na frequência respiratória basal e induzidos por hipercapnia de animais não-anestesiados. Abreviações: SNr: substância negra reticular; SNc: substância negra compacta; ml: leminiscu medial; VTA: área tegmental ventral; *diferença estatística em relação ao veículo (Tuppy et al., 2015, modificada).

Ao serem analisados os encéfalos dos animais após 60 dias da lesão, observou-se não apenas uma intensa redução no número de neurônios catecolaminérgicos da SNc, mas também no número de neurônios Phox2b no NTS em sua porção comissural (NTSc) e intermediária (NTSi) e no RTN (Figura 3) (FALQUETTO et al., 2017; TUPPY et al., 2015). 


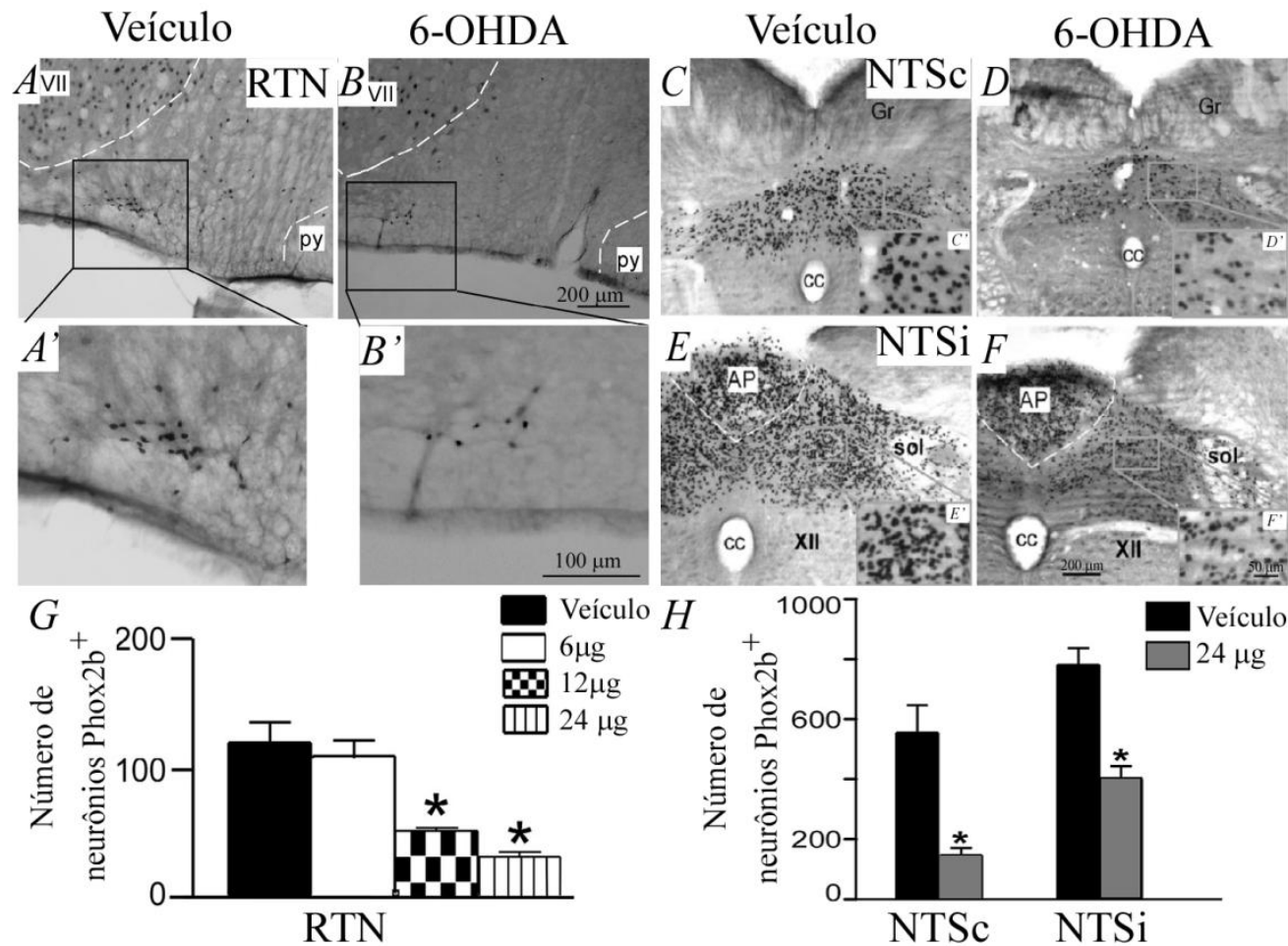

Figura 3 - Redução de neurônios Phox2b do RTN e NTS. Fotomicrografias do RTN (A e B), NTSc (C e D) e NTSi ( $E$ e F) de animal que recebeu injeção no estriado bilateralmente de veículo ( $A, A^{\prime}, C$ e E) ou $24 \mu \mathrm{g}$ de 6-OHDA (B, B',D e F). G) Número de neurônios imunorreativos para Phox2b do RTN em diferentes doses em comparação ao grupo veículo. H) Número de neurônios imunorreativos para Phox2b do NTSc e NTSi comparado ao veículo. Abreviações: VII,núcleo motor do facial; py, trato piramidal; cc, canal central; AP, área postrema; sol, trato solitário, XII, núcleo do hipoglosso e Gr, núcleo grácil. * $p<0,05$ em relação ao veículo (Falquetto et al., 2017; Tuppy et al., 2015 modificada).

Foi possível observar também em nossos trabalhos, uma redução na densidade de receptores de NK1 no preBotC, mesma região analisada por Benarroch e colaboradores e no rVRG (Figura 4), sugerindo que essas alterações neuroanatômicas em regiões encefálicas envolvidas no controle neural da respiração no modelo animal de DP podem contribuir de forma significativa para o aparecimento de distúrbios respiratórios associados à doença (FALQUETTO et al., 2017; TUPPY et al., 2015). 


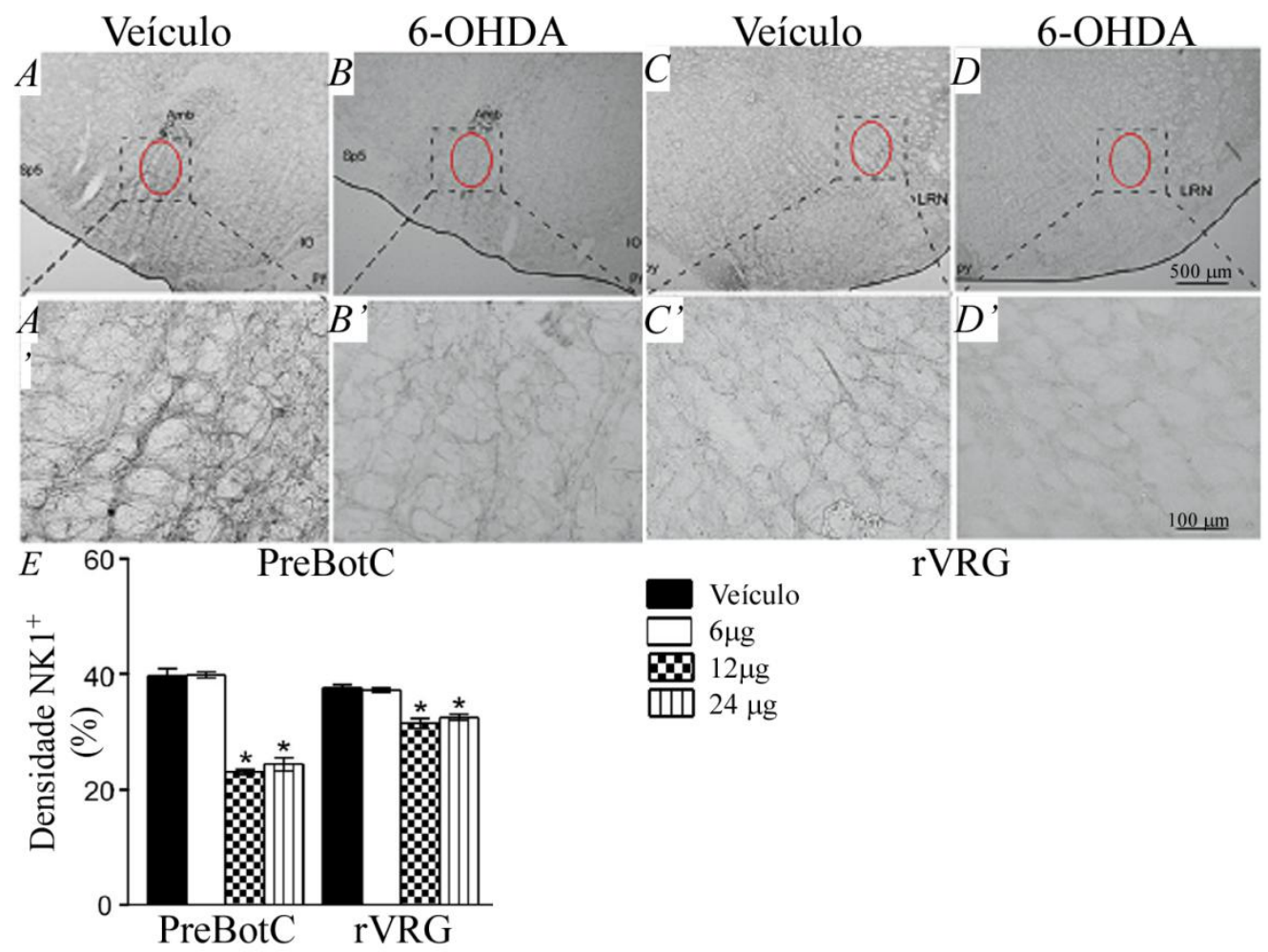

Figura 4 - Redução na densidade de receptores NK1 no preBotC e rVRG. Fotomicrografias do preBotc ( $A$ e $B$ ) ou rVRG ( $C$ e $D)$ de animal que recebeu injeção no estriado bilateralmente de veículo ( $A, A^{\prime}, C$ e $\left.C^{\prime}\right)$ ou $24 \mu \mathrm{g}$ de 6-OHDA (B, B',D e $\left.D^{\prime}\right)$. E) Densidade de receptores NK1 no preBotC e rVRG em diferentes doses em comparação ao grupo veículo. Abreviações: Amb, núcleo ambíguos; IO; oliva inferior; Sp5: núcleo espinal do trigêmeo; LRN, núcleo reticular lateral. * $p<0,05$ em relação ao veículo (Tuppy et al., 2015, modificada).

Contudo, deve-se considerar que as respostas neurais estão intimamente associadas às funções gliais e, portanto, não seria possível desprezar a contribuição direta ou indireta das células da glia para a neurodegeneração e o comprometimento funcional respiratório observados com o avançar da DP, apesar de não existir estudos na literatura que descrevam essas alterações.

\subsection{Células da glia}

O tecido nervoso é composto por neurônios, células endoteliais e células da neuróglia ou simplesmente células da glia. Até pouco tempo atrás, as células da glia eram consideradas células de suporte do encéfalo, passivas e à margem do seu funcionamento. Especialmente na última década, a neurociência foi palco de uma mudança de paradigma relacionada à função dessas células na fisiologia e patologia neurais (GOMES et al., 2013; MOTA; HERCULANO-HOUZEL, 2014).

A glia é formada por dois grupos de células distintas morfológica e funcionalmente de acordo com sua origem embriológica: a microglia, de origem 
mesodermal, principal componente da defesa imune intrínseca no sistema nervoso central (SNC) e a macroglia, de origem ectodermal, composta por: i) oligodendrócitos, responsáveis pela mielinização dos axônios no SNC; ii) ependimócitos ou células ependimárias que revestem os ventrículos encefálicos, o canal central da medula e que produzem o líquido cefalorraquidiano e iii) astroglia que inclui astrócitos (GOMES et al., 2013). Este estudo destaca o envolvimento dos astrócitos e da microglia na neurodegeneração observada em um modelo experimental da DP.

\subsubsection{Astrócitos}

Os astrócitos são as células gliais mais numerosas no encéfalo de mamíferos e possuem uma série de importantes propriedades fisiológicas relacionadas à homeostase do SNC (LEE; MACLEAN, 2015). Além de serem consideradas células de suporte, podem agir como uma interface entre os neurônios e vasos sanguíneos e ainda, neurônios e fluido cérebro-espinal, constituindo parte de uma importante barreira de proteção do nosso SNC, conhecida como barreira hematoencefálica (GOMES et al., 2013; LEE; MACLEAN, 2015; TESCHEMACHE et al., 2015).

O interesse em relação aos astrócitos tem aumentado significantemente nos últimos anos, atribuindo-lhes uma variedade de novas funções. Por exemplo, atualmente eles são reconhecidos como participantes ativos na regulação da função sináptica, absorção de neurotransmissores e participam de ajustes metabólicos (ERLICHMAN, 2010; LEE; MACLEAN, 2015). Nesse último caso, a participação se dá devido ao fato de que os astrócitos regulam o tônus vascular encefálico e com isso, contribuem em muito para a regulação do fluxo sanguíneo encefálico, atendendo as demandas metabólicas neurais, além do transporte de água, concentrações extracelulares de íons e neurotransmissores (ANDERSON; SWANSON, 2000; DING, 2014; ERLICHMAN, 2010; FREEMAN, 2010; LEE; MACLEAN, 2015; TESCHEMACHE et al., 2015).

Os astrócitos estão estrategicamente no centro de uma rede complexa de interações neurais e vasculares, em que essa relação parece também the conferir uma maior sensibilidade de perceber alterações nas concentrações de gases sanguíneos e pH, respondendo ativamente a essas alterações, por meio de 
elevação intracelular de Cálcio $\left(\mathrm{Ca}^{2+}\right)$ e liberação de trifosfato de adenosina (ATP) que teria uma ação sobre o neurônio (ERLICHMAN, 2010; GOURINE et al., 2010).

Sabe-se que a base molecular e celular da quimiorrecepção respiratória central baseia-se na detecção de dióxido de carbono $\left(\mathrm{CO}_{2}\right)$ por meio de receptores intrínsecos. A literatura recente descreve pelo menos três teorias que tentam explicar o mecanismo da quimiorrecepção respiratória central:

i. quimiorreceptores respiratórios especializados: nesta teoria, preconizase que apenas neurônios de regiões muito específicas do encéfalo teriam a capacidade de detectar alterações na $\mathrm{pCO}_{2}$ e informar essas alterações para os grupamentos de neurônios que compõem a coluna respiratória ventral. Acredita-se que a principal região do encéfalo com característica quimiossensível seria a região do RTN (LOESCHCKE, 1982; MITCHELL et al., 1963; MULKEY et al., 2004; TAKAKURA et al., 2006; 2008; TROUTH et al., 1973);

ii. quimiorreceptores respiratórios não especializados: nesta teoria, acredita-se que diversos grupamentos neuronais são capazes de detectar alterações de $\mathrm{CO}_{2}$ (COATES et al., 1993; KUWAKI et al., 2010; NATTIE, 1999);

iii. quimiorreceptores localizados em astrócitos: nesta teoria, acredita-se que os quimiorreceptores também podem estar localizados em astrócitos presentes em regiões específicas do bulbo e que, portanto, estariam envolvidos no controle respiratório. Esses astrócitos detectariam as alterações de $\mathrm{CO}_{2}$ e $\mathrm{pH}$ e influenciariam ativamente neurônios para produzir respostas respiratórias (GOURINE et al., 2010; MOREIRA et al., 2015).

A literatura atual mostra que a ativação optogenética de astrócitos localizados na superfície ventral do bulbo leva à liberação de ATP que, por sua vez, estimula a respiração (GOURINE et al., 2010). Além disso, esse trabalho também mostrou que - ATP pode ser liberado em resposta ao aumento de $\mathrm{CO}_{2}$ ou redução de $\mathrm{pH}$, também levando a um aumento na respiração (GOURINE et al., 2010). Assim, fica claro que os astrócitos que se localizam na superfície ventral do bulbo, 
especificamente na região do RTN, podem ser apontados como moduladores da atividade respiratória uma vez que possuem capacidade de estimular os neurônios envolvidos no controle da respiração, como os do RTN, pela liberação de ATP.

Os astrócitos desempenham papéis primordiais na sobrevivência e função neuronal em várias doenças neurodegenerativas. As alterações astrocitárias têm sido demonstradas em uma variedade de afecções do SNC, incluindo a DP em que, apesar dos neurônios dopaminérgicos serem os primeiros afetados, o envolvimento dessas células gliais tem sido amplamente sugerido (DUTRA et al., 2012; MARAGAKIS; ROTHSTEIN, 2006). No presente estudo, buscamos, então, avaliar se existe uma contribuição dos astrócitos corroborando com a terceira teoria da quimiorrecepção respiratória central em um modelo animal de DP.

Ademais, existem evidencias de que os astrócitos localizados em outras regiões desempenham um importante papel na resposta imune inata do SNC, reagindo a perturbações com aumentos na expressão do filamento intermediário, hipertrofia e proliferação celular, produções de citocina e quimiocinas, formação de cicatrizes gliais e recrutamento de microglias para área lesada (GALLO; DENEEN, 2014; SOFRONIEW; VINTERS, 2010; SOFRONIEW, 2009). A ativação dessas vias imunes inatas ocorre em uma variedade de insultos como lesões cerebrais, isquemias, bem como em transtornos neurodegenerativos, por meio de um processo denominado astrogliose reativa, que se tornou uma característica patológica das lesões estruturais do SNC (FARINA et al., 2007; SOFRONIEW; VINTERS, 2010). Estes papéis ainda não estão totalmente compreendidos, mas, gradualmente, estão sendo elucidados (LIDDELOW et al., 2017).

Em modelos animais da DP, pode-se observar que os astrócitos reativos são abundantes na SNc (MCGEER; MCGEER, 2008). Porém, até o momento, não existem estudos que avaliam as reações astrocíticas em regiões encefálicas envolvidas no controle neural da respiração. Portanto, a hipótese do presente estudo é que a DP promove alteração não só na via nigroestrial, mas também envolve, além da perda neural, a perda astrocitária em importantes áreas encefálicas envolvidas na geração da atividade/controle ventilatório, o que poderia estar contribuindo para o aparecimento de distúrbios respiratórios associados à progressão da doença, justificando a relevância desta etapa do estudo. 


\subsubsection{Microglia}

As microglias constituem cerca de $10 \%$ de todas as células gliais, distribuídas uniformemente por todo o parênquima encefálico, possuem diversas ramificações, mas não se tocam (MCGEER; MCGEER, 2008), cada célula ocupa seu próprio espaço e estão em constante atividade, avaliando o microambiente e respondendo a uma variedade de estímulos (BICKFORD et al., 2017; NIMMERJAHN et al., 2005).

Sabe-se que as microglias representam o sistema imunológico do encéfalo de mamíferos (NIMMERJAHN et al., 2005). Assemelha-se com os macrófagos em sua origem e desempenham funções importantes na regulação do sistema imune e reparo de danos (CHHOR et al., 2013). São apontadas como participantes ativas nesses processos, responsáveis pela liberação de citocinas, manutenção e supressão de respostas imunes (ASCHNER, 1998a). Este processo é conhecido como microgliose reativa e também é uma característica comum nas doenças neurodegenerativas (GAO; HONG, 2008).

Até o momento, não está claro quais mecanismos induzem a microgliose reativa, mas existem indícios de que os fatores tóxicos liberados pelos neurônios lesados no microambiente microglial são responsáveis (LONG-SMITH et al., 2009). A ativação da microglia é fundamental para a função encefálica normal, a fim de controlar o microambiente neuronal, promovendo efeitos benéficos aparentes sobre as células circundantes. Contudo, quando a ativação microglial é persistente, os efeitos prejudiciais resultam em matar de forma desordenada o tecido nervoso sadio. Devido ao possível envolvimento da inflamação mediada pela microglia na DP e outras doenças neurodegenerativas, tem sido postulado que pode ocorrer um ciclo vicioso de inflamação nessas patologias, independentemente do insulto inicial (LONG-SMITH et al., 2009).

Estudos realizados com cérebros de pacientes pós mortem observaram um aumento significativo da microglia na SNc em torno dos neurônios dopaminérgicos degenerados e ainda, confirmam o envolvimento da resposta imune inata e adaptativa, característicos de neuroinflamação, concomitantemente com uma expressão aumentada de mediadores pró-inflamatórios (BANATI et al., 1998; HIRSCH et al., 2012; IMAMURA et al., 2003; SAWADA et al., 2006). Ainda, utilizando o modelo animal de DP induzido pela 6-OHDA também é possível 
observar este aumento microglial na SNc de ratos (AKIYAMA; MCGEER, 1989; DEPINO et al., 2003; HE et al., 2001).

Os achados consistentes obtidos por vários modelos animais de DP sugerem que a neuroinflamação é um contribuinte importante para a patogênese da doença e pode ainda impulsionar a perda progressiva de neurônios dopaminérgicos da via nigroestrial (TUFEKCl et al., 2012). São capazes de desencadear uma variedade de eventos nocivos relacionados à persistência dessas respostas (YOKOYAMA et al., 2011).

Resumidamente, alguns estudos discutem sobre a neuroinflamação exercendo papéis prejudiciais nas doenças neurodegenerativas (LIU; HONG, 2003; PURISAI et al., 2007), outros indicam que a inflamação é crucial para a recuperação em certas circunstâncias de patologias (GLEZER et al., 2007; SCHWARTZ; ZIV, 2008). Em comum, diversos estudos enfatizam os efeitos observados na região da $\mathrm{SN}$, porém, até o momento, não se sabe se existe a ativação ou não destas células em áreas encefálicas envolvidas no controle respiratório, que poderiam estar inviabilizando a atividade celular nessas regiões, contribuindo com a deficiência respiratória apresentada no nosso modelo experimental, justificando a relevância desta etapa no presente estudo. 


\section{OBJETIVOS}

Sabe-se que os distúrbios respiratórios podem ser considerados os principais responsáveis pelas morbidades e mortalidade em pacientes portadores da DP. Contudo, até o presente momento, poucos estudos demonstram alterações neuroanatômicas em áreas encefálicas envolvidas no controle respiratório relacionados à progressão da doença, não existindo ainda estudos que relatem alterações envolvendo células da glia na região.

Diante disso, torna-se importante avaliar se em um modelo da DP em que foram observadas alterações respiratórias e neuronais, existem alterações gliais em regiões encefálicas envolvidas no controle da respiração, pois essas alterações podem contribuir para a deficiência da função respiratória e/ou redução do número desses neurônios.

Pelo exposto, este estudo objetivou:

i. Avaliar temporalmente alterações gliais, especificamente de astrócitos e microglias no NTS, preBotC, rVRG e RTN em um modelo de DP induzido pela injeção de 6-OHDA no CPu;

ii. Correlacionar as possíveis alterações gliais com alterações nas respostas ventilatórias basais e induzidas por hipercapnia. 


\section{EXPERIMENTOS REALIZADOS}

\subsection{Avaliação temporal de alterações gliais em áreas encefálicas envolvidas no controle neural da respiração, no modelo de DP induzida pela injeção de 6- OHDA no CPu}

Um dia antes, 30, 40 ou 60 dias após a cirurgia de indução da DP pela injeção de 6-OHDA ou veículo no $\mathrm{CPu}$, os animais foram colocados individualmente em uma câmara de pletismografia. A câmara foi ventilada com ar atmosférico umedecido $\left(21 \%\right.$ de oxigênio $\left.\left(\mathrm{O}_{2}\right)\right)$. Após as fases exploratórias que variam entre 45 e 60 minutos, a medida de ventilação basal e durante hipercapnia foi efetuada. No $30^{\circ}$, $40^{\circ}$ ou $60^{\circ}$ dias, logo após o experimento de pletismografia, os animais foram profundamente anestesiados, perfundidos e tiveram os encéfalos retirados para análise imunoistoquímica. Foram analisados marcadores específicos para TH a fim de quantificar o tamanho da lesão na SN promovida pela injeção de 6-OHDA no $\mathrm{CPu}$, além de astrócitos (GFAP) e microglia (IBA) em áreas envolvidas no controle neural da respiração. Após os tratamentos, os cortes foram montados em lâminas, analisados num microscópio para análise e quantificação dos resultados obtidos. Foram utilizados diferentes grupos de animais para o período de 30,40 e 60 dias. Após a aquisição e análise dos resultados, foi feita a correlação de Pearson a fim de observarmos de forma estatística a presença de alguma correlação entre as alterações funcionais e gliais. 


\section{MATERIAIS E MÉTODOS}

\subsection{Animais}

Foram utilizados ratos Wistar, adultos, com peso variando entre 250 e 300 gramas, aproximadamente 2 a 4 meses de idade no momento da cirurgia, procedentes do Biotério Central do Instituto de Ciências Biomédicas (ICB) da Universidade de São Paulo (USP). Os animais foram mantidos em caixas com no máximo quatro animais por caixa, com água e ração (Nuvlab) ad libitum. A temperatura do biotério variou entre $22^{\circ}$ e $24^{\circ} \mathrm{C}$. O ciclo claro-escuro do biotério ocorreu respeitando a oscilação circadiana do animal, alterando a cada 12 horas. Os protocolos experimentais deste trabalho estão de acordo com os Princípios Éticos de Experimentação Animal adotado pelo Conselho Nacional de Experimentação Animal (CONCEA) e aprovado pela Comissão de Ética no Uso de Animais (CEUA) do ICB USP (CEUA: 104- 23, livro 03, ano 2014).

\subsection{Procedimentos cirúrgicos (Estereotaxia)}

Em todos os procedimentos cirúrgicos foram utilizados métodos assépticos para evitar os riscos de infecções. Os animais foram, inicialmente, anestesiados intraperitonealmente (i.p) com cetamina $(100 \mathrm{mg} / \mathrm{kg})$ e xilazina $(7 \mathrm{mg} / \mathrm{kg})$ e adaptados a um aparelho estereotáxico Kopf (Modelo 1760). Após uma incisão longitudinal na pele e no tecido subcutâneo para a exposição da calota craniana, o lambda e o bregma foram utilizados como referência para nivelar as cabeças dos animais. Foram realizadas 2 injeções de 6-OHDA (24 $\mu \mathrm{g} / \mu \mathrm{l})$ ou salina $+0,3 \%$ de ácido ascórbico (veículo) por lado com coordenadas distintas para atingir o CPu: 1) 2,7 mm lateral à linha média, $0 \mathrm{~mm}$ rostral ao bregma e 4,5 $\mathrm{mm}$ ventral à dura-máter e 2) 3,2 mm lateral à linha média, $0,5 \mathrm{~mm}$ rostral ao bregma e $4,5 \mathrm{~mm}$ ventral à duramáter. As injeções bilaterais (volume de 0,5 $\mu$ l/injeção) de 6-OHDA ou veículo no $\mathrm{CPu}$ foram realizadas utilizando-se de uma seringa de Hamilton de $10 \mu \mathrm{l}$.

Após as injeções da toxina, as cabeças dos animais foram suturadas, os animais receberam uma dose profilática de pentabiótico intramuscular (Fort Dodge Saúde Animal Ltda) e do analgésico/anti-inflamatório Ketoflex (cetoprofeno 1\%, 0,02 $\mathrm{ml} /$ rato) subcutâneo. Foram colocados em caixas com água e ração "ad libitum" e 
mantidos em salas com temperatura e luminosidade controladas, por um período determinado, de acordo com o protocolo experimental.

\subsection{Fármacos utilizados}

O fármaco utilizado foi a 6-OHDA $(24 \mu \mathrm{g} / \mu \mathrm{l}$, 6-OHDA Hydrochloride-H4381Sigma ${ }^{\circledR}$, Saint Louis, MO, USA): toxina que não cruza a barreira hematoencefálica, sendo então administrada estereotaxicamente no próprio CPu bilateralmente para efetuar uma lesão retrógrada dos neurônios nigroestriais (revisado por BLUM et al., 2001). A 6-OHDA foi dissolvida em salina $+0,3 \%$ de ácido ascórbico para diminuir a oxidação do fármaco.

\subsection{Medida da ventilação pulmonar}

Foi utilizada nesta etapa do protocolo a avaliação da ventilação (VE) por meio de registros pletismográficos automáticos e contínuos (EMKA Technologies, Falls Church, VA, USA). Este método baseia-se no princípio de que um animal, dentro de uma câmara, terá seu volume de ar corrente inspirado aquecido, da temperatura da câmara à temperatura corporal e saturado com vapor de água. Durante a expiração, o volume de ar corrente é resfriado até a temperatura da câmara, havendo perda de vapor de água. Essas condições, de aquecimento e umidificação do ar inspirado bem como de resfriamento e desidratação do ar expirado, são acompanhadas de mudanças de pressão no interior da câmara de registro (MENKES; DUBOIS, 1969).

A câmara de pletismografia utilizada neste protocolo foi uma caixa de acrílico de 5 litros, onde os animais foram colocados, permitindo sua livre movimentação. Esta câmara é composta por quatro vias de acesso, sendo duas de entrada e duas vias de saída. A primeira via de entrada conecta-se com o ventilador (VENT- 4C1) ofertando uma mistura de gás que foi inalado pelo animal durante o experimento em questão. O fluxo e a pressão de gás são regulados pelo sistema (Flow regulation Alicat Scientific) de acordo com o protocolo proposto. A segunda via de entrada corresponde ao sistema de calibração, a qual, um volume referencial de ar é injetado na câmara fechada e vazia, por meio de uma seringa de $20 \mathrm{ml}$ (no intervalo de tempo de 2s). As vias de saída referem-se aos sensores de umidade, temperatura e ao transdutor diferencial de pressão (DPT Respiratory Flow Head, EMKA Technologies), conectados a um pré-amplificador e ao software de análise (modelo 
EMKA-IOX 2, versão 2.8.0.1.9). Ademais, uma bomba de sucção de ar (VENT-2) conectada a um dispositivo desumidificador com sílica em seu interior, remove o ar expirado completando o circuito. Duas variáveis respiratórias foram medidas; a frequência respiratória (fR) e o volume corrente $(\mathrm{VT})^{1}$. A VE foi calculada pelo produto entre fR e VT.

Foram realizadas medidas da temperatura corporal de cada animal por meio de termômetro digital clínico (Termo Med Incoterm) antes e após a avaliação pletismográfica. Os parâmetros respiratórios foram automaticamente calculados, utilizando a fórmula de Drorbaugh and Fenn (1955) e posteriormente corrigidos pela massa corporal. Modificações na temperatura, umidade e pressão atmosférica dentro da câmara de registro foram continuamente registradas e utilizadas para correção automática do cálculo do VT. A principal vantagem deste método de pletismografia automática em relação ao método de captação de dados analógico consiste no fato de que não se faz necessário abrir a câmara entre os registros. Deste modo, o registro contínuo permite que o microambiente no interior da câmara seja preservado.

Os animais permaneceram inicialmente livres para exploração e posterior adaptação ao ambiente da câmara por um período de 45 a 60 minutos. Antes de cada registro a câmara foi ventilada com ar atmosférico $\left(21 \%\right.$ de $\left.\mathrm{O}_{2}\right)$. Após a fase exploratória, a mensuração das variáveis respiratórias basal foi efetuada por 15 minutos. Em seguida, os animais foram submetidos por um período de 10 minutos à hipercapnia (mistura gasosa de $7 \%$ de $\mathrm{CO}_{2}$, balanceada com $21 \%$ de $\mathrm{O}_{2}$ e $72 \%$ de nitrogênio $\left.\left(\mathrm{N}_{2}\right)\right)$. Ao final desse intervalo, a câmara foi ventilada com ar atmosférico por 30 minutos e as variáveis respiratórias mensuradas novamente. Os procedimentos de registros nesse pletismógrafo foram realizados 1 dia antes, 30, 40 ou 60 dias após a injeção de veículo ou 6-OHDA no CPu.

${ }^{1}$ Fórmula de cálculo para VT :

$$
V T=\frac{P T}{P K} \times V K \times \frac{T C}{T R} \times \frac{(P B-P C)}{(P B-P C)-\frac{T C}{T b} \times(P B-P R)}
$$

Definição dos símbolos da equação: VT: Volume de ar corrente; VK: Volume de ar injetado na câmara do animal para calibração; PT: Deflexão de pressão associada com cada volume de ar corrente; PK: Deflexão de pressão associada ao volume injetado para calibração; Tb: Temperatura corporal (em Kelvin); TC: Temperatura do ar dentro da câmara do animal; PB: Pressão barométrica; 
PR: Pressão de vapor de água a temperatura corporal; PC: Pressão de vapor de água na câmara do animal; TR: Temperatura ambiente.

\subsection{Perfusão}

Ao final dos experimentos, os animais foram profundamente anestesiados com pentobarbital de sódio (60 mg/kg, i.p.) e perfundidos através do ventrículo cardíaco esquerdo com solução salina tamponada com fosfato (PBS) $(\mathrm{pH} 7,4)$, seguido de formaldeído ( $4 \%$ em 0,1 M de fosfato, $\mathrm{pH} 7,4$ ), utilizando-se uma bomba de perfusão com a rotação ajustada para 50 rpm.

\subsection{Imunoistoquímica}

Ao término da perfusão, os animais tiveram seus encéfalos retirados e submersos no fixador e mantidos no agitador por 4 horas. Após este período, 0 material foi transferido para uma solução contendo sacarose a $20 \%$ em PBS para desidratação a $4{ }^{\circ} \mathrm{C}$. Após 24 horas, os encéfalos foram cortados em microtómo numa espessura de $40 \mu \mathrm{m}$ e guardados em solução crioprotetora (20\% de glicerol, $30 \%$ de etileno glicol em $50 \mathrm{mM}$ de fostato, $\mathrm{pH}$ 7.4) em placas de 24 poços, preservando as qualidades do tecido (SCHREIHOFER; GUYENET 1997).

Foram quantificadas 1 em 6 séries de seções do encéfalo de $40 \mu \mathrm{m}$ por animal, totalizando uma distância de $240 \mu \mathrm{m}$ entre os cortes. Para avaliar a extensão da lesão nigral causada pela 6-OHDA e a seletividade da mesma, os cortes da SN foram selecionados e submetidos à metodologia de imunoperoxidase com anticorpo primário específico para detecção da enzima limitante da síntese de dopamina, TH (Mouse anti- TH, 1:1000).

A proteína glial fibrilar ácida (GFAP) é um componente chave no citoesqueleto de astrócitos de vertebrados. São proteínas que garantem a integridade e resiliência astrocitária, compondo uma rede de filamentos intermediários no citoplasma, que passa a partir da região perinuclear à sua periferia. Sendo assim, são classicamente utilizadas como marcadores de astrócitos (MIDDELDORP; HOL, 2011; QUINLAN et al., 2007; SUKHORUKOVA et al., 2015). Portanto, para avaliar alterações de astrócitos, os cortes contendo as regiões do NTS, RTN, preBotC e rVRG foram selecionados e submetidos à metodologia de imunoperoxidase com anticorpo primário específico para GFAP (mouse anti-GFAP, 1:5000). 
A lonized calcium binding adaptor molecule 1 (Iba1) é uma proteína ligante de actina cruzada (IBA) especificamente expressa em membranas de macrófagos, como a microglia, reguladas positivamente quando estas são ativadas (SASAKI et al., 2001). Sendo as microglias ativadas por vários estímulos ambientais causados pela lesão neural ou ainda doenças neurodegenerativas (IMAI ; KOHSAKA, 2002) é amplamente aceito seu uso em diversos estudos como marcador específico de microglia. Deste modo, para avaliar alterações da microglia, os cortes contendo as regiões do NTS, RTN, preBotC e rVRG foram selecionados e submetidos à metodologia de imunoperoxidase com anticorpo primário específico para IBA (Rabbit anti-IBA, 1:2000).

Nenhuma marcação foi observada quando a reação foi realizada na ausência do anticorpo primário.

Finalmente, após tratamento imunoistoquímico, os cortes encefálicos foram montados em sequência rostro-caudal em lâminas, desidratados com álcool e xilol e posteriormente cobertos com Kristalon (EMD Chermicals Inc, NJ). A quantificação da lesão e a localização dos grupamentos neuronais avaliados neste estudo consideraram estruturas anatômicas baseadas no Atlas de Paxinos e Watson (1998). Imagens dos cortes encefálicos foram capturadas por fotomicrografia em microscópio de luz transmitida (NIKON Eclipse E-800) acoplado a uma câmara digital (NIKON DSF1) e posterior análise utilizando o programa ImageJ programa de software de domínio público (disponível a partir do site http://rsb.info.nih.gov/ij/).

Foram selecionados cinco cortes rostrais ao término do núcleo geniculado medial (bregma - 6,30mm) para a quantificação da $\mathrm{SN}$, correspondentes ao intervalo de bregma entre - 5,34 a - 6,30 mm. A extensão da lesão foi analisada pela quantificação do número de neurônios marcados com TH.

Para avaliar as alterações gliais na região do NTSc e NTSi foram utilizados quatro cortes caudais ao fechamento do 4 ventrículo (bregma - 13,68 mm), correspondentes ao intervalo de bregma entre - 13,68 a - $14.40 \mathrm{~mm}$. Para região do RTN localizados ventralmente à porção caudal do núcleo motor facial e próximo à superfície ventral do bulbo foram considerados cinco cortes rostrais à porção mais caudal do núcleo facial (bregma - 11,60 mm), correspondentes ao intervalo de bregma entre - 10,64 a - 11,60 mm. A análise do preBotC e do rVRG que se 
localizam ventralmente à porção compacta ou não do núcleo ambíguos, respectivamente, foram considerados 4 cortes caudais ao surgimento do núcleo linear (bregma - 12,30 mm). Com isso, os cortes analisados correspondem ao intervalo de bregma entre - 12,30 a - 13,02 mm. As alterações gliais do NTS, RTN, preBotC e do rVRG foram analisadas por densidade integrada utilizando a ferramenta threshold, para astrócitos marcados com GFAP e microglias marcadas com IBA.

Para as regiões do NTSc e NTSi, a região a ser analisada foi definida e contornada segundo o atlas de Paxinos e Watson (1998). O rVRG e o preBotC foram definidos por um círculo de $0,875 \mathrm{~mm}$ de diâmetro com a parte superior centrada na borda ventral do núcleo ambíguos (TOTOLA et al., 2017). O RTN foi definido por uma figura com as dimensões em que foi feito o contorno a partir do meio do núcleo facial para o centro da porção ventral e então perpendicular à superfície ventral. A região continuou medialmente ao longo da superfície ventral para a borda medial do trato piramidal, finalizando com uma diagonal até o meio do núcleo facial (TAKAKURA et al., 2008). Todas as análises foram feitas bilateralmente nas regiões encefálicas descritas, de acordo com estudos prévios do nosso laboratório. As imagens foram obtidas usando o mesmo tempo de exposição, as regiões foram calculadas pelo software e os dados são representados em porcentagem da área marcada com a imunorreatividade, tendo o total da área analisada (marcada e não pela imunorreatividade) como 100\%.

\subsection{Análise estatística}

A análise estatística foi realizada utilizando-se o programa Sigma Stat 3.0 (Jandel Corporation, Point Richmond, CA). Os dados foram tabelados e representados em gráficos como média \pm erro padrão da média. Para análise estatística foi utilizada análise de variância (ANOVA) One Way seguida pelos póstestes de Dunn's, Teste $\mathrm{t}$ - pareado e Teste t que foram utilizados para comparações entre os valores obtidos. Correlação de Pearson foi utilizada para avaliar a associação entre os parâmetros ventilatórios (basais ou durante hipercapnia) e a densidade de astrócitos (GFAP-ir) e microglia (IBA-ir), nas regiões de interesse descritas. $O$ índice de significância foi fixado em $p<0,05$. 


\section{RESULTADOS}

As três primeiras sessões de descrição dos resultados (5.1, 5.2 e 5.3) correspondem à confirmação do modelo estudado. Assim, nessas sessões analisamos o tamanho da lesão efetuada na $\mathrm{SNc}$ e as alterações respiratórias basais e induzidas por hipercapnia observadas nesse modelo.

\subsection{Efeito da injeção bilateral de 6-OHDA no $\mathrm{CPu}$ sobre neurônios dopaminérgicos da SN}

A fim de confirmarmos a efetividade do modelo, torna-se necessária a quantificação da lesão na SNc produzida pela injeção de 6-OHDA no CPu. Foram utilizados neste protocolo 31 animais. Destes, 11 receberam solução veículo (salina) e, portanto, foram utilizados como controles. Sendo assim, 20 animais receberam injeções bilaterais de 6-OHDA (24 $\mathrm{\mu g} / \mu \mathrm{l})$ no $\mathrm{CPu}, 5$ pertencentes ao grupo analisado 30 dias após a indução do modelo experimental (grupo 30 dias), 8 animais analisados 40 dias após (grupo 40 dias) e 7 animais 60 dias após (grupo 60 dias). Os nossos resultados mostraram que os animais que receberam a injeção de 6OHDA e foram analisados 30, 40 e 60 dias após a injeção apresentaram, respectivamente, redução de 74,10\%, 72,19\% e 78,36\% dos neurônios dopaminérgicos da SNc $(381,40 \pm 38,32,409,50 \pm 20,79$ e $318,57 \pm 32,57$, vs. veículo: 1472,64 $\pm 56,82$ neurônios, $p<0,05$, Figura 5). 

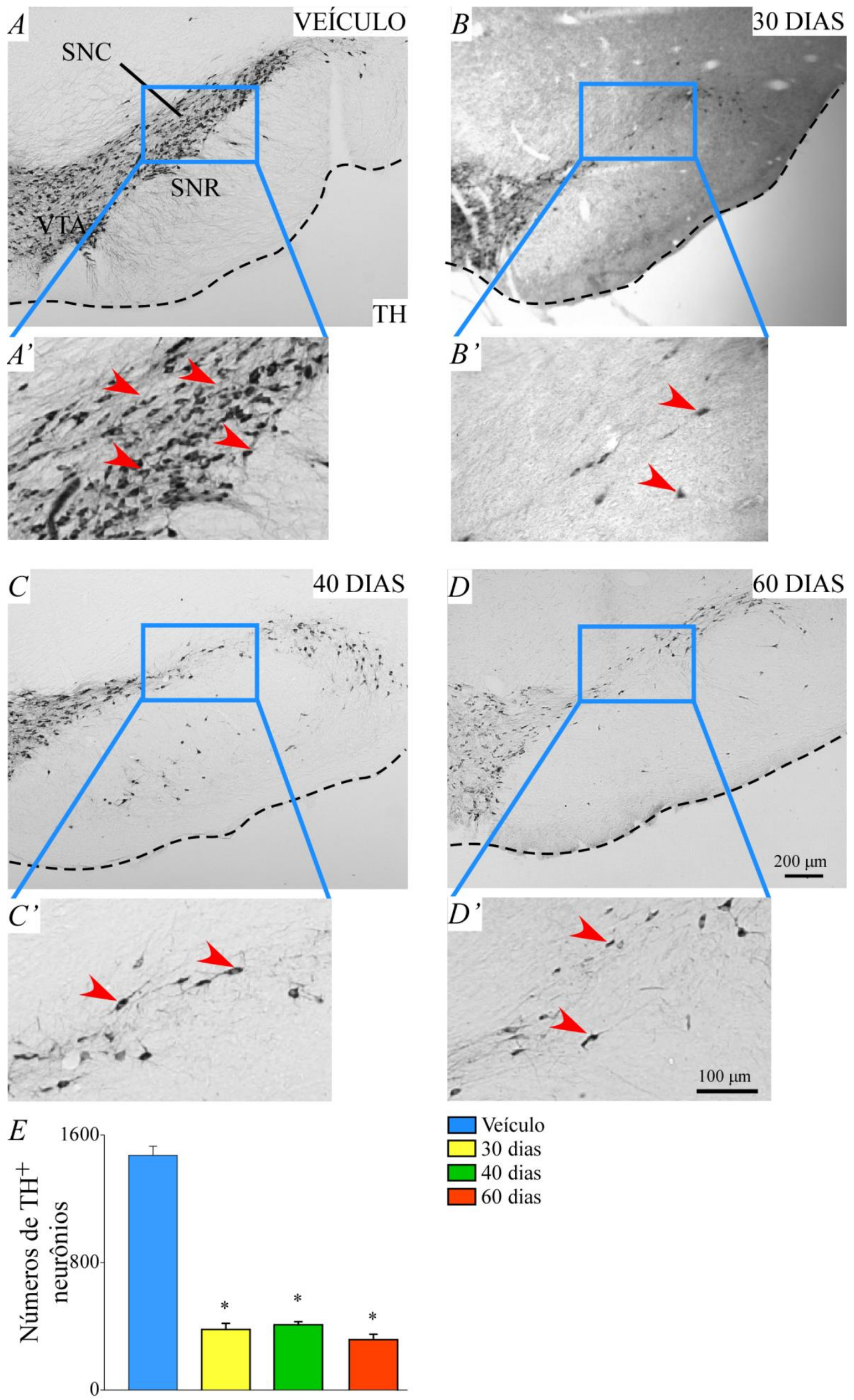

Figura 5 - Efeito da injeção bilateral de 6-OHDA no CPu sobre neurônios dopaminérgicos da SN. Fotomicrografias da SNc de animais que receberam injeção bilateral de veículo (A) ou 6-OHDA (24 $\mu \mathrm{g} / \mu \mathrm{l}$ ) e foram sacrificados 30 (B), 40 (C) ou 60 (D) dias após a injeção da toxina (bregma: - 5,82). As setas vermelhas representam exemplos de neurônios que apresentaram imunorreatividade para $\mathrm{TH}$. E) Número de neurônios imunorreativos para tirosina-hidroxilase (TH) na SNc. Análise de Variância (ANOVA) one-way com pós teste de Dunn's. ${ }^{*} p<0,05$ em relação ao grupo veículo. Abreviações: SNC, substância negra compacta; SNR, substância negra reticulada; VTA, área tegmental ventral. A escala apresentada em D deve ser aplicada para A-D e em D' para A'-D'. 


\subsection{Efeitos da injeção bilateral de 6-OHDA no CPu na respiração basal de ratos não anestesiados}

Para as análises funcionais foram avaliados 21 animais, sendo 15 que receberam de 6 -OHDA $(24 \mu \mathrm{g} / \mu$ ) bilateralmente no $\mathrm{CPu}$ (30 dias, $\mathrm{n}=5 ; 40$ dias, $\mathrm{n}=$ 5 e 60 dias, $n=5$ ) e 6 pertencentes ao grupo controle. Não foram considerados para análise os dados funcionais dos demais animais que receberam 6-OHDA ou veículo por problemas na aquisição de dados confiáveis durante os registros da ventilação, pela movimentação dos animais.

Quarenta e sessenta dias após a injeção bilateral de 6-OHDA observou-se redução na fR (40 dias: 76,04 $\pm 2,63$, vs. antes: $91,51 \pm 2,91$ e 60 dias: 80,48 $\pm 3,86$, vs. antes: $111,18 \pm 5,22 \mathrm{rpm}, \mathrm{p}<0,05$ ) (Figura $6 \mathrm{C}-\mathrm{D}$ ). Não foram observadas alterações na fR dos animais do grupo de 30 dias $(84,24 \pm 2,05$, vs. antes: $87,86 \pm$ $2,34 \mathrm{rpm}$, Figura $6 \mathrm{~B})$ e grupo veículo $(96,44 \pm 6,17$, vs. antes: $97,63 \pm 4,36 \mathrm{rpm}$, Figura 6A).

Devido à redução da $f R$ observou-se redução na VE após quarenta e sessenta dias após a injeção de 6-OHDA no CPu (40 dias: 319,21 $\pm 67,82$, vs. antes: $507,95 \pm 70,59$ e 60 dias: $305,58 \pm 20,63$, vs. antes: $456,10 \pm 40,24 \mathrm{ml} / \mathrm{kg} / \mathrm{min}, \mathrm{p}<$ 0,05 ) (Figura $6 \mathrm{~L}-\mathrm{M}$ ). Não foram observadas alterações na VE dos animais do grupo de 30 dias (220,56 $\pm 13,68$, vs. antes: $250,96 \pm 19,81 \mathrm{ml} / \mathrm{kg} / \mathrm{min}$, Figura $6 \mathrm{~J})$ e grupo veículo $(329,35 \pm 41,98$, vs. antes: $342,76 \pm 35,92 \mathrm{ml} / \mathrm{kg} / \mathrm{min}$, Figura $6 \mathrm{l})$.

Não houve diferença no VT em nenhum dos grupos analisados. 


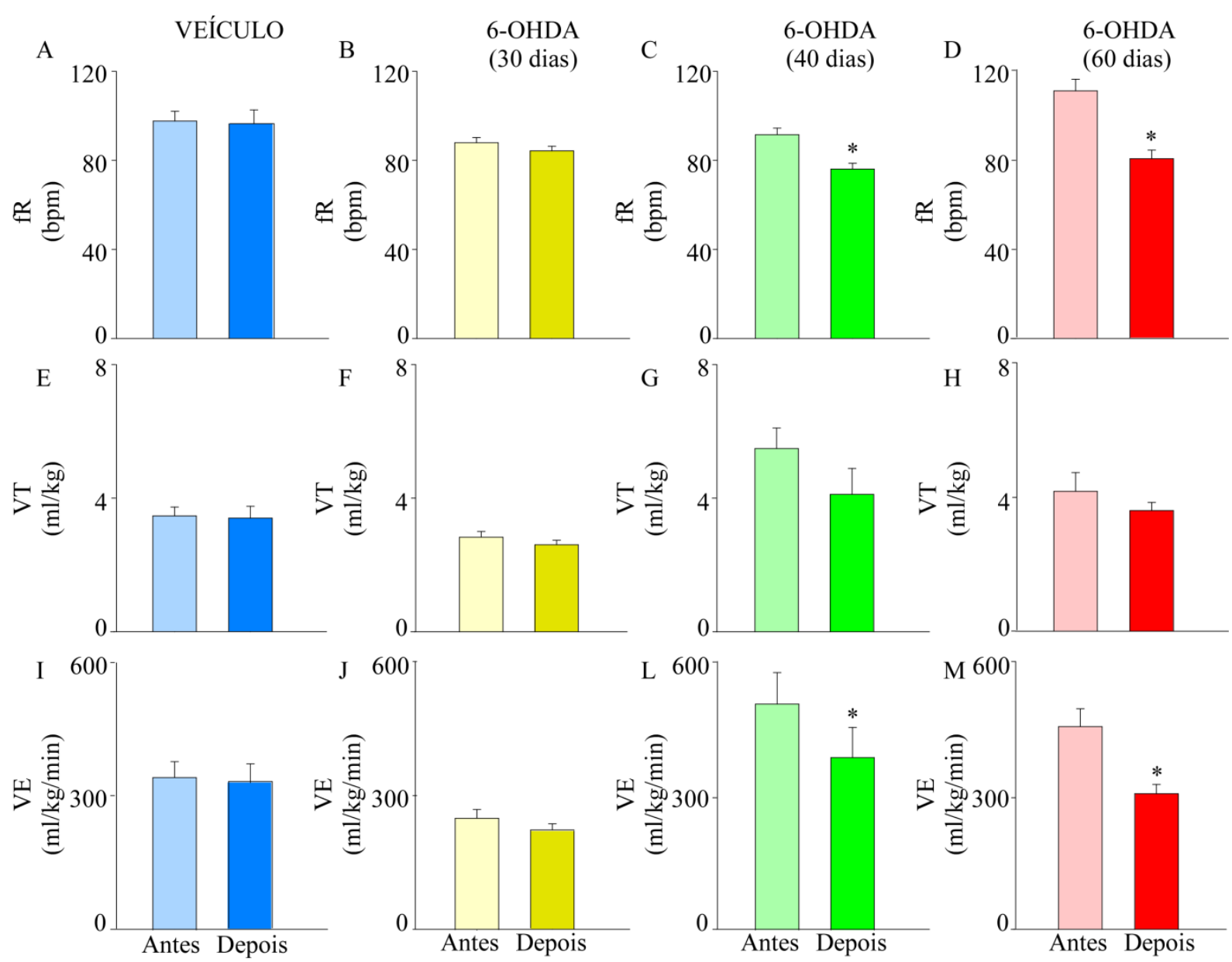

Figura 6 - Efeitos da injeção bilateral de 6-OHDA no CPu na respiração basal de ratos não anestesiados. Alterações na A-D) frequência respiratória (fR), E-H) volume corrente (VT) e $I-J)$ ventilação (VE) basais de ratos não anestesiados que receberam a injeção de $A, E, I)$ veículo ou 6OHDA (24 $\mathrm{\mu g} / \mu \mathrm{l})$ no CPu e foram analisados após B, F, J) 30 dias, C, G, L) 40 dias ou D, H, M) 60 dias. Teste t pareado, ${ }^{*} p<0,05$, comparados ao registro anterior à injeção da toxina. 


\subsection{Efeitos da injeção bilateral de 6-OHDA no CPu nas respostas respiratórias produzidas por hipercapnia em ratos não anestesiados}

Nos mesmos grupos de animais descritos acima, 30, 40 e 60 dias após a injeção bilateral de 6-OHDA ou veículo foi avaliado se a lesão do CPu é capaz de reduzir o efeito estimulatório na ventilação produzido pela ativação dos quimiorreceptores centrais, por exemplo, após uma condição de hipercapnia (7\% $\mathrm{CO}_{2}$ ). Foi possível observar que as respostas na $\mathrm{fR}, \mathrm{VT}$ e VE induzidas pela hipercapnia foram reduzidas no grupo de 40 dias após injeção bilateral de 6-OHDA $(24 \mu \mathrm{g} / \mu \mathrm{l})$ no CPu em animais acordados (fR: $105 \pm 3,5$, vs. antes: 128,66 $\pm 2,5 \mathrm{rpm}$, VT: $6,8 \pm 0,2$, vs. antes: $8,82 \pm 0,33 \mathrm{ml} / \mathrm{kg}$; e VE: $720,59 \pm 6,46$ vs. antes: $1136,47 \pm$ $56,48 \mathrm{ml} / \mathrm{kg} / \mathrm{min}, \mathrm{p}<0,05$ ) (Figura $7 \mathrm{C}, \mathrm{G} \mathrm{e} \mathrm{L}$ ).

Os animais controles e o grupo de 30 e 60 dias foram capazes de atingir valores semelhantes de aumento de fR, VT e VE durante a hipercapnia comparados ao período antes da injeção de 6-OHDA ou veículo (Figura 7A-B, D, E-F, H, I-J, M). 
$\square$ Antes $\quad+$ Diferente de normocapnia

$\circ$ Depois * Diferente de antes
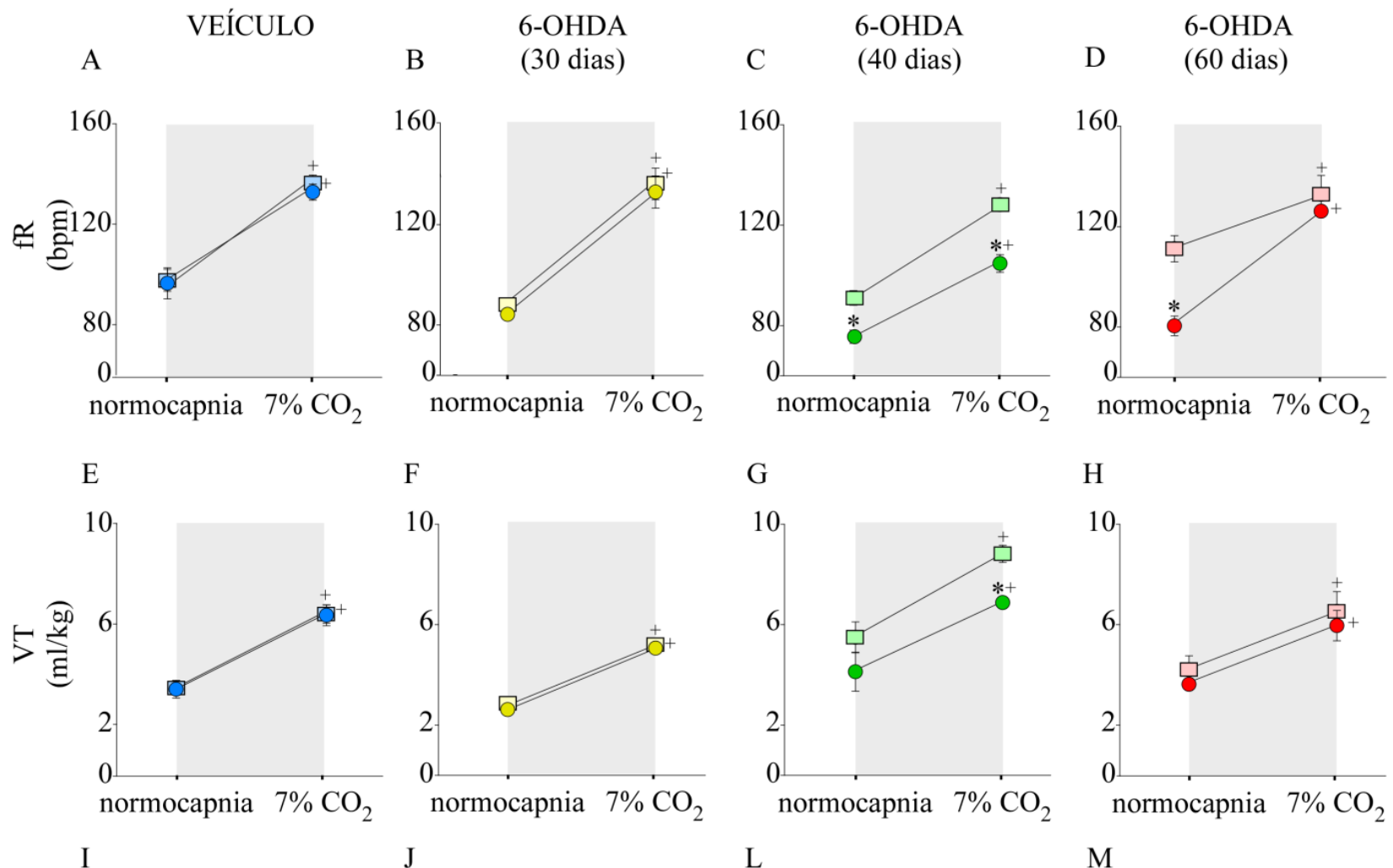

G
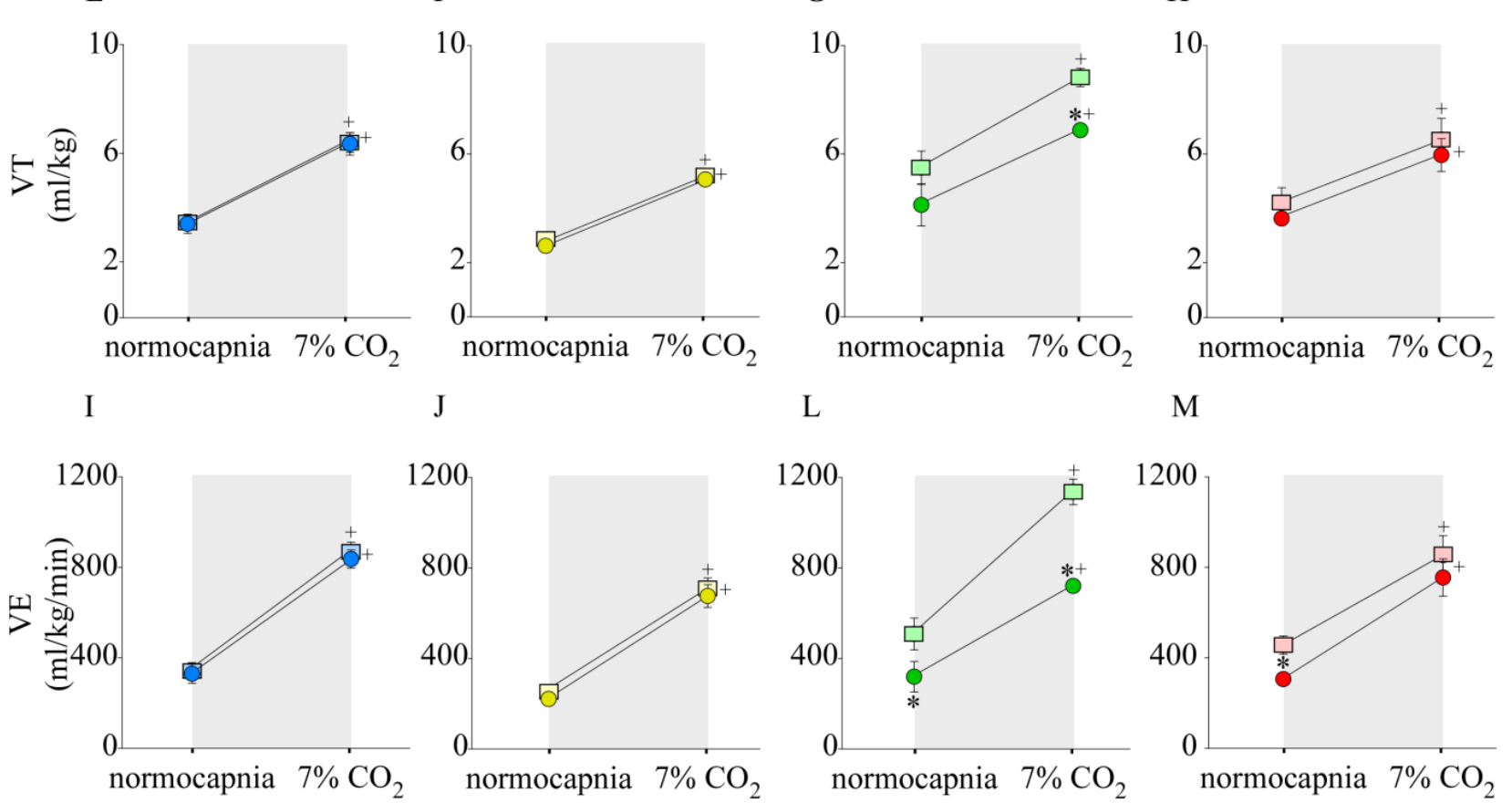

Figura 7 - Efeitos da injeção bilateral de 6-OHDA no CPu nas respostas respiratórias produzidas por hipercapnia em ratos não anestesiados. Alterações na $A-D)$ frequência respiratória (fR), $E-H)$ volume corrente (VT) e I-M) ventilação (VE) produzidas por hipercapnia em ratos não anestesiados que receberam a injeção de $A, E, I)$ veículo ou $6-\mathrm{OHDA}(24 \mu \mathrm{g} / \mu \mathrm{l})$ no $\mathrm{CPu}$ e foram analisados após $\mathrm{B}, \mathrm{F}$, J) 30 dias, C, G, L) 40 dias ou $D, H, M) 60$ dias. Teste t pareado, ${ }^{*} p<0,05$ (comparados ao registro anterior à injeção da toxina) $+p<0,05$ (comparado ao período de normocapnia).

A partir da validação do modelo, as próximas séries de experimentos representam a avaliação da glia em regiões envolvidas no controle neural da respiração nesse modelo experimental de DP. Para essas análises foram utilizados 3 animais do grupo veículo (30 dias), 3 animais do grupo veículo (40 dias), 3 animais do grupo veículo (60 dias), 5 animais do grupo 6-OHDA (30 dias), 5 animais do grupo 6-OHDA (40 dias) e 5 animais do grupo 6-OHDA (60 dias). 


\subsection{Efeito da injeção bilateral de 6-OHDA no CPu sobre a expressão de GFAP nas regiões envolvidas no controle neural da respiração}

Os resultados mostraram que apenas no rVRG ocorreu uma redução de $14,7 \%$ na densidade astrocitária após a indução do modelo experimental no grupo de 30 dias, comparado ao seu grupo veículo $(10,45 \pm 0,51$, vs. veículo: 12,25 \pm $1,07 \%$ de imunorreatividade para GFAP na área analisada, ${ }^{*} p<0,05$, Figura 10) e essa redução permaneceu durante todo o período analisado (40 dias: 42,7\% e 60 dias $60,8 \%)$.

A partir de 40 dias, observou-se uma redução de 40,80\% no RTN (5,55 \pm 0,35 , vs. veículo: $9,37 \pm 0,73 \%$ de imunorreatividade para GFAP na área analisada, ${ }^{*} \mathrm{p}<0,05$, Figura 12) que permaneceu após 60 dias $(62,92 \%)$.

Por fim, a partir de 60 dias, a redução também se tornou significante no restante das regiões analisadas. No NTSc observou-se uma redução de 47,98\% $(18,90 \pm 2,50$, vs. veículo: $36,33 \pm 2,33 \%$ de imunorreatividade para GFAP na área analisada, ${ }^{*} p<0,05$, Figura 8), no NTSi observou-se uma redução de $45,67 \%(23,00$ $\pm 1,40$, vs. veículo: $42,33 \pm 3,33 \%$ de imunorreatividade para GFAP na área analisada, ${ }^{*} p<0,05$, Figura 9$)$ e no preBotC de $51,1 \%$ (7,45 $\pm 1,65$, vs. veículo: 15,25 $\pm 2,20 \%$ de imunorreatividade para GFAP na área analisada, ${ }^{*} p<0,05$, Figura11). 
VEÍCULO

30 DIAS

40 DIAS

60 DIAS
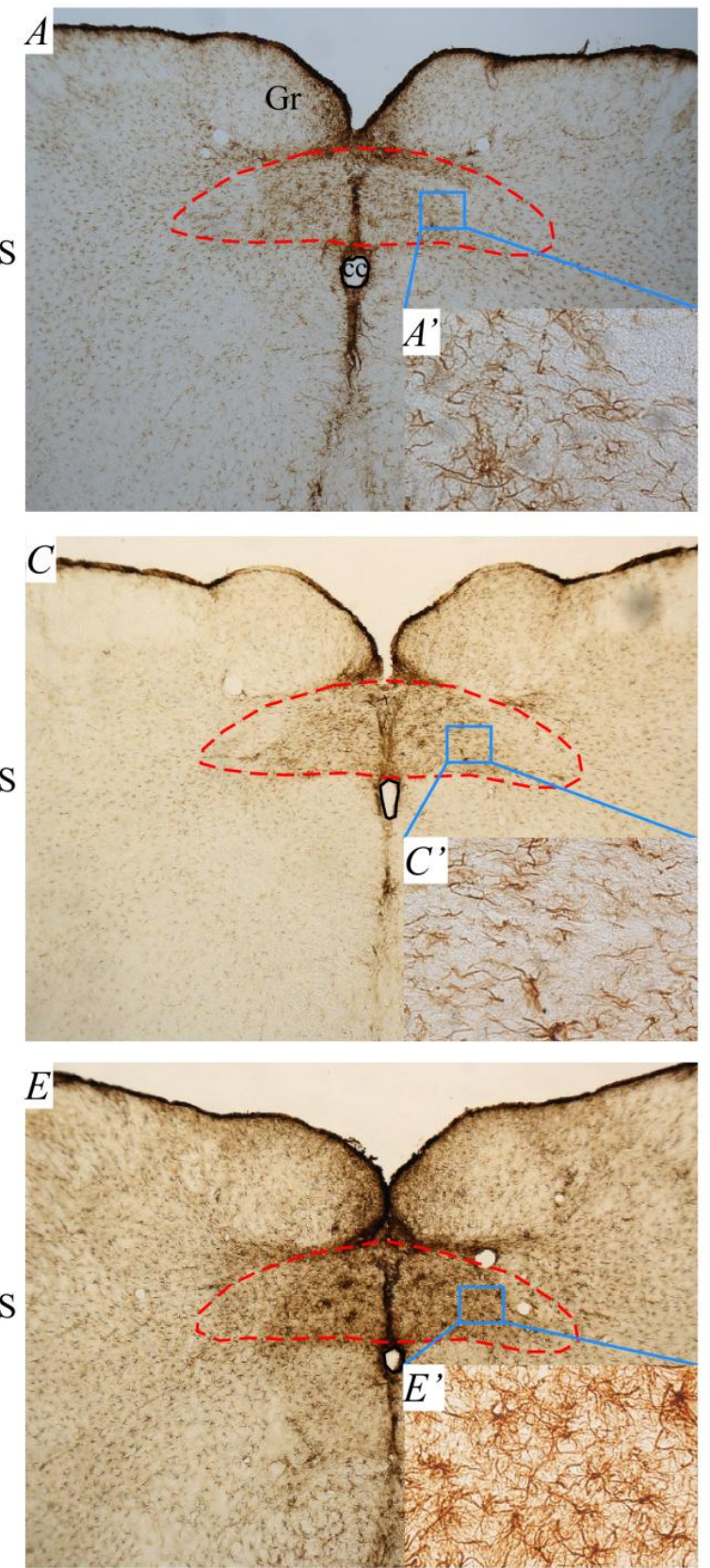
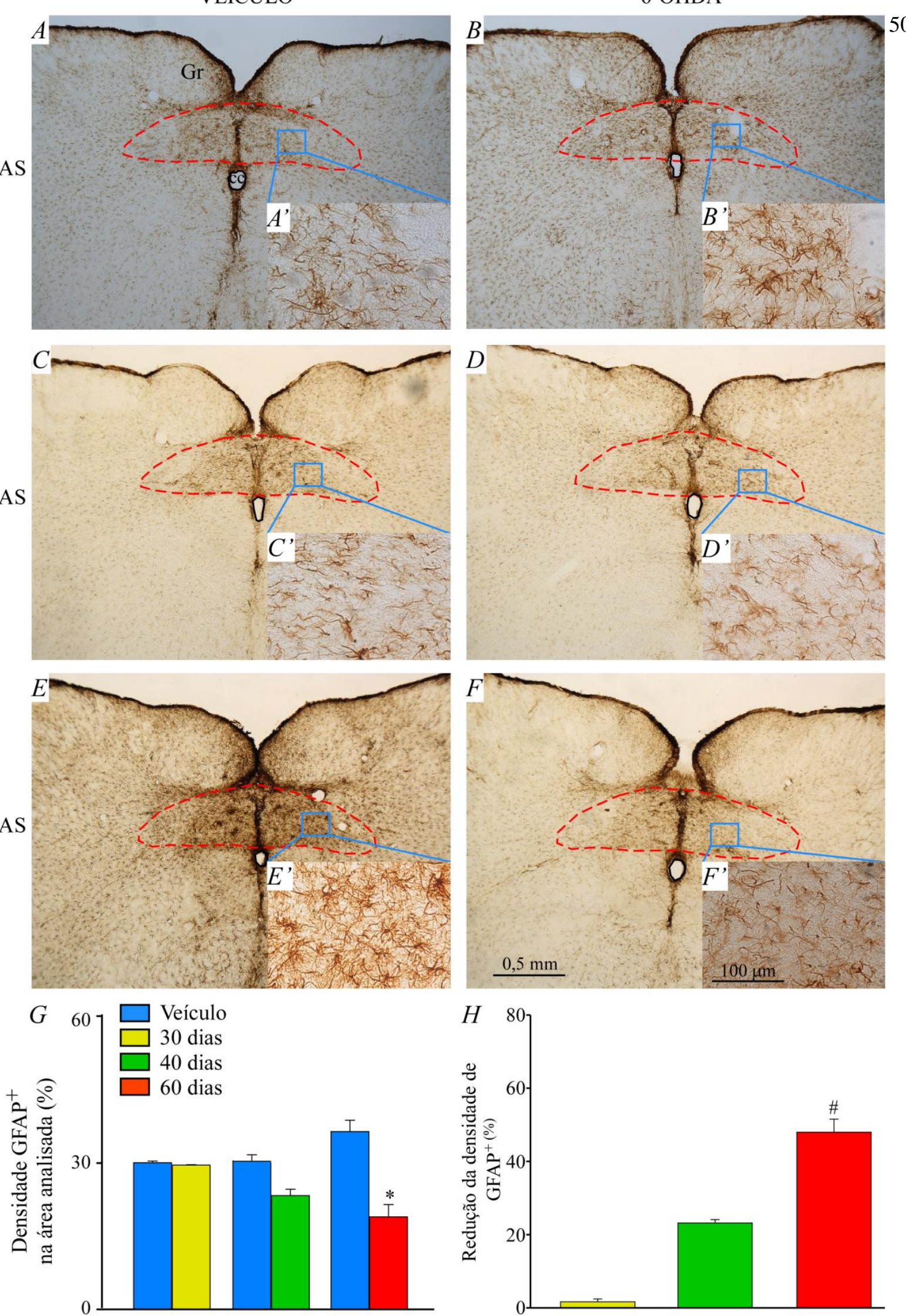

Figura 8 - Efeito da injeção bilateral de 6-OHDA no CPu sobre a expressão de GFAP no NTSc. Fotomicrografias do NTSc de animais que receberam injeção bilateral de veículo (A, C, E) ou 6-OHDA $(24 \mu \mathrm{g} / \mathrm{\mu l}$ ) e foram sacrificados 30 (B), 40 (D) ou 60 (F) dias após a injeção da toxina (bregma - 14,16 $\mathrm{mm}$ ). G) Porcentagem de densidade de imunorreatividade para GFAP na área analisada do NTSc. H) Porcentagem de redução da densidade de imunorreatividade para GFAP 30, 40 ou 60 dias após injeção de 6-OHDA no CPu comparado com respectivo veículo. Teste- $t$, " $\mathrm{p}<0,05$ (diferente de respectivo veículo), One Way, \# p<0,05 (diferente de 30 dias). Abreviações: $c c$, canal central; Gr, núcleo grácil. 
VEÍCULO

30 DIAS

40 DIAS

60 DIAS
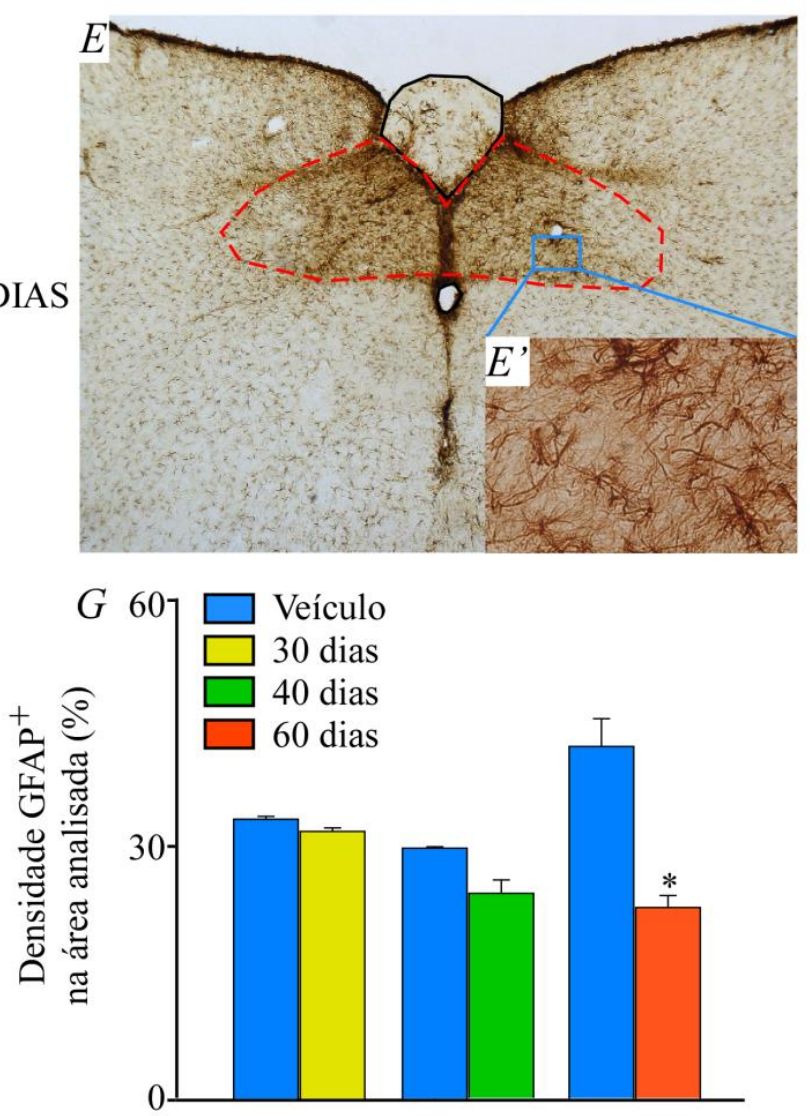

6-OHDA
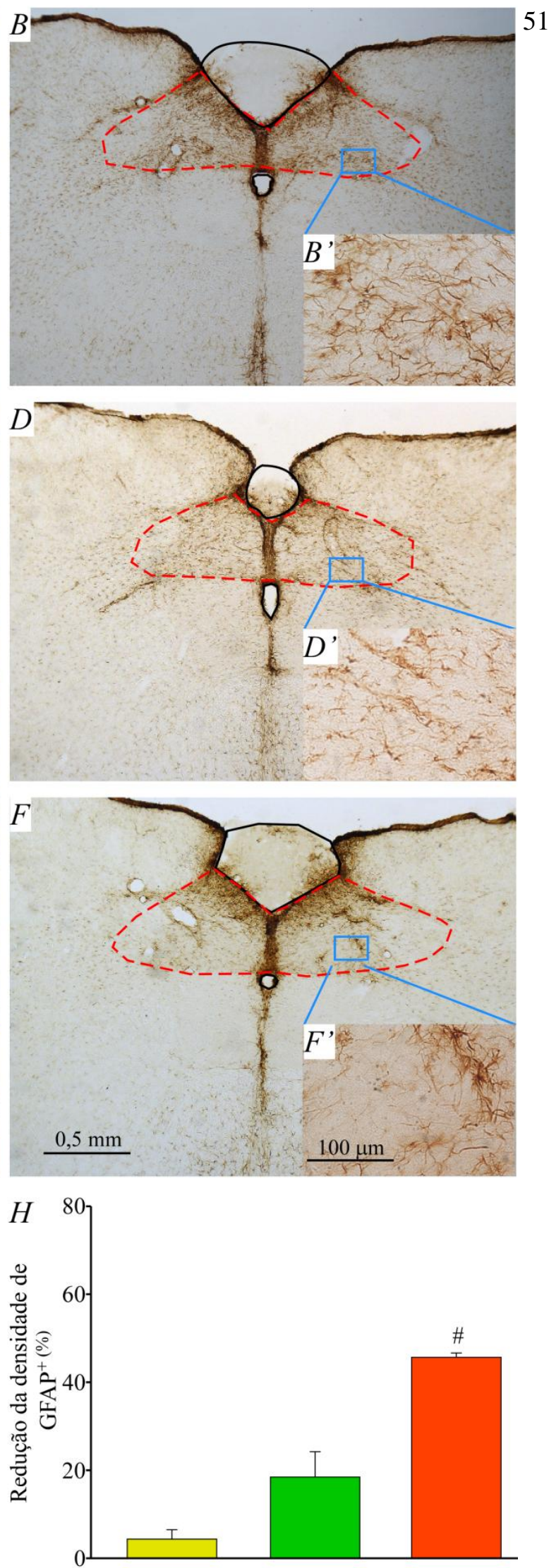

Figura 9 - Efeito da injeção bilateral de 6-OHDA no CPu sobre a expressão de GFAP no NTSi. Fotomicrografias do NTSi de animais que receberam injeção bilateral de veículo (A, C, E) ou 6-OHDA $(24 \mu \mathrm{g} / \mathrm{\mu l})$ que foram sacrificados 30 (B), 40 (D) ou 60 (F) dias após a injeção da toxina (bregma $13,92 \mathrm{~mm}$ ). G) Porcentagem da densidade de imunorreatividade para GFAP na área analisada do NTSi. H) Porcentagem de redução da densidade de imunorreatividade para GFAP 30, 40 ou 60 dias após injeção de 6-OHDA no CPu comparado com respectivo veículo. Teste- $t$, ${ }^{*} p<0,05$ (diferente de respectivo veículo), One Way, \# $p<0,05$ (diferente de 30 dias). Abreviações: $c c$,canal central; AP, área postrema. 

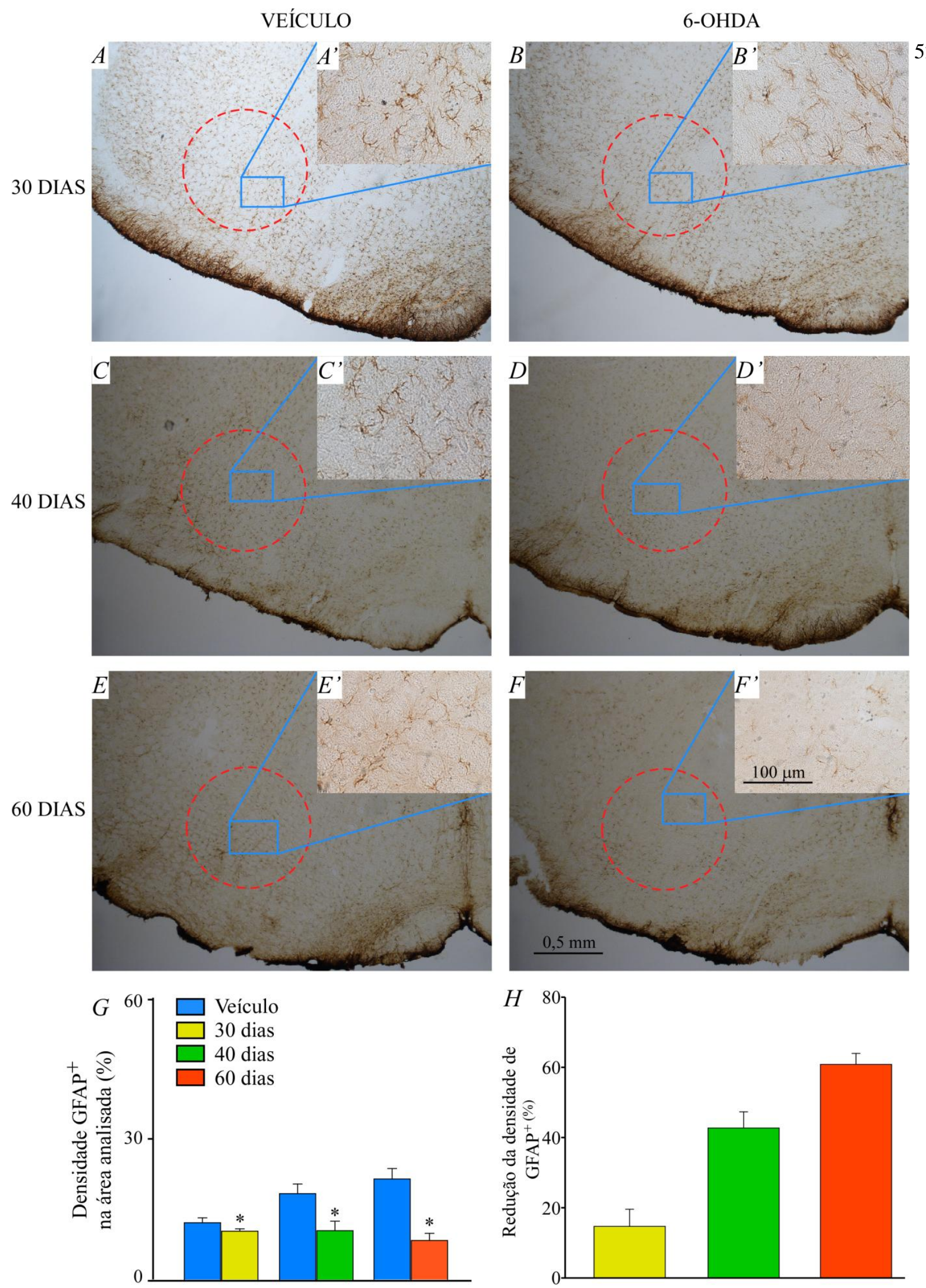

Figura 10 - Efeito da injeção bilateral de 6-OHDA no CPu sobre a expressão de GFAP no rVRG. Fotomicrografias do rVRG de animais que receberam injeção bilateral de veículo (A, C, E) ou 6-OHDA $(24 \mu \mathrm{g} / \mu \mathrm{l})$ que foram sacrificados 30 (B), 40 (D) ou 60 (F) dias após a injeção da toxina (bregma $13,02 \mathrm{~mm}$ ). G) Porcentagem de densidade de imunorreatividade para GFAP na área analisada do rVRG. H) Porcentagem de redução da densidade de imunorreatividade para GFAP 30, 40 ou 60 dias após injeção de 6-OHDA no CPu comparado com respectivo veículo. Teste- $t$, ${ }^{*} p<0,05$ (diferente de respectivo veículo). 

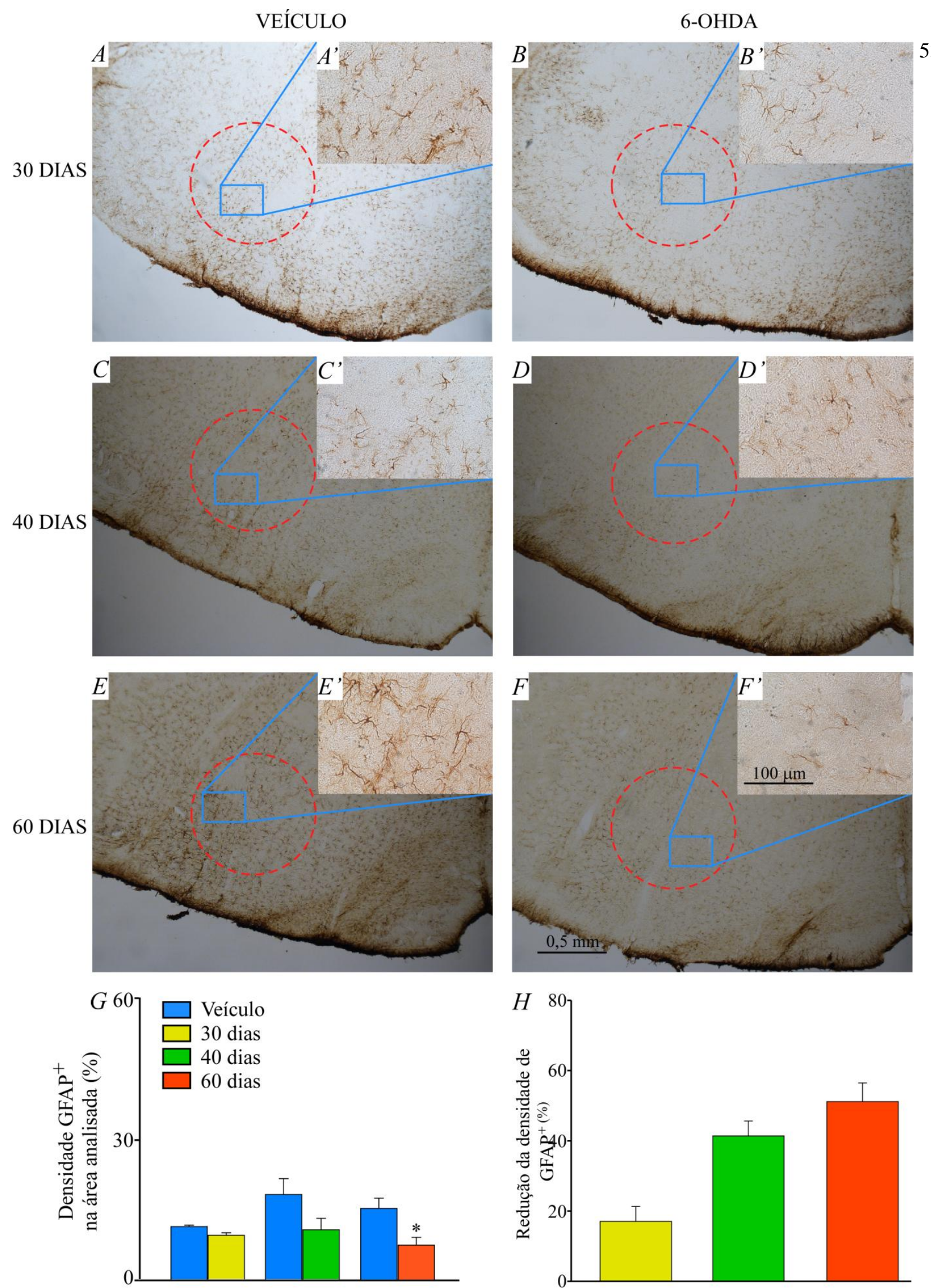

Figura 11 - Efeito da injeção bilateral de 6-OHDA no CPu sobre a expressão de GFAP no preBotC. Fotomicrografias do preBotC de animais que receberam injeção bilateral de veículo $(A, C, E)$ ou 6OHDA $(24 \mu \mathrm{g} / \mu \mathrm{l})$ que foram sacrificados 30 (B), 40 (D) ou 60 (F) dias após a injeção da toxina (bregma - 12,54 mm). G) Porcentagem de densidade de imunorreatividade para GFAP na área analisada do preBotC. H) Porcentagem de redução da densidade de imunorreatividade para GFAP 30,40 ou 60 dias após injeção de 6-OHDA no CPu comparado com respectivo veículo. Teste- $t$, ${ }^{*} p<$ 0,05 (diferente de respectivo veículo). 

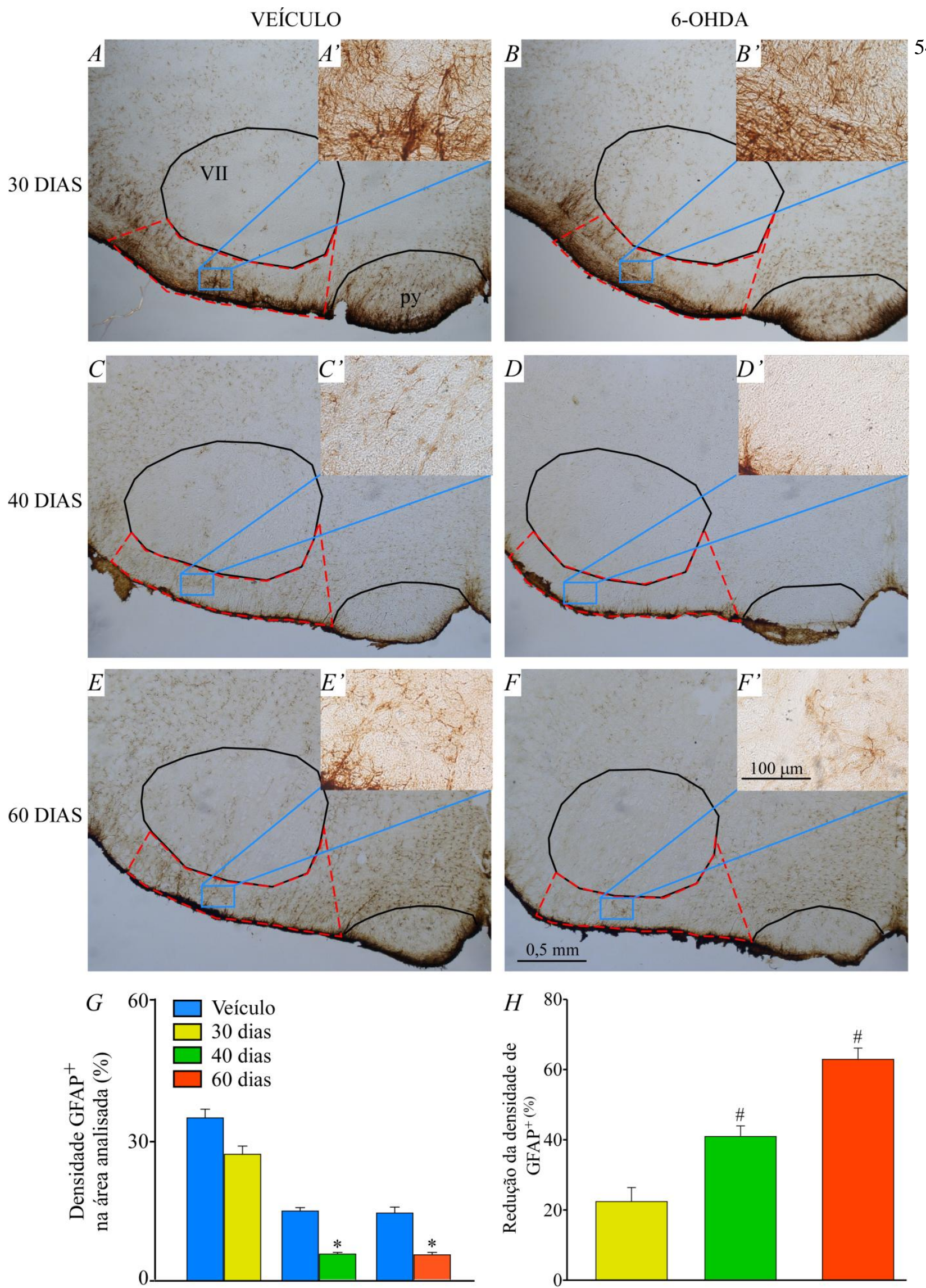

Figura 12 - Efeito da injeção bilateral de 6-OHDA no CPu sobre a expressão de GFAP no RTN. Fotomicrografias do RTN de animais que receberam injeção bilateral de veículo (A, C, E) ou 6-OHDA $(24 \mu \mathrm{g} / \mu \mathrm{l})$ que foram sacrificados 30 (B), 40 (D) ou 60 (F) dias após a injeção da toxina (bregma - 11,6 $\mathrm{mm}$ ). G) Porcentagem de densidade de imunorreatividade para GFAP na área analisada do RTN. H) Porcentagem de redução da densidade de imunorreatividade para GFAP 30, 40 ou 60 dias após injeção de 6-OHDA no CPu comparado com respectivo veículo. Teste- $t$, ${ }^{*} \mathrm{p}<0,05$ (diferente de respectivo veículo), One Way, \# p<0,05 (diferente de 30 dias). Abreviações: py, pirâmide; VII, núcleo facial. 


\subsection{Correlação entre as alterações de freqüência respiratória basais e induzidas por hipercapnia e o total de GFAP nas regiões envolvidas no controle neural da respiração}

A fim de melhor analisarmos a associação entre a redução de astrócitos das regiões respiratórias e a redução na $\mathrm{fR}$ basal ou induzida por hipercapnia, avaliamos a correlação entre a variação na resposta de $f R$ basal e induzida por hipercapnia e o total de densidade de imunorreatividade para GFAP no NTSc, NTSi, rVRG, preBotC e RTN.

Com relação às alterações basais, os nossos resultados mostraram que existe uma forte e significante correlação entre esses fatores para a região do NTSi $\left(r^{2}=0,5254 ; p=0,0004\right)$, preBotC $\left(r^{2}=0,5733 ; p=0,0002\right)$ e $\operatorname{rVRG}\left(r^{2}=0,4027 ; p=\right.$ 0,004) (Figura $13 \mathrm{~A}-\mathrm{C}$ ).

Já com relação às alterações induzidas por hipercapnia, os nossos resultados mostraram que existe uma forte e significante correlação entre esses fatores para a região apenas do RTN $\left(r^{2}=0,222 ; p=0,04\right)$ (Figura 13D). 


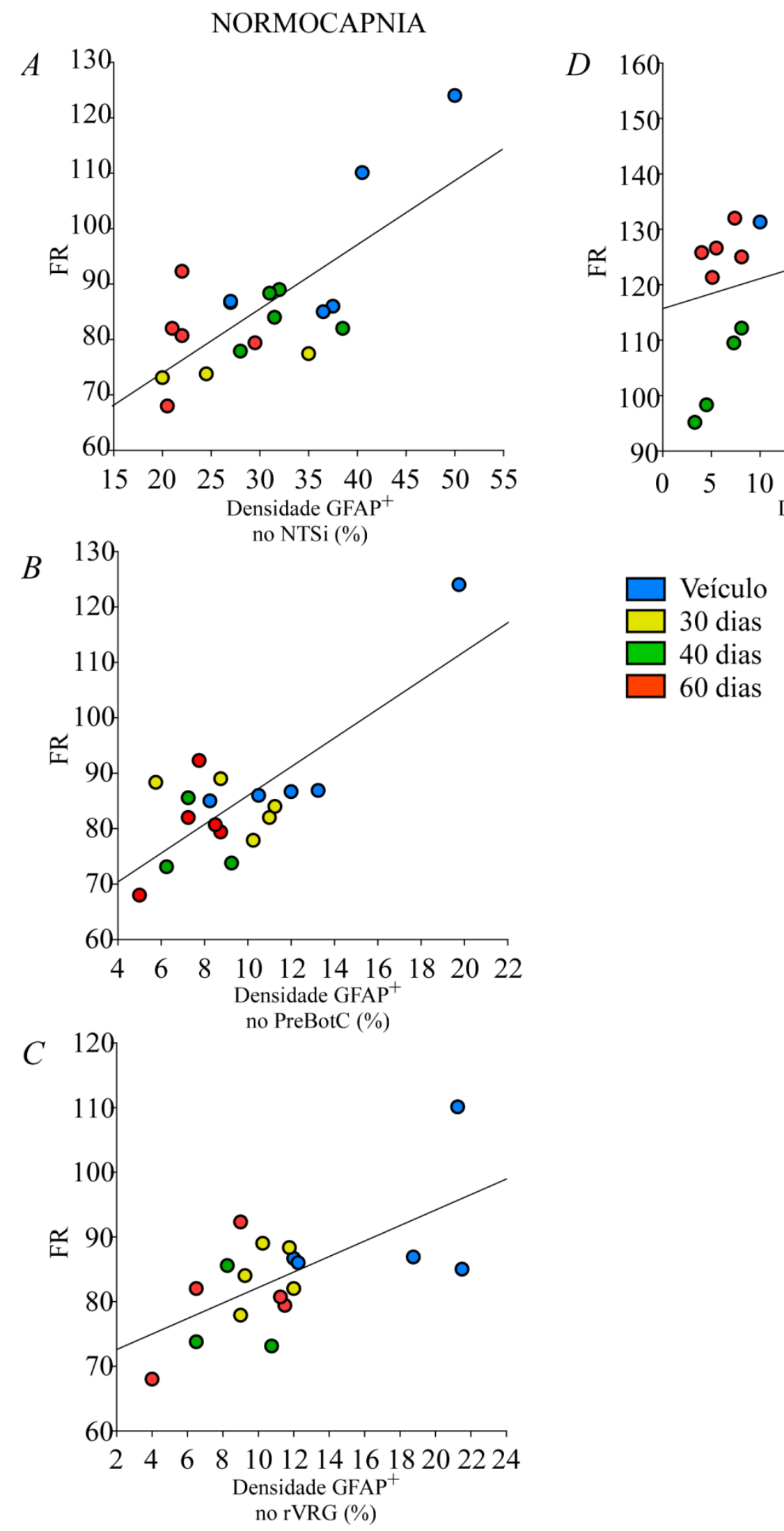

HIPERCAPNIA

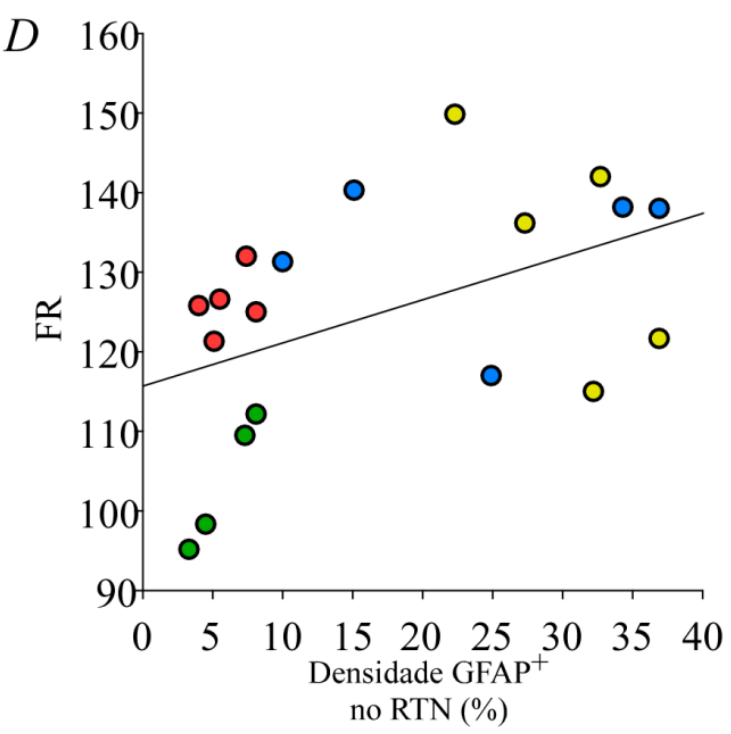

Figura 13 - Correlação entre as alterações de freqüência respiratória basais e induzidas por hipercapnia e o total de GFAP nas regiões envolvidas no controle neural da respiração. Gráficos de fR durante o repouso com relação à densidade de imunorreatividade para GFAP no A) NTSi ( $p=$ $0,0004$ para diferenças entre as curvas; $r 2=0,5254)$, B) preBotC $(p=0,0002$ para diferenças entre as curvas; $r 2=0,5733$ ) e C) $r V R G$ ( $p=0,004$ para diferenças entre as curvas; $r 2=0,4027$. $D) ~ X-Y$ gráfico de pico de aumento na $f R$ durante hipercapnia com relação à densidade de imunorreatividade para GFAP no RTN ( $p=0,04$ para diferenças entre as curvas; $r 2=0,222)$. 


\subsection{Efeito da injeção bilateral de 6-OHDA no CPu sobre a expressão de IBA nas regiões envolvidas no controle neural da respiração}

Os resultados mostraram que apenas no RTN ocorreu um aumento de 25,25 e $20,50 \%$ na densidade microglial após a indução do modelo experimental nos grupo de 30 e 40 dias, respectivamente, comparados ao seu grupo veículo (30 dias: 18,62 $\pm 0,53 \%$, vs. veículo: $14,87 \pm 0,85 \%$ e 40 dias: $19,32 \pm 0,38 \%$, vs. veículo: $16,03 \pm$ $0,58 \%, p<0,05$, Figura 18). Sessenta dias após a injeção de 6-OHDA no $\mathrm{CPu}$, a densidade de imunorreatividade para IBA no RTN não foi alterada $(14,40 \pm 0,28 \%$, vs. veículo: $15,87 \pm 0,52 \%, p>0,05$, Figura 18 ).

Em todos os períodos investigados, não se observou alteração na densidade de imunorreatividade para IBA nas regiões do NTSc (30 dias: $22,10 \pm 1,30 \%$, vs. veículo: $25 \%$, 40 dias: $21,60 \pm 0,60 \%$, vs. veículo: $23,83 \pm 1,50 \%$ e 60 dias: $22,50 \pm$ $1,10 \%$, vs. veículo: $22,33 \pm 0,67 \%, p>0,05$, Figura 14), NTSi (30 dias: $22,80 \pm$ 0,60\%, vs. veículo: $26,67 \%$, 40 dias: $24,60 \pm 0,40 \%$, vs. veículo: $23,17 \pm 1,50 \%$ e 60 dias: $21,80 \pm 1,20 \%$, vs. veículo: $24,33 \pm 0,67 \%, p>0,05$, Figura 15), rVRG (30 dias: $17,55 \pm 0,17 \%$, vs. veículo: $16,50 \pm 0,62 \%, 40$ dias: $16,30 \pm 0,37 \%$, vs. veículo: $18,17 \pm 0,50 \%$ e 60 dias: $12,10 \pm 0,06 \%$, vs. veículo: $15,08 \pm 0,37 \%, p>0,05$, Figura 16) e preBotC (30 dias: 17,20 $\pm 0,39 \%$, vs. veículo: $16,08 \pm 0,91 \%, 40$ dias: $18,20 \pm$ $0,53 \%$, vs. veículo: $16,92 \pm 0,50 \%$ e 60 dias: $12,70 \pm 0,33 \%$, vs. veículo: $15,00 \pm$ $0,30 \%, p>0,05$, Figura 17$)$. 

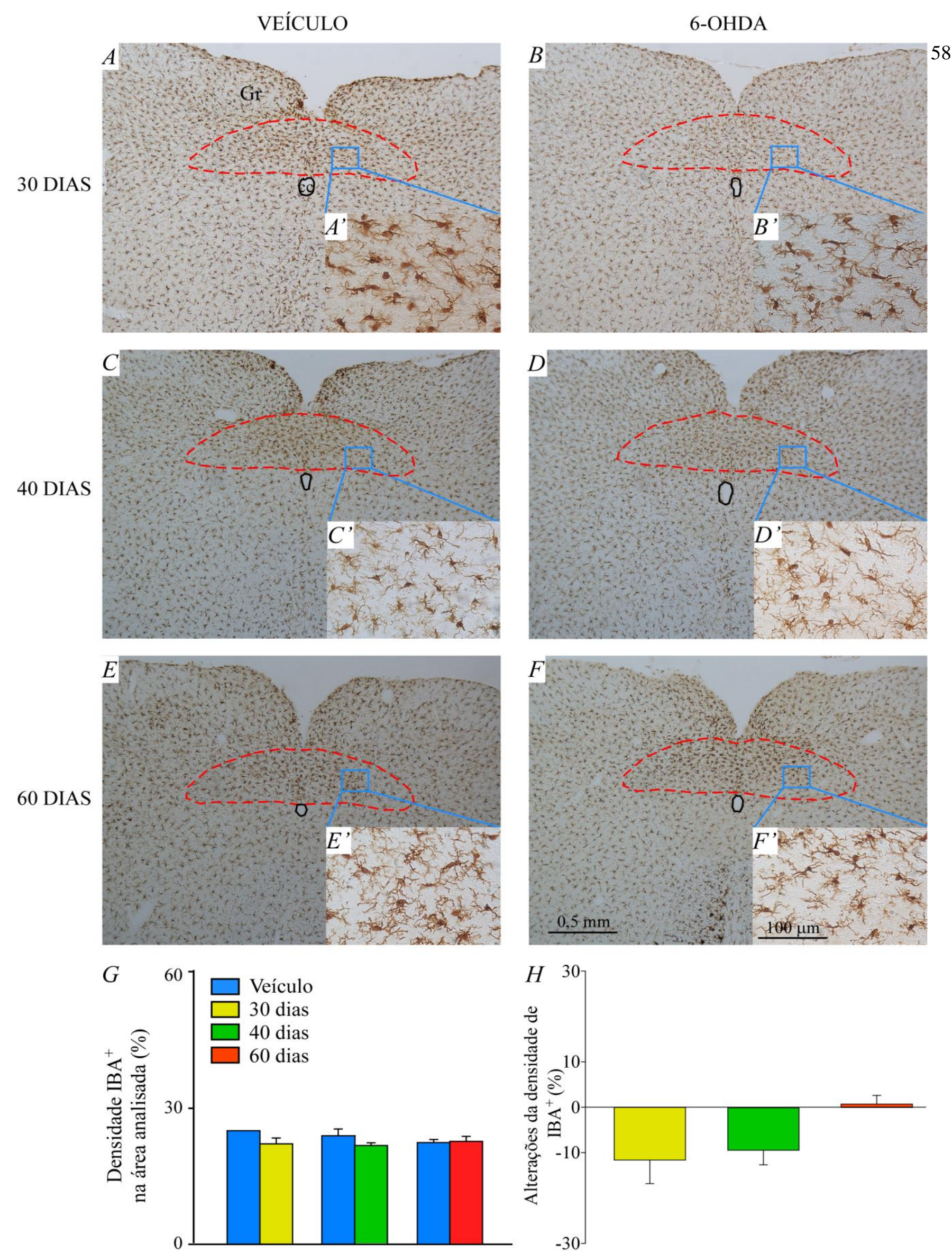

Figura 14 - Efeito da injeção bilateral de 6-OHDA no CPu sobre a expressão de IBA no NTSc. Fotomicrografias do NTSc de animais que receberam injeção bilateral de veículo (A, $C, E)$ ou 6-OHDA $(24 \mu \mathrm{g} / \mu \mathrm{l})$ e foram sacrificados 30 (B), 40 (D) ou 60 (F) dias após a injeção da toxina (bregma - 14,16 $\mathrm{mm}$ ). G) Porcentagem de densidade de imunorreatividade para IBA na área analisada do NTSc. H) Porcentagem de alteração da densidade de imunorreatividade para IBA 30, 40 ou 60 dias após injeção de 6-OHDA no CPu comparado com respectivo veículo. Teste- t, p>0,05 (comparado ao respectivo veículo). Abreviações: cc, canal central; Gr, núcleo grácil. 
VEÍCULO

30 DIAS
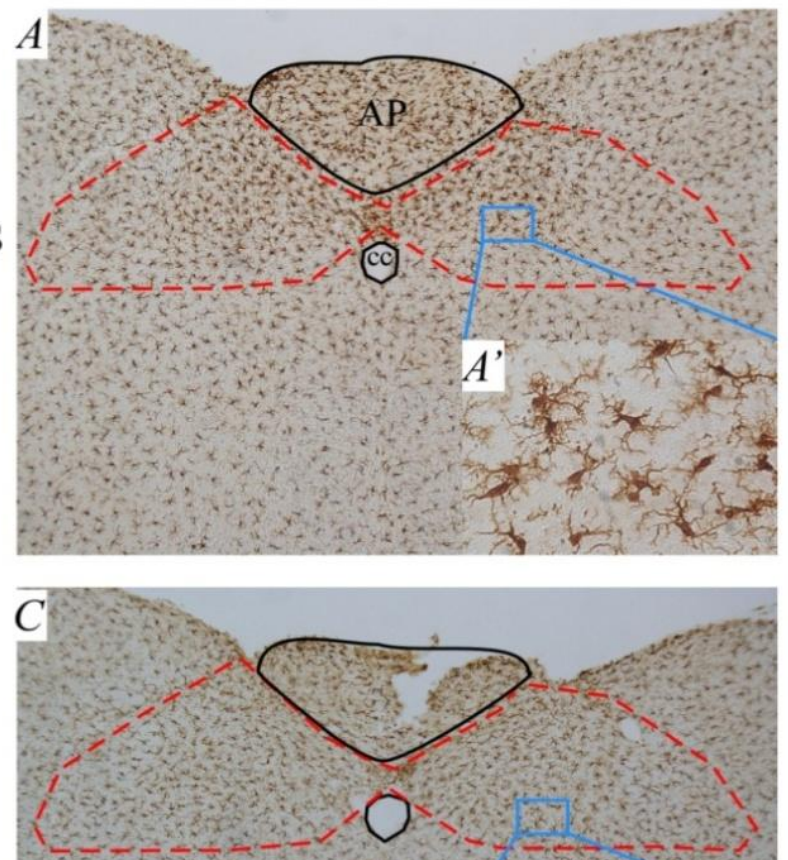

40 DIAS
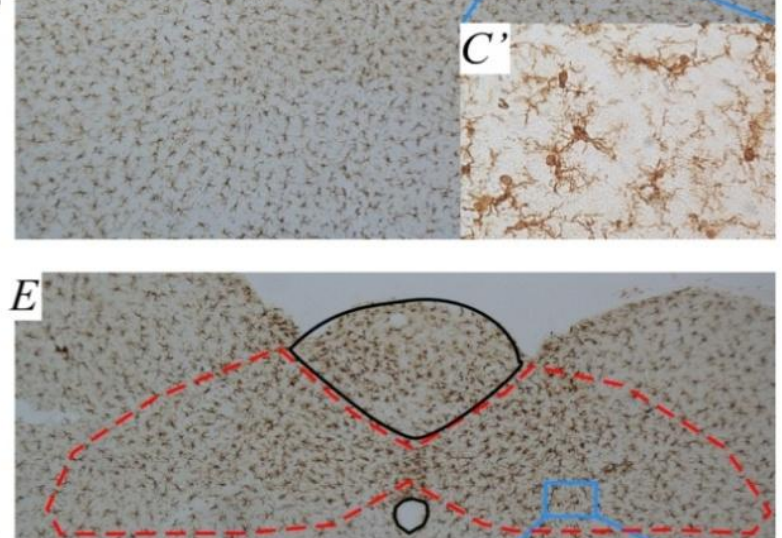

60 DIAS
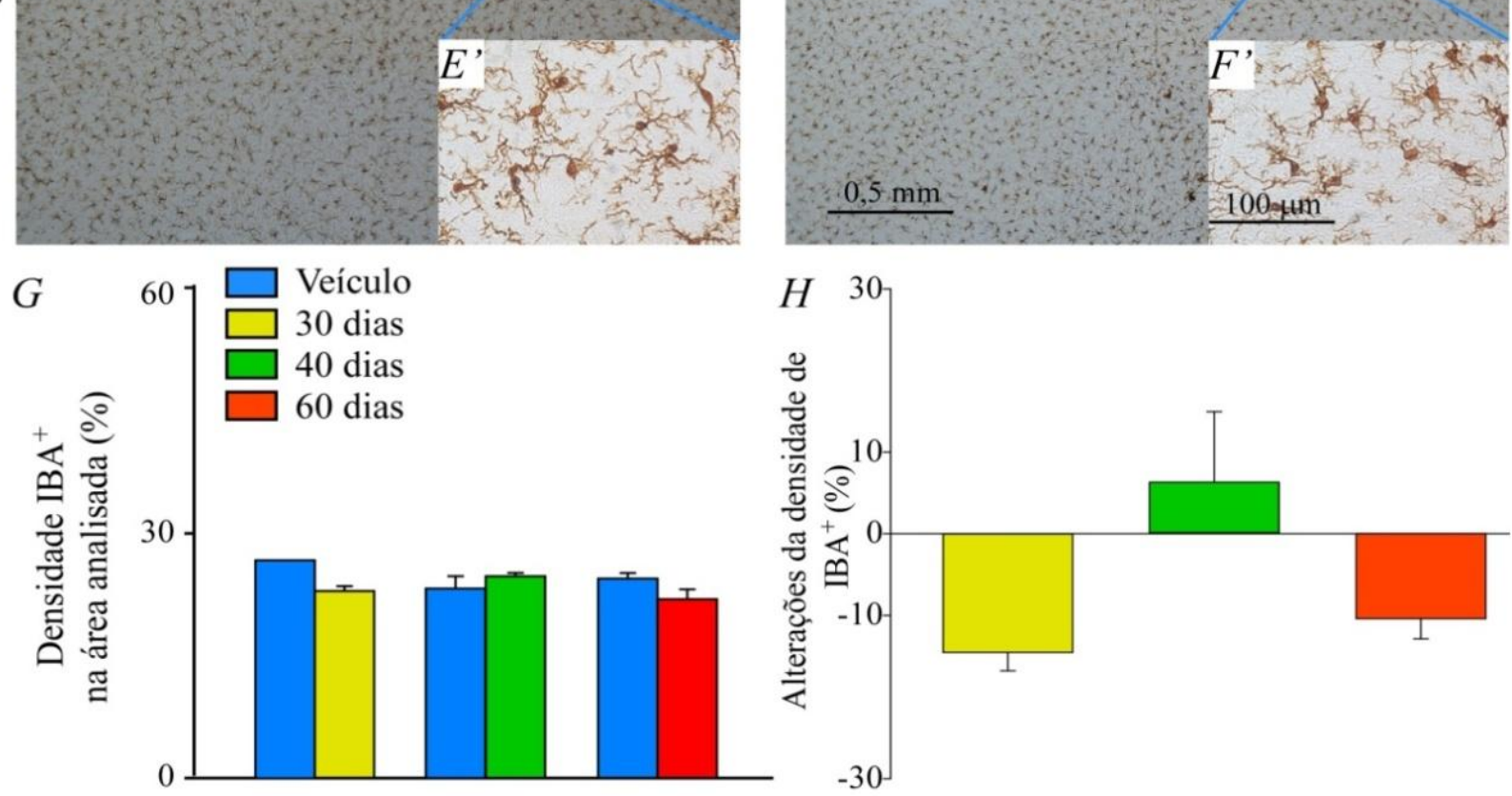

Figura 15 - Efeito da injeção bilateral de 6-OHDA no CPu sobre a expressão de IBA no NTSi. Fotomicrografias do NTSi de animais que receberam injeção bilateral de veículo $(A, C, E)$ ou 6-OHDA $(24 \mu \mathrm{g} / \mathrm{\mu l}$ ) e foram sacrificados 30 (B), 40 (D) ou 60 (F) dias após a injeção da toxina (bregma - 13,68 $\mathrm{mm}$ ). G) Porcentagem de densidade de imunorreatividade para IBA na área analisada do NTSi. H) Porcentagem de alteração da densidade de imunorreatividade para IBA 30, 40 ou 60 dias após injeção de 6-OHDA no CPu comparado com respectivo veículo. Teste- $t, p>0,05$ (comparado ao respectivo veículo). Abreviações: cc, canal central; AP, área postrema. 

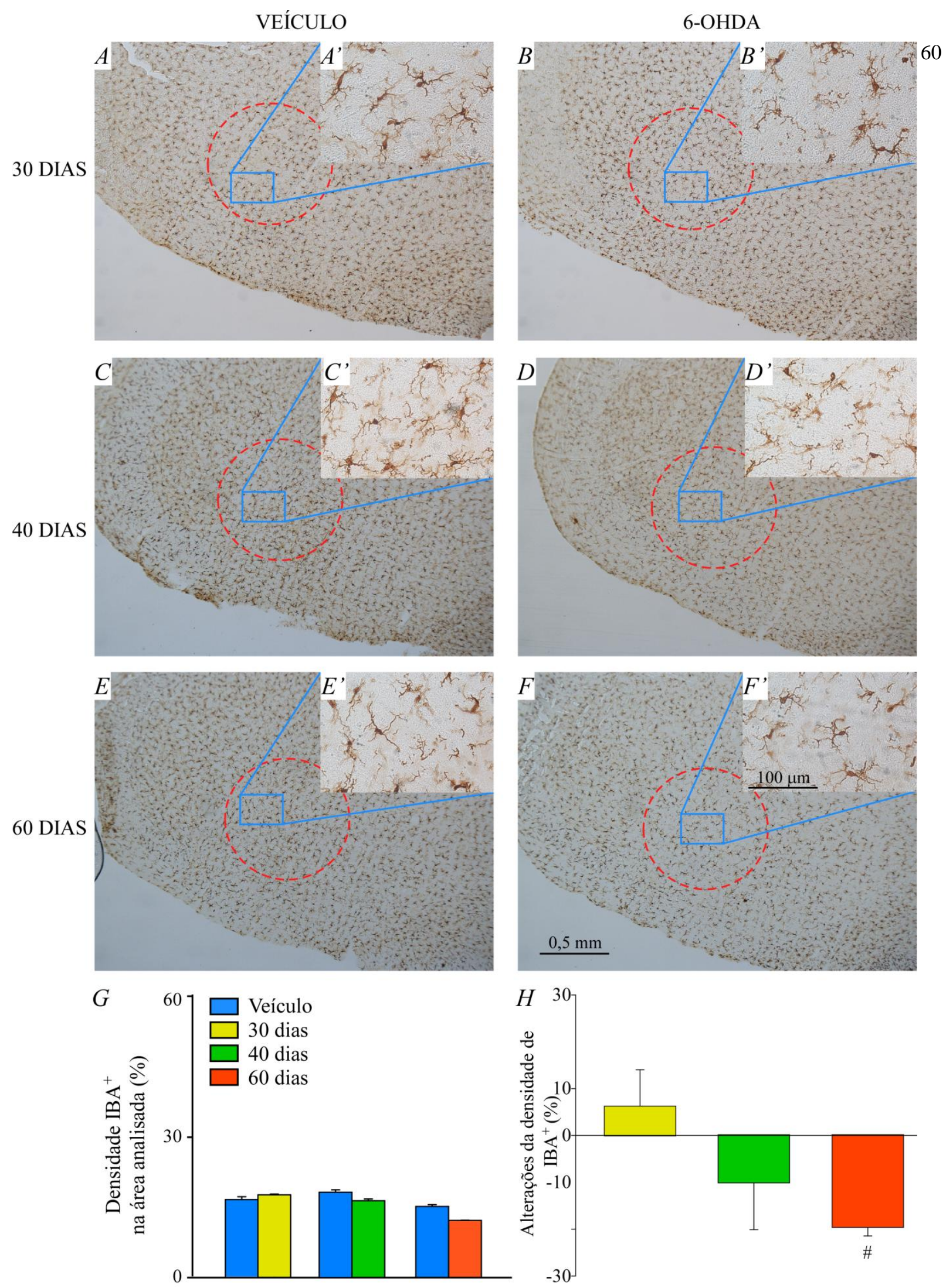

Figura 16 - Efeito da injeção bilateral de 6-OHDA no CPu sobre a expressão de IBA no rVRG. Fotomicrografias do rVRG de animais que receberam injeção bilateral de veículo (A, $C, E)$ ou 6-OHDA $(24 \mu \mathrm{g} / \mathrm{\mu l})$ e foram sacrificados $30(\mathrm{~B}), 40(\mathrm{D})$ ou $60(\mathrm{~F})$ dias após a injeção da toxina (bregma - 13,02 $\mathrm{mm}$ ). G) Porcentagem de densidade de imunorreatividade para IBA na área analisada do rVRG. H) Porcentagem de alteração da densidade de imunorreatividade para IBA 30, 40 ou 60 dias após injeção de 6-OHDA no CPu comparado com respectivo veículo. One Way, \# $p<0,05$ (diferente de 30 dias). Teste- $t, p>0,05$ (comparado ao respectivo veículo). 

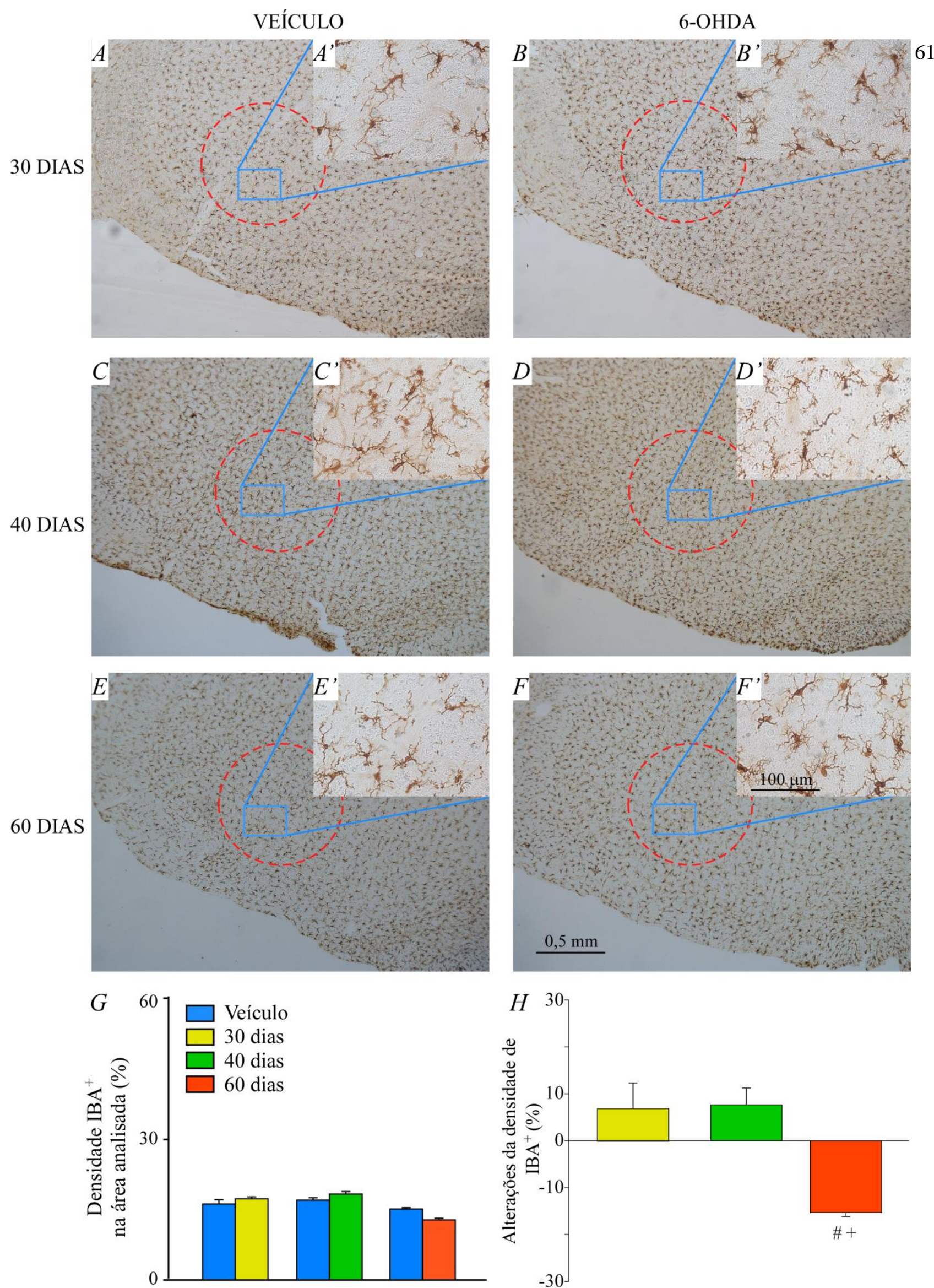

Figura 17 - Efeito da injeção bilateral de 6-OHDA no CPu sobre a expressão de IBA no preBotC. Fotomicrografias do preBotC de animais que receberam injeção bilateral de veículo $(A, C, E)$ ou 6 OHDA $(24 \mu \mathrm{g} / \mu \mathrm{l})$ e foram sacrificados $30(\mathrm{~B}), 40(\mathrm{D})$ ou $60(\mathrm{~F})$ dias após a injeção da toxina (bregma $12,54 \mathrm{~mm}$ ). G) Porcentagem de densidade de imunorreatividade para IBA na área analisada do preBotC. H) Porcentagem de alteração da densidade de imunorreatividade para IBA 30, 40 ou 60 dias após injeção de 6-OHDA no CPu comparado com respectivo veículo. One Way, \# $p<0,05$ (diferente de 30 dias), $+p<0,05$ (diferente de 40 dias). Teste- $t, p>0,05$ (comparado ao respectivo veículo). 

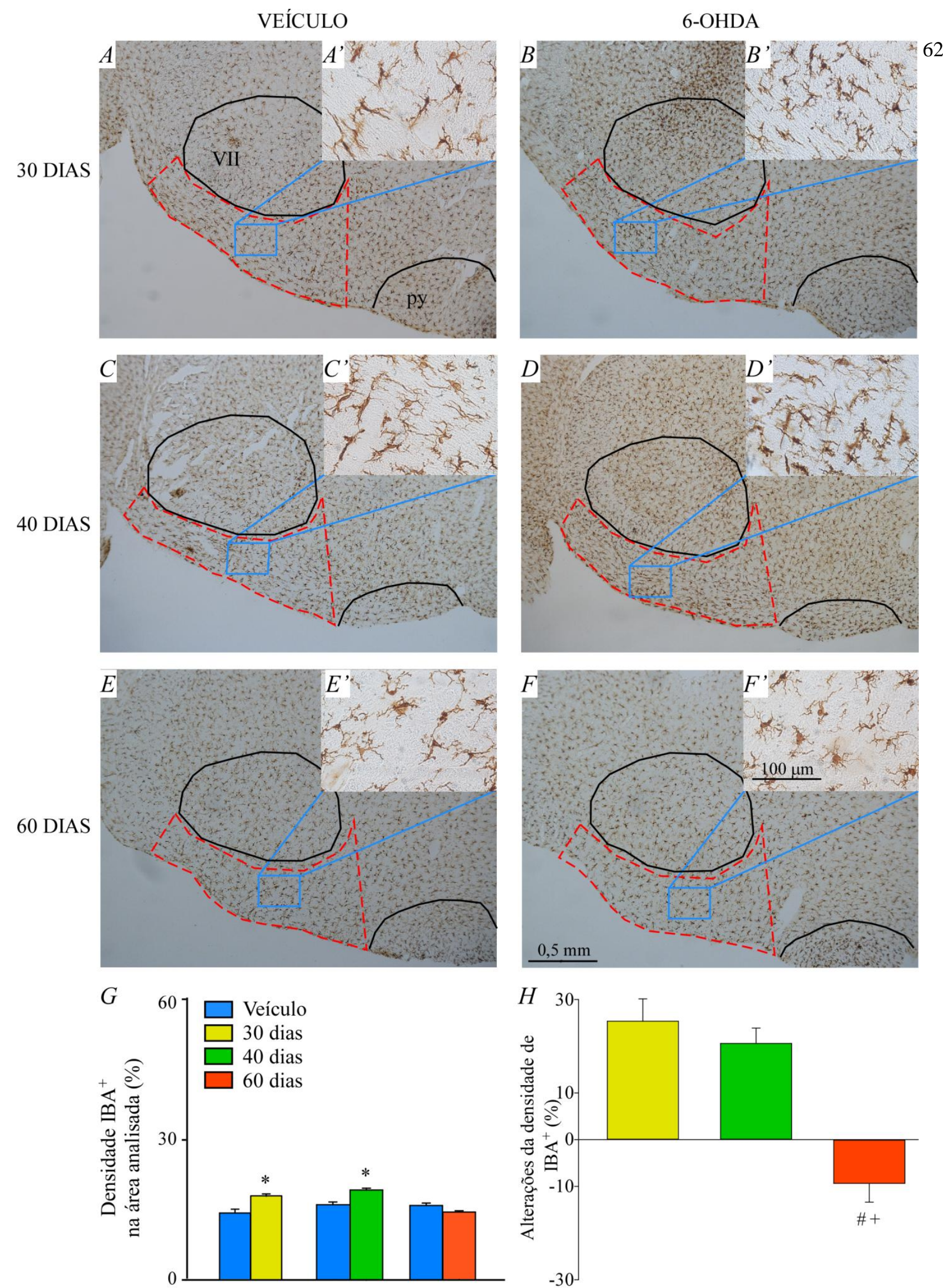

Figura 18 - Efeito da injeção bilateral de 6-OHDA no CPu sobre a expressão de IBA no RTN. Fotomicrografias do RTN de animais que receberam injeção bilateral de veículo (A, C, E) ou 6-OHDA $(24 \mu \mathrm{g} / \mu \mathrm{l})$ e foram sacrificados $30(\mathrm{~B}), 40(\mathrm{D})$ ou $60(\mathrm{~F})$ dias após a injeção da toxina (bregma - 11,60 $\mathrm{mm}$ ). G) Porcentagem de densidade de imunorreatividade para IBA na área analisada do RTN. H) Porcentagem de alteração da densidade de imunorreatividade para IBA 30, 40 ou 60 dias após injeção de 6-OHDA no CPu comparado com respectivo veículo. Teste- $t,{ }^{*} \mathrm{p}<0,05$ (diferente de respectivo veículo). One Way, \# $p<0,05$ (diferente de 30 dias), + $p<0,05$ (diferente de 40 dias). Abreviações: py, pirâmide; VII, núcleo facial. 
5.7 Correlação entre as alterações de freqüência respiratória basais e induzidas por hipercapnia e o total de IBA nas regiões envolvidas no controle neural da respiração

A fim de melhor analisarmos a associação entre 0 aumento na imunorreatividade para microglia do RTN e as alterações ventilatórias basal ou induzida por hipercapnia, avaliamos a correlação entre essas variações respiratórias e o total de densidade de imunorreatividade para IBA no RTN.

Os resultados mostraram que não existe correlação entre esses fatores tanto com relação às alterações basais (fR: $r^{2}=5,62 ; p=0,928$; VE: $r^{2}=7,82 ; p=0,736$ ) quanto as induzidas por hipercapnia (fR: $r^{2}=0,069 ; p=0,305 ; \mathrm{VE}: r^{2}=0,099 ; p=$ $0,217)$. 


\section{DISCUSSÃO}

A tabela 1 abaixo aponta o resumo dos resultados obtidos com o presente estudo. Esses dados propõem que o comprometimento da ventilação em condições de repouso e durante hipercapnia observadas no modelo animal de DP induzida pela injeção bilateral da toxina 6-OHDA no estriado, podem estar associados não somente à redução no número de neurônios (FALQUETTO et al., 2017; TUPPY et al., 2015) mas também a alterações em células gliais, principalmente os astrócitos. Neste contexto, nossos resultados demonstram uma redução de astrócitos nas principais regiões envolvidas no controle neural da respiração, como NTS, RTN, preBotC e rVRG, e uma forte correlação entre as alterações respiratórias basais e a redução na densidade de astrócitos nas regiões do NTSi, preBotC e rVRG e as alterações respiratórias induzidas por hipercapnia e a redução da densidade de astrócitos no RTN, contribuindo para o déficit respiratório observado nesse modelo experimental. Além disso, sugerimos que as alterações microgliais observadas apenas na região do RTN evidenciam um processo de neuroinflamação local podendo ser um dos mecanismos responsáveis pela perda celular nessa região.

\begin{tabular}{|c|c|c|c|c|c|c|c|c|c|c|c|c|c|c|c|}
\hline \multirow{2}{*}{ GFAP } & - & - & $\downarrow$ & - & - & $\downarrow$ & $\downarrow$ & $\downarrow$ & $\downarrow$ & - & - & $\downarrow$ & - & $\downarrow$ & $\downarrow$ \\
\hline IBA & - & - & - & - & - & - & - & - & - & - & - & - & $\uparrow$ & $\uparrow$ & - \\
& 30d & ${ }_{\text {40d }}$ & 60d & 30d & 40d & 60d & 30d & 40d & 60d & 30d & 40d & 60d & 30d & 40d & 60d \\
\hline
\end{tabular}

Tabela 1 - Resumo dos resultados obtidos. Legenda: - não altera a densidade; $\downarrow$ : reduz a densidade; $\uparrow$ : aumenta a densidade.

\subsection{Alterações neuronais e funcionais respiratórias encontradas no modelo animal de DP}

À medida que a DP progride, é comum o aparecimento de distúrbios respiratórios, sendo estes responsáveis por diversas morbidades e por grande parte da taxa de mortalidade dos portadores desta doença (BROWN, 2014; SHILL; STACY, 1998). Sabe-se que o comprometimento motor e a fraqueza encontrados nos músculos ventilatórios avaliados em pacientes com DP, por si, seriam insuficientes para justificar esse declínio na atividade respiratória. Além disso, sabe- 
se que estes pacientes apresentavam um déficit de $47 \%$ na resposta à hipercapnia, mas não em condições de hipóxia, sugerindo, portanto, uma alteração no controle neural da respiração (SECCOMBE et al., 2011).

Essas evidências vão ao encontro do fato da AOS ser apontada como principal causa de morte entre estes pacientes (GJERSTAD et al., 2007; LEES et al., 1988; MEHANNA et al., 2010). Isso porque alguns trabalhos especulam que nesta patologia pode ocorrer uma degeneração em neurônios responsáveis por comandar a atividade respiratória (GILMAN et al., 2003).

Durante um episódio de AOS num indivíduo sadio, o aumento nas concentrações plasmáticas de $\mathrm{CO}_{2}$ e redução de $\mathrm{O}_{2}$ estimulam neurônios que possuem os quimiorreceptores centrais, como aqueles localizados no RTN, iniciando um novo ciclo respiratório (DAMASCENO et al., 2014; DEMPSEY et al., 2010; FERREIRA et al., 2015). Entretanto, num indivíduo que tem uma redução do número de neurônios dessa região, pode-se observar uma deficiência na resposta neural frente a esse estímulo, não iniciando um novo ciclo respiratório, podendo, então, justificar a morte desses indivíduos por AOS. Assim, a perda neuronal observada em regiões importantes para o controle neural da respiração pode prejudicar a resposta de reativação da respiração durante AOS, podendo ser esse um dos principais fatores responsáveis pelo óbito na DP.

A atividade respiratória depende de uma rede neuronal no tronco encefálico que modula os neurônios motores que inervam os músculos respiratórios. Esta rede inclui os grupamentos neurais da região dorsal e ventral do bulbo, que disparam principalmente durante a inspiração, pós-inspiração ou expiração, controlando assim o ritmo e a geração de padrões respiratórios (FELDMAN et al., 2013; NOGUÉS et al., 2002). Deste modo, pode-se dizer que a respiração é comandada pelo SNC, que promove a homeostase, regulando os níveis de $\mathrm{O}_{2}$ e $\mathrm{CO}_{2}$ no sangue e nos tecidos. Assim, os movimentos respiratórios rítmicos devem ocorrer de forma contínua, sendo cruciais para a vida (SILVESTRELLI et al., 2012).

O RTN constitui um dos principais grupamentos desta rede por ser altamente sensível ao aumento na $\mathrm{PCO}_{2}$ e na concentração de $\mathrm{H}^{+}$in vivo e in vitro (GUYENET; BAYLISS, 2015; SMITH et al., 2013; TAKAKURA et al., 2006). Nestas condições, os 
neurônios do RTN são ativados e, por meio de suas projeções excitatórias para a CRV, que inclui os grupamentos de neurônios do preBotC, rVRG e cVRG, estimula o aumento rápido da atividade respiratória, restabelecendo a homeostase (GUYENET et al., 2005; MULKEY et al., 2007; NATTIE; LI, 2002; ROSIN et al., 2006; STORNETTA et al., 2006).

Estudo realizado no nosso laboratório mostrou que no modelo da DP induzido pela injeção de 6-OHDA no CPu ocorre uma degeneração de neurônios na SN mas, além disso, mostrou que coexiste uma perda maciça de neurônios do RTN, NTSi, NTSc e densidade de receptores NK1 nas regiões do preBotC e rVRG (FALQUETTO et al., 2017; TUPPY et al., 2015). Resultados ainda não publicados mostraram por meio de injeção de traçadores anterógrado e retrógrado que não existe uma via direta entre a SN e essas regiões envolvidas no controle neural da respiração, mas possivelmente, com relação ao RTN, a comunicação entre SN e RTN faça-se de uma forma indireta, envolvendo neurônios da Substância Cinzenta Periaquedutal (PAG) (LIMA et al., 2016 - dados não publicados).

Ademais, estudos realizados em animais que receberam a injeção de 6OHDA no CPu, mostraram que a perda desses neurônios ocasiona alterações na respiração em repouso e durante as condições hipercápnicas (TUPPY et al., 2015). Nossos dados funcionais corroboram com este trabalho. Em nossos dados, mostramos que os animais que foram analisados 40 e 60 dias após a injeção de 6OHDA tiveram uma redução de neurônios da SN maior que 70\%, apresentaram também uma redução na fR e na VE na respiração basal, sem alterar o VT. Com relação às respostas respiratórias frente à hipercapnia, também pudemos confirmar os dados já publicados, pois também observamos um prejuízo no aumento da fR e VE 40 dias após a injeção da toxina, mas essa resposta foi restaurada após 60 dias.

Considerando o conjunto de informações até aqui apresentados, a redução do número de neurônios do RTN justificaria por si, o comprometimento da ventilação em condições de repouso e hipercapnia encontradas no modelo animal da DP induzido pela injeção de 6-OHDA no CPu. Entretanto, este trabalho propõe a hipótese de que as células gliais de regiões encefálicas envolvidas na atividade respiratória poderiam também contribuir de forma significativa para o aparecimento dos distúrbios respiratórios na DP. 


\subsection{Alterações astrocitárias observadas em regiões encefálicas envolvidas no controle respiratório em um modelo animal de DP}

A base molecular e celular da quimiorrecepção respiratória central baseia-se na detecção de $\mathrm{CO}_{2}$ e alterações de $\mathrm{pH}$ por meio de receptores intrínsecos, no caso os receptores GPR4 e TASK-2 (BAYLISS et al., 2015; GUYENET et al., 2016; KUMAR et al., 2015; WANG et al., 2013). Os receptores GPR4 são acoplados à proteína $\mathrm{G}$ ativados por prótons e sua exposição a níveis elevados de $\mathrm{H}^{+}$ desencadeia a cascata intracelular envolvendo o aumento dos níveis de adenosina monofosfato cíclico (AMPc) (KUMAR et al., 2015; LUDWIG et al., 2003; MURAKAMI et al 2004; RADU et al., 2005). Já os TASK-2 são canais para potássio modulados pela alcalinização. Quando expostos à acidificação extracelular promove a fechamento dos seus poros, levando à despolarização celular (NIEMEYER et al., 2010; WANG et al., 2013). Esses receptores são expressos na superfície ventral do bulbo, co-localizados na região dos neurônios que expressam o fator de transcrição Phox2 $\mathrm{b}^{+}$, portanto a região do RTN (BAYLISS et al., 2015; GESTREAU et al., 2010; GUYENET et al., 2016).

Além disso, literatura recente descreve pelo menos três teorias que tentam explicar o mecanismo da quimiorrecepção respiratória central, como descrito na Introdução do presente estudo. A teoria que preconiza a participação dos astrócitos nesse reflexo está intimamente relacionada aos resultados encontrados no presente estudo. Nessa teoria, preconiza-se que os astrócitos presentes em regiões muito específicas do bulbo (superfície ventrolateral) contribuiriam para a detecção de aumento de $\mathrm{CO}_{2} \mathrm{e} \mathrm{H}^{+}$. Assim, acredita-se que os tanto neurônios quanto astrócitos possuem receptores que detectam essas variações. Recentemente, estudos da literatura mostraram que os astrócitos são capazes de liberar ATP frente ao aumento de $\mathrm{CO}_{2}$ e queda do $\mathrm{pH}$, levando a um aumento na respiração (GOURINE et al., 2010). Evidências sugerem que esta sinalização purinérgica parece coordenar as respostas respiratórias e cardiovasculares desencadeadas pela hipóxia e hipercapnia, ativando neurônios do RTN e outros grupamentos neurais envolvidos no controle cardiorrespiratório (GOURINE et al., 2010; MOREIRA et al., 2015). Sabese que a ativação optogenética de astrócitos na superfície ventral do bulbo leva à liberação de ATP que, por sua vez, estimula a respiração deixando claro que os astrócitos que se localizam nesta região, podem ser apontados como moduladores 
da atividade respiratória uma vez que possuem capacidade de estimular os neurônios envolvidos no controle da respiração (GOURINE et al., 2010).

Deste modo, a hipótese deste trabalho foi que no modelo de DP induzido pela injeção de 6-OHDA no $\mathrm{CPu}$, encontraríamos alterações astrocitárias em importantes regiões que controlam a respiração e considerando a coexistência de uma redução dos neurônios anteriormente descrita, justificariam o prejuízo respiratório observado neste modelo experimental.

Essa hipótese foi confirmada ao avaliar todas as regiões respiratórias no presente estudo. Aparentemente, as alterações astrocitárias se iniciam nos neurônios pré-motores inspiratórios do rVRG (30 dias) e, a partir disso (40 dias) o RTN passa também a apresentar redução, concomitantemente com o período em que as alterações funcionais aparecem, ou seja, redução na $f R$ e VE basais e induzidas por hipercapnia. No último período analisado (60 dias) também passamos a observar uma redução na densidade de astrócitos nas demais regiões: NTSc, NTSi e preBotC e nesse período, as alterações respiratórias basais persistiram. Ao analisarmos os dados de correlação, pudemos observar uma forte correlação com a redução na fR basal e a redução de densidade de astrócitos no NTSi, preBotC e rVRG. Os neurônios do preBotC são os responsáveis pela geração da atividade inspiratória, ou seja, têm uma forte relação com a fR. Os neurônios do rVRG são pré-motores inspiratórios. A perda astrocitária nessas regiões contribuiria em muito para uma deficiência na atividade dos neurônios dessa região, acarretando na bradipnéia observada nesses animais que receberam a injeção de 6-OHDA no CPu. Os dados da correlação também nos mostraram uma forte relação entre a redução da densidade de astrócitos na região do RTN com o prejuízo da resposta respiratória frente à hipercapnia. Mais uma vez, esses dados confirmam a contribuição dos astrócitos da região do RTN para a resposta respiratória decorrente da ativação do quimiorreflexo central.

Um estudo realizado por Sobrinho e colaboradores em 2014 demonstra que a sinalização purinérgica estimulada a partir de uma acidose hipercápnica é um importante componente para a quimiorrecepção central (SOBRINHO et al., 2014). Esse mesmo estudo sugere ainda que esta sinalização purinérgica é uma característica única do RTN para a ativação das respostas ventilatórias frente a um 
estímulo hipercápnico tanto in vitro como in vivo, descartando a contribuição de outras regiões como por exemplo da rafe e do NTS nesta via (SOBRINHO et al., 2014).

Os quimiorreceptores centrais, a partir do aumento da $\mathrm{pCO}_{2}$ ativam os centros respiratórios para regular a fR (FELDMAN et al., 2003; HUCKSTEPP; DALE, 2011). Este processo é especialmente importante durante o sono e seu comprometimento tem sido associado à AOS em alguns estudos (DEMPSEY et al.,2010), indo ao encontro do quadro encontrado em pacientes com DP. No entanto, apesar da importância dos quimiorreceptores centrais, o mecanismo celular e molecular subjacentes a este processo ainda não foram completamente elucidados (SOBRINHO et al., 2014).

Nos últimos anos, a literatura sobre DP que utiliza modelos experimentais, tem explorado significativamente a relação astrocítica-neuronal. Sugerimos que a redução astrocitária encontradas no modelo de DP induzido pela injeção de 6-OHDA no CPu e possível detrimento da sinalização purinérgica nas regiões envolvidas na atividade respiratória podem, de fato, contribuir para o aparecimento de alterações respiratórias neste modelo experimental. Propomos então, que este estudo seja mais uma evidência para conduzir novas abordagens terapêuticas modificadoras contra processos neurodegenerativos.

\subsection{Alterações microgliais observadas em regiões encefálicas envolvidas no controle respiratório em um modelo animal de DP}

Sabe-se que uma das características compartilhadas por vários tipos de doenças neurodegenerativas é a presença da neuroinflamação (CHAO et al., 2014). Contudo, ainda não existem evidências de processos neuroinflamatórios em regiões encefálicas envolvidas no controle neural da respiração que poderiam estar inviabilizando a atividade celular nessas regiões, contribuindo com o prejuízo respiratório apresentado no nosso modelo experimental.

A perda neural comumente está relacionada a processos secundários como disfunções mitocondriais, estresse oxidativo, excitotoxicidade, detrimento bioenergético neuronal e neuroinflamação, considerados os mais evidentes eventos, intimamente ligados a apoptose precoce (BEAL, 2007; CALABRESE et al., 2005; 
FERNÁNDEZ-CHECA et al., 2010; GOBEL; ERB, 2014; LIN; BEAL, 2006; WALLIMANN et al., 2011). A influência desses fatores recentemente passou a ser atribuída à patogênese de diversas doenças neurodegenerativas, incluindo a DP.

Os dados do presente estudo apontam que existe uma intensa ativação microglial no RTN a partir de 30 dias após injeção bilateral da toxina 6-OHDA no estriado, perdurando até 40 dias. Esses resultados corroboram com dados de estudo realizados em nosso laboratório, ainda não publicados, que demonstram a redução no número de neurônios que expressam o fator de transcrição Phox2b nessa região a partir de 30 dias após a injeção da toxina no $\mathrm{CPu}$, sugerindo então que essa seja uma das possíveis causas dessa perda neural (FERNANDESJUNIOR e colaboradores - dados não publicados).

\subsection{Limitações das técnicas}

Ao longo dos anos, o estudo científico do sistema nervoso passou por grandes avanços, principalmente por causa de progressos simultâneos em outras áreas afins, tais como a computação, eletrofisiologia e biologia molecular, porém, não foram suficientes para vencer o fator limitante que continua sendo o acesso ao SNC em humanos, uma vez que a manipulação é inviável e impossibilita estudos mais aprofundados (FUNCHAL; DANI,2014). Dessa forma, a utilização de modelos experimentais é de extrema importância, permitindo um conhecimento mais detalhado dos mecanismos fisiológicos e patogênicos de doenças que afetam 0 SNC. Neste estudo, optamos por um modelo animal de DP induzido pela injeção de 6-OHDA no CPu por apresentar-se mais seguro, de fácil manejo e por trabalhos anteriores mostrarem a presença de alterações não-motoras nesse mesmo modelo (MCDOWELL; CHESSELET, 2012; TUPPY et al., 2015). A 6-OHDA não atravessa a barreira hematoencefálica e, portanto, apresenta efeitos apenas se administrada diretamente no local desejado (BLANDINI et al., 2008). A literatura mostra que a 6OHDA quando administrada no $\mathrm{CPu}$ em ratos pode ser utilizada nas doses que variam de 1,25 a $24 \mu \mathrm{g} / \mu \mathrm{l}$ (CHUDLER; LU, 2008; PRZEDBORSKI et al., 1995; TADAIESKY et al., 2008; TUPPY et al., 2015). Nos nossos experimentos, optamos por utilizar a dose de $24 \mu \mathrm{g} / \mu \mathrm{l}$, pois observamos que essa dose, nas nossas condições experimentais, possibilitava uma lesão dos neurônios da SNc de pelo menos $70 \%$. Na DP, para que as alterações motoras comecem a ser percebidas, 
existe a necessidade de lesão de pelo menos $60 \%$ dos neurônios da SNc e redução de pelo menos $80 \%$ dos níveis de dopamina no estriado (SCHULZ; FALKENBURGER, 2004). No nosso caso, como estamos investigando um sintoma (deficiência respiratória) que ocorre normalmente em fases mais avançadas da doença, precisávamos de uma redução de neurônios da SNc que fosse ainda maior do que aquela necessária para o aparecimento dos sintomas motores.

O tratamento imunoistoquímico realizado neste estudo para identificação de astrócitos utiliza antígenos da proteína GFAP, que são componentes dos filamentos de tamanho intermediário do citoesqueleto presente nessas células (ENG; GHIRNIKAR, 1994). A função da GFAP em astrócitos não é clara. Camundongos geneticamente modificados que apresentam ausência de GFAP crescem e se reproduzem normalmente (PEKNY et al.,1995). Apesar disso, não se sabe se alterações funcionais nesses animais podem ser observadas em situação de desafio ou com a idade. Mesmo assim, atualmente, o GFAP tem sido classicamente utilizado como marcador de astrócitos em modelos experimentais como Esclerose Lateral Amiotrófica (ELA), doença de Alzheimer, doença de Huntington, Doença de Alexander e DP, sendo amplamente aceito na literatura (MARAGAKIS; ROTHSTEIN, 2006; MIDDELDORP; HOL, 2011; QUINLAN et al., 2007; SUKHORUKOVA et al., 2015).

Deve-se considerar que astrócitos não são uniformes, suas funções e morfologia diferem muito dependendo da sua localização, subtipos e o estágio de desenvolvimento (PENKY; PEKNA, 2014). Além disso, a expressão da imunorreatividade de GFAP pode apresentar-se diferente quanto ao padrão de coloração dependendo do anti-soro utilizado. Esta variação tem apresentado implicações importantes para a interpretação dos resultados usando tecidos humanos (HALLIDAY et al.,1996). Outro aspecto relevante é o tempo entre a lesão e o início de alterações astrocitária, em que em alguns processos patológicos, os astrócitos respondem prontamente tornando-se reativos pela proliferação (astrocitose) e/ou como pela hipertrofia (astrogliose) (MALHOTRA et al., 1990; MONTGOMERY, 1994; SHIMADA et al., 1998), entretanto ainda não é conhecida a janela de tempo que separa a reatividade e sua perda. Por isso, indispensavelmente, todos os grupos foram comparados apenas com seu respectivo controle de tempo, mantendo o mesmo padrão de anti-soro. 
Outro tratamento imunoistoquímico realizado neste estudo, agora com o intuito de identificar microglias, utiliza antígenos da proteína lba1 que é uma proteína ligante de actina cruzada especificamente expressa em membranas de macrófagos, sendo regulada positivamente em microglias ativadas após injurias ao SNC. Neste sentido, tem sido relatada como uma molécula chave nas vias de sinalizações, diretamente envolvida com processos neuroinflamatórios, sendo amplamente aceito na literatura como marcador específico desta célula da glia (revisado por OHSAWA et al., 2004). Deste modo, optamos por utilizá-la neste trabalho, seguindo ainda as devidas cautelas descritas anteriormente para o uso do GFAP.

A avaliação da densidade integrada de astrócitos imunorreativos para GFAP e microglia imunorreativas para IBA no bulbo utilizando a ferramenta threshold do ImageJ é considerada uma análise sensível e exige critérios bem elaborados para não interferir nos resultados. Os critérios que seguimos neste estudo se iniciam no momento do tratamento imunoistoquímico, quando necessariamente os animais que receberam a injeção de veículo eram tratados ao mesmo tempo em que os animais que receberam a 6-OHDA. A partir daí os grupos eram identificados apenas por período de 30, 40 e 60 dias. Montados em lâminas e desidratados nas mesmas condições. Além disso, após os tratamentos imunoistoquímicos, a aquisição dos dados foi feito por imagens que foram capturadas no mesmo dia, mantendo todas as condições de iluminação, foco, ampliações e possíveis interferências ambientais. Por fim, ao utilizar os recursos do programa de análise, o filtro marcador da densidade era mantido constante, variando minimamente para adequação da região a ser analisada.

Por fim, uma outra limitação do nosso estudo foi uma amostra relativamente pequena para afirmar o impacto das alterações gliais nas respostas respiratórias neste modelo experimental, utilizando as correlações de Pearson. Para esse tipo de análise, o ideal é que se tenha um número maior de animais. Assim, o ideal seria que esse número fosse aumentado para confirmação dos resultados de correlação obtidos. 


\section{CONCLUSÃO}

Desde a descoberta da DP há mais de 200 anos, o foco principal de investigação para elucidar os mecanismos de morte celular neste distúrbio neurológico tem sido os neurônios dopaminérgicos da SN (RAPPOLD; TIEU, 2011). $\mathrm{O}$ tratamento medicamentoso mais utilizado visa à correção dos sintomas motores com a reposição da dopamina ausente (BRONSTEIN et al., 2011; RAJPUT, 2001). Entretanto, com a progressão da DP, são os sintomas não-motores, principalmente alterações respiratórias, os responsáveis por grande parte das morbidades e mortalidade destes pacientes (BROWN, 1994). Portanto, torna-se crucial investigar os mecanismos envolvidos nesse processo.

Os estudos prévios do nosso laboratório sugerem que a degeneração dos neurônios dopaminérgicos da $\mathrm{SN}$, induzida pela injeção bilateral da toxina 6-OHDA no $\mathrm{CPu}$, leva ao comprometimento da ventilação em condições de repouso e hipercapnia. Essas alterações podem estar relacionadas a uma redução no número de neurônios observada em importantes regiões bulbares que controlam a respiração (FALQUETTO et al., 2017;TUPPY et al., 2015).

Finalmente, os resultados do presente estudo acrescentam que coexiste uma redução astrocitária nas regiões encefálicas envolvidas no controle respiratório que poderia também contribuir para a redução da atividade respiratória basal e induzida por hipercapnia neste modelo experimental. Ainda, sugerimos que exista uma neuroinflamação local, justificando tanto a perda neural, quanto astrocitária na região do RTN. Esses dados acrescentam na literatura uma notória participação das células gliais na patogênese da DP favorecendo um auspicioso caminho para novas estratégias terapêuticas. 


\section{REFERÊNCIAS}

ACADEMIA BRASILEIRA DE NEUROLOGIA (ABN). Conheça os sintomas do mal de Parkinson. Portal do Brasil. 2014. Disponível em: $<$ http://abneuro.org.br/clippings/detalhes/150/conheca-os-sintomas-do-mal-deparkinson>. Acesso em: 20 Fev. 2017.

AGID Y. Parkinson's disease: pathophysiology. Lancet, v.337, n.8753, p.1321-1324, 1991.

AKIYAMA H.; MCGEER P. L. Microglial response to 6-hydroxydopamine-induced substantia nigra lesions. Brain Res., v. 489, n.2, p. 247-253,1989.

ANDERSON C. M.; SWANSON R.A. Astrocyte glutamate transport: review of properties, regulation, and physiological functions. Glia, v.32, n.1, p.1-14, 2000.

ASCHNER M. Astrocytes as mediators of immune and inflammatory responses in the CNS. Neurotoxicology, v.19, n.2, p.269-281,1998a.

ASCHNER M. Immune and inflammatory responses in the CNS: modulation by astrocytes. Toxicol Lett, v.28, n.102-103, p.283-287, 1998b.

BANATI R. B.; DANIEL S. E.; BLUNT S. B.Glial pathology but absence of apoptotic nigral neurons in long-standing Parkinson's disease. Mov Disord., v.13, n.2, p. 221227. 1998.

BAPTISTA M. A.; DAVE K. D.; SHETH N. P.; DE SILVA S. N.; CARLSON K. M.; AZIZ Y. N.; FISKE B. K.; SHERER T. B.; FRASIER M. A. A strategy for the generation, characterization and distribution of animal models by The Michael J. Fox Foundation for Parkinson's Research. Dis Model Mech., v.6, n.6, p.1316-1324, 2013.

BARBOSA M. T.; CARAMELLI P.; MAIA D. P.; CUNNINGHAM M. C.; GUERRA H. L.; LIMA-COSTA M. F.; CARDOSO F. Parkinsonism and Parkinson's disease in the elderly: a community-based survey in Brazil (the Bambuí study). Mov Disord., v.21, n.6, p. 800-808, 2006.

BAYLISS D. A.; BARHANIN J., GESTREAU C.; GUYENET P. G. The role of pHsensitive TASK channels in central respiratory chemoreception. Pflugers Arch., v.467, n.5, p.917-929, 2015.

BEAL, M.F. Mitochondria and neurodegeneration. Novartis Found Symp., v.287: 183-92; discussion 192-196, 2007.

BENARROCH E. E., SCHMEICHEL A. M., LOW P. A., PARISI J. E. Depletion of ventromedullary NK-1 receptorimmunoreactive neurons in multiple system atrophy. Brain. A Journal of Neurology., v.126, p. 2183-2190, 2003.

\footnotetext{
De acordo com: ASSOCIAÇÃO BRASILEIRA DE NORMAS TÉCNICAS. NBR
} 6023: informação e documentação: referências: elaboração. Rio de Janeiro, 2002. 
BIANCHI A. L.; DENAVIT-SAUBIÉ M.; CHAMPAGNAT J. Central control of breathing in mammals: neuronal circuitry, membrane properties, and neurotransmitters. Physiol Rev., v.75, n.1, p.1-45, 1995.

BICKFORD P. C.; FLOWERS A.; GRIMMIG B. Aging leads to altered microglial function that reduces brain resiliency increasing vulnerability to neurodegenerative diseases. Exp Gerontol., v. 5565, n.17, p.30098-30100, 2017.

BLANDINI F.; ARMENTERO M.T.; MARTIGNONI E. The 6-hydroxydopamine model: news from the past. Parkinsonism Relat Disord. v.14 Suppl 2, p.124-129, 2008.

BLUM D.; TORCH S.; LAMBENG N.; NISSOU M.; BENABID A. L.; SADOUL R.; VERNA J. M. Molecular pathways involved in the neurotoxicity of 6-OHDA, dopamine and MPTP: contribution to the apoptotic theory in Parkinson's disease. Prog Neurobiol., v.65, n.2, p.135-172, 2001.

BLUM-DEGEN D., MÜLLER T.; KUHN W.; GERLACH M.; PRZUNTEK H.; RIEDERER P. Interleukin-1 beta and interleukin- 6 are elevated in the cerebrospinal fluid of Alzheimer's and de novo Parkinson's disease patients. Neurosci Lett, v.202, n.1-2, p.17-20, 1995.

BOVÉ J.; SERRATS J.; MENGOD G.; CORTÉS R.; TOLOSA E.; MARIN C. Neuroprotection induced by the adenosine A2A antagonist CSC in the 6-OHDA rat model of parkinsonism: effect on the activity of striatal output. Exp Brain Res., v.165, v.3, p.362-374, 2005.

BRAVO, P. A. F.; NASSIF, M. C. Doença de Parkinson: terapêutica atual e avançada. Infarma, v.18, n.9, p. 25-29, 2006.

BRONSTEIN J. M.; TAGLIATI M.; ALTERMAN R. L.; LOZANO A. M.; VOLKMANN J.; STEFANI A.; HORAK F. B.; OKUN M. S.; FOOTE K. D.; KRACK P., PAHWA R.; HENDERSON J. M.; HARIZ M. I.; BAKAY R. A.; REZAI A.; MARKS W. J. JR.; MORO E.; VITEK J. L.; WEAVER F. M.; GROSS R. E.; DELONG M. R. Deep brain stimulation for Parkinson disease: an expert consensus and review of key issues. Arch Neurol., v.68, n.2, p.165 -171, 2011.

BROWN L. K. Respiratory dysfunction in Parkinson's disease. Clin Chest Med., v.15, n.4, p. 715-727, 1994.

BROWN T. P., RUMSBY P. C.; CAPLETON A. C.; RUSHTON L.; LEVY L. S. Pesticides and Parkinson's disease--is there a link? Environ Health Perspect., v.114, n.2, p.156-164, 2006.

CALABRESE, V.; LODI, R.; TONON, C.; D'AGATA, V.; SAPIENZA, M.; SCAPAGNINI, G.; MANGIAMELI, A.; PENNISI, G.; STELLA, A. M.; BUTTERFIELD, D. A. Oxidative stress, mitochondrial dysfunction and cellular stress response in Friedreich's ataxia. J Neurol Sci., v.233, n.1-2, p.145-162, 2005.

CANNON J. R.; TAPIAS V.; NA H. M.; HONICK A. S.; DROLET R. E.; GREENAMYRE J. T. A highly reproducible rotenone model of Parkinson's disease. Neurobiol Dis., v.34, n.2, p.279-290, 2009.

CARSON M. J.; DOOSE J. M.; MELCHIOR B.; SCHMID C. D.; PLOIX C. C. CNS immune privilege: hiding in plain sight. Immunol Rev, v.213, p.48-65, 2006. 
CHAO Y.; WONG S. C.; TAN E. K. Evidence of Inflammatory System Involvement in Parkinson's Disease. Biomed Res Int, v. 2014, p.1-9, 2014.

CHENG J. B.; WATSON J. W.; PAZOLES C. J.; ESKRA J. D.; GRIFFITHS R. J.; COHAN V. L.; TURNER C. R.; SHOWELL H. J.; PETTIPHER E. R. The phosphodiesterase type 4 (PDE4) inhibitor CP-80,633 elevates plasma cyclic AMP levels and decreases tumor necrosis factor-alpha (TNFalpha) production in mice: effect of adrenalectomy. J Pharmacol Exp Ther., v.280, n.2, p.621-626,1997.

CHHOR V.; LE CHARPENTIER T.; LEBON S.; ORÉ M. V.; CELADOR I. L.; JOSSERAND J.; DEGOS V.; JACOTOT E.; HAGBERG H.; SÄVMAN K.; MALLARD C.; GRESSENS P.; FLEISS B. Characterization of phenotype markers and neuronotoxic potential of polarised primary microglia in vitro. Brain Behav Immun, v.32, p.70-85, 2013.

CHUDLER E. H.; LU Y. Nociceptive behavioral responses to chemical, thermal and mechanical stimulation after unilateral, intrastriatal administration of 6hydroxydopamine. Brain Res. v.5, n..1213, p.41-47, 2008.

COATES E. L.; LI A.; NATTIE E. E. Widespread sites of brain stem ventilatory chemoreceptors.J Appl Physiol. v.75, p.5-14, 1993.

CONNELLY C. A.; DOBBINS E. G.; FELDMAN J. L. Pre-Bötzinger complex in cats: respiratory neuronal discharge patterns. Brain Res., v. 590, n.1-2, p.337-340, 1992.

CONNELLY C. A.; ELLENBERGER H. H.; FELDMAN J.L. Are there serotonergic projections from raphe and retrotrapezoid nuclei to the ventral respiratory group in the rat? Neurosci Lett., v.105, n.1-2, p. 34-40, 1989.

CORREALE J.; VILLA A. The neuroprotective role of inflammation in nervous system injuries. J Neurol, v.251, n.11, p.1304-1316, 2004.

CUMMINGS J.L. Depression and Parkinson's disease: a review. Am J Psychiatry., v. 149, n.4, p.443-454, 1992.

CZŁONKOWSKA A.; KOHUTNICKA M.; KURKOWSKA-JASTRZEBSKA I.; CZŁONKOWSKI A. Microglial reaction in MPTP (1-methyl-4-phenyl-1,2,3,6tetrahydropyridine) induced Parkinson's disease mice model. Neurodegeneration. $v$. 5, n.2, p.137-143, 1996.

DAMASCENO RS1, TAKAKURA AC, MOREIRA TS. Respiratory and sympathetic chemoreflex regulation by Kölliker-Fuse neurons in rats. Pflugers Arch., v.467, n.2, p. 231-239, 2014.

DEMPSEY J. A.; VEASEY S. C.; MORGAN B. J.; O'DONNELL C. P. Pathophysiology of sleep apnea. Physiol Rev. v.90, n.1, p.47-112, 2010.

DEPINO A. M.; EARL C.; KACZMARCZYK E.; FERRARI C, BESEDOVSKY H.; DEL REY A.; PITOSSI F. J.; OERTEL W. H. Microglial activation with atypical proinflammatory cytokine expression in a rat model of Parkinson's disease. Eur $\mathrm{J}$ Neurosci., v.18, n.10, p.2731-2742, 2003. 
DEUMENS R.; BLOKLAND A.; PRICKAERTS J. Modeling Parkinson's disease in rats: an evaluation of 6-OHDA lesions of the nigrostriatal pathway. Exp Neurol., v.175, n.2, p.303-317, 2002.

DING S. Dynamic reactive astrocytes after focal ischemia. Neural Regen Res. v.9, n.23, p. 2048-2052, 2014.

DUTRA M. F.; JAEGER M.; ILHA J.; KALIL-GASPAR P. I.; MARCUZZO S.; ACHAVAL M. Exercise improves motor deficits and alters striatal GFAP expression in a 6-OHDA-induced rat model of Parkinson's disease. Neurol Sci. v.33, n.5, p.11371144. 2012.

ENG L.F.; GHIRNIKAR R.S. GFAP and astrogliosis. Brain Pathol. v.4, n.3, p.229237, 1994.

ENGELHARDT B. The blood-central nervous system barriers actively control immune cell entry into the central nervous system. Curr Pharm Des, v.14, n.16, p.1555-1565, 2008.

ERLICHMAN J. S.; LEITER J. C.; GOURINE A.V. ATP, glia and central respiratory control. Respir Physiol Neurobiol, v.173, n.3, p.305-311, 2010.

ERRCHIDI S.; MONTEAU R.; HILAIRE G. Noradrenergic modulation of the medullary respiratory rhythm generator in the newborn rat: an in vitro study. $\mathbf{J}$ Physiol., v.443, p. 477-498, 1991.

EZURE K. Synaptic connections between medullary respiratory neurons and considerations on the genesis of respiratory rhythm. Prog Neurobiol., v.35, n.6, p. 429-450, 1990.

EZURE K.; TANAKA I.; SAITO Y. Brainstem and spinal projections of augmenting expiratory neurons in the rat. Neurosci Res., v.45, n.1, p.41-51, 2003.

FALQUETTO B.; TUPPY M.; POTJE S. R.; MOREIRA T. S.; ANTONIALI C.; TAKAKURA A. C. Cardiovascular dysfunction associated with neurodegeneration in an experimental model of Parkinson's disease. Brain Res., v.1657, p.156-166, 2017.

FARINA C.; ALOISI F.; MEINL E. Astrocytes are active players in cerebral innate immunity. Trends Immunol., v.28, n.3, p.138-145, 2007.

FAULL R. L.; LAVERTY R. Changes in dopamine levels in the corpus striatum following lesions in the substantia nigra. Exp Neurol., v.23, n.3, p.332-340, 1969.

FELDMAN J. L.; ELLENBERGER H. H. Central coordination of respiratory and cardiovascular control in mammals. Annu Rev Physiol., v.50, p.593-606, 1988.

FELDMAN J. L.; MITCHELL G. S.; NATTIE E. E. Breathing: rhythmicity, plasticity, chemosensitivity. Annu Rev Neurosci. v.26, p.239-266, 2003.

FELDMAN J.L .Neurophysiology of breathing in mammals. In: Geiger SR(ed) Handbook of Physiology: A critical, Comprehensive Presentation of Physiological Knowledge and Concepts, section 1, the Nervous System, v. 4, p. 463-524, 1986. 
FELDMAN J.L.; DEL NEGRO C. A.; GRAY P.A. Understanding the rhythm of breathing: so near, yet so far. Annu Rev Physiol. v.75, p.423-452, 2013.

FERNÁNDEZ-CHECA, J. C.; FERNÁNDEZ, A.; MORALES, A.; MARÍ, M.; GARCÍARUIZ, C.; COLLEL, A. Oxidative stress and altered mitochondrial function in neurodegenerative diseases: lessons from mouse models. CNS Neurol Disord Drug Targets., v.9, n.4, p.439-454, 2010.

FERREIRA C. B.; SCHOORLEMMER G. H.; ROSSI M. V.; TAKAKURA A. C.; BARNA B. F.; MOREIRA T. S.; CRAVO S. L. Brainstem areas activated by intermittent apnea in awake unrestrained rats. Neuroscience., v. 297, p.262-271, 2015.

FREEMAN M. R. Specification and morphogenesis of astrocytes. Science. v.330, n.6005, p. 774-778, 2010.

FUNCHAL C.; DANI C. Neurociências: modelos experimentais em animais. 1. Ed. Porto Alegre: Metodista IPA; EDIPUCRS, 2014.

GALLO V.; DENEEN B. Glial development: the crossroads of regeneration and repair in the CNS. Neuron., v. 83, n.2, p.283-308, 2014.

GAO H. M.; HONG J. S. Why neurodegenerative diseases are progressive: uncontrolled inflammation drives disease progression. Trends Immunol., v.29, n.8, p.357-365, 2008.

GESTREAU C.; HEITZMANN D.; THOMAS J.; DUBREUIL V.; BANDULIK S.; REICHOLD M.; BENDAHHOU S.; PIERSON P.; STERNER C.; PEYRONNET-ROUX J.; BENFRIHA C.; TEGTMEIER I.; EHNES H.; GEORGIEFF M.; LESAGE F.; BRUNET J. F.; GORIDIS C.; WARTH R.; BARHANIN J. Task2 potassium channels set central respiratory CO2 and O2 sensitivity. Proc Natl Acad Sci U S A., v.107,n.5, p. 2325-2330, 2010.

GILMAN S.; CHERVIN R. D.; KOEPPE R. A.; CONSENS F. B.; LITTLE R. Obstructive leep apnea is related to a thalamic cholinergic deficit in MSA. Neurology, v.61, n.1, p.35-39, 2003.

GJERSTAD M.; WENTZEL-LARSEN T.; AARSLAND D.; LARSEN J. Insomnia in Parkinson's disease: frequency and progression over time. J Neurol Neurosurg Psychiatry. v.78, p.476-479, 2007.

GLEZER I.; SIMARD A. R.; RIVEST S. Neuroprotective role of the innate immune system by microglia. Neuroscience, v.147, n.4, p.867-883, 2007.

GÖBEL, K.; ERB, C. Neurological disorders and glaucoma - an overview. Klin Monbl Augenheilkd, v.231, n.2, p.130-135, 2014.

GOEDERT M.; SPILLANTINI M. G.; DEL TREDICI K., BRAAK H. 100 years of Lewy pathology. Nat Rev Neurol,v.9, n.1, p.13-24, 2013.

GOMES F. C. A.; TORTELLI V. P.; DINIZ L. Glia: dos velhos conceitos às novas funções de hoje e as que ainda virão. Estud. av. v.27, n.77, p.61-84, 2013. 
GOURINE A. V.; KASYMOV V.; MARINA N.; TANG F.; FIGUEIREDO M. F.; LANE S.; TESCHEMACHER A. G.; SPYER K. M.; DEISSEROTH K.; KASPAROV $S$. Astrocytes control breathing through pH-dependent release of ATP. Science, v.329, n.5991, p.571-575, 2010.

GUYENET P. G.; BAYLISS D. A. Neural Control of Breathing and CO2 Homeostasis. Neuron. v.87, n.5, p.946-961, 2015.

GUYENET P. G.; BAYLISS D. A.; STORNETTA R. L.; LUDWIG M. G.; KUMAR N. N.; SHI Y.; BURKE P. G.; KANBAR R.; BASTING T. M.; HOLLOWAY B. B.; WENKER I. C. Proton detection and breathing regulation by the retrotrapezoid nucleus. J Physiol., v.594, n.6, p. 1529-1551, 2016.

GUYENET P. G.; STORNETTA R. L.; BAYLISS D. A.; MULKEY D. K. Retrotrapezoid nucleus: a litmus test for the identification of central chemoreceptors. Exp Physiol. v.90, n.3, p. 247-253, 2005.

HALLIDAY G.M.; CULLEN K. M.;. KRIL J. J.; HARDING A. J.; HARASTY J. Glial fibrillary acidic protein (GFAP) immunohistochemistry in human cortex: a quantitative study using different antisera. Neurosci Lett. v.209, n.1, p.29-32, 1996.

HASSE, D. C. B. V.; MACHADO, D. C.; OLIVEIRA, J. G. D. Atuação da fisioterapia no paciente com doença de Parkinson. Fisioter. Mov., v. 21, n. 1, p. 79-85, 2008.

HE Y.; APPEL S.; LE W. Minocycline inhibits microglial activation and protects nigral cells after 6-hydroxydopamine injection into mouse striatum. Brain Res., v.909, n.12, p.187-193, 2001.

HIRSCH E. C. Glial cells and Parkinson's disease. J Neurol, v.247, n. 2:II, p.58-62, 2000.

HIRSCH E. C.; BREIDERT T.; ROUSSELET E.; HUNOT S.; HARTMANN A.; MICHEL P. P. The role of glial reaction and inflammation in Parkinson's disease. Ann N Y Acad Sci, v.991, p.214-228, 2003.

HIRSCH E. C.; VYAS S.; HUNOT S. Neuroinflammation in Parkinson's disease. Parkinsonism Relat Disord., v.18 Suppl 1:S210-212, 2012.

HUCKSTEPP R. T.; DALE N. Redefining the components of central CO2 chemosensitivity--towards a better understanding of mechanism. J Physiol. v.589, n.(Pt 23), p.5561-5579, 2011.

HUGHES A. J.; DANIEL S. E.; BLANKSON S.; LEES A. J. A clinicopathologic study of 100 cases of Parkinson's disease. Arch Neurol., v.50, n.2, p.140-148, 1993.

IMAI Y.; KOHSAKA S. Intracellular signaling in M-CSF-induced microglia activation: role of lba1. Glia, v.40, n.2, p.164-174, 2002.

IMAMURA K.; HISHIKAWA N., SAWADA M.; NAGATSU T.; YOSHIDA M.; HASHIZUME Y. Distribution of major histocompatibility complex class II-positive microglia and cytokine profile of Parkinson's disease brains. Acta Neuropathol., v.6, p.518-526, 2003. 
KANG B. J.; CHANG D. A.; MACKAY D. D.; WEST G. H.; MOREIRA T. S.; TAKAKURA A. C.; GWILT J. M.; GUYENET P. G.; STORNETTA R. L. Central nervous system distribution of the transcription factor Phox $2 b$ in the adult rat. $\mathbf{J}$ Comp Neurol., v.503, n.5, p.627-641, 2007.

KOHUTNICKA M.; LEWANDOWSKA E.; KURKOWSKA-JASTRZEBSKA I.; CZŁONKOWSKI A.; CZŁONKOWSKA A. Microglial and astrocytic involvement in a murine model of Parkinson's disease induced by 1-methyl-4-phenyl-1,2,3,6tetrahydropyridine (MPTP). Immunopharmacology, v.39, n.3, p.167-180, 1998.

KUMAR N. N.; VELIC A.; SOLIZ J.; SHI Y.; LI K.; WANG S.; WEAVER J. L. SEN J.; ABBOTT S. B.; LAZARENKO R. M.; LUDWIG M. G.; PEREZ-REYES E.; MOHEBBI N.; BETTONI C.; GASSMANN M.; SUPLY T.; SEUWEN K.; GUYENET P. G.; WAGNER C. A.; BAYLISS D. A. PHYSIOLOGY. Regulation of breathing by $\mathrm{CO}_{2}$ requires the proton-activated receptor GPR4 in retrotrapezoid nucleus neurons. Science., v. 348, n.6240, p.1255-1260, 2015.

KUMAR P.; KAUNDAL R. K.; MORE S.; SHARMA S. S. Beneficial effects of pioglitazone on cognitive impairment in MPTP model of Parkinson's disease. Behav Brain Res, v.197, n.2, p.398-403, 2009.

KUWAKI T.; LI A.; NATTIE E. State-dependent central chemoreception: A role of orexin. Respir Physiol Neurobiol. v.173, p.223-229, 2010.

LEE C. S.; SAUER H.; BJORKLUND A. Dopaminergic neuronal degeneration and motor impairments following axon terminal lesion by instrastriatal 6-hydroxydopamine in the rat. Neuroscience. v.72, n.3, p.641-653, 1996.

LEE K. M.; MACLEAN A. G. New advances on glial activation in health and disease. World J Virol. v.4, n.2, p.42-55, 2015.

LEES A. J.; BLACKBURN N. A.; CAMPBELL V.L. The nighttime problems of Parkinson's disease. Clin Neuropharmacol. v.11, n.6, p. 512-519, 1988.

LIDDELOW S. A.; GUTTENPLAN K. A.; CLARKE L. E.; BENNETT F. C.; BOHLEN C. J.; SCHIRMER L.; BENNETT M. L.; MÜNCH A. E.; CHUNG W.; PETERSON T. C.; WILTON D. K.; FROUIN A.; NAPIER B. A.; PANICKER N.; KUMAR M.; BUCKWALTER M. S.; ROWITCH D. H.; DAWSON V. L.; DAWSON T. M.; STEVENS B.; BARRES B. A. Neurotoxic reactive astrocytes are induced by activated microglia. Nature., v. 541, n.7638, p.481-487, 2017.

LIN, M. T; BEAL, M. F. Mitochondrial dysfunction and oxidative stress in neurodegenerative diseases. Nature, v.443, n.7113, p.787-795, 2006.

LIU B.; HONG J. S. Role of microglia in inflammation-mediated neurodegenerative diseases: mechanisms and strategies for therapeutic intervention. J Pharmacol Exp Ther, v.304, n.1, p.1-7, 2003.

LOESCHCKE H. H. Central chemosensitivity and the reaction theory. J Physiol. v.332, p.1-24, 1982.

LONG-SMITH C.M.; SULLIVAN A. M.; NOLAN Y. M. The influence of microglia on the pathogenesis of Parkinson's disease. Prog Neurobiol., v.89, n.3, p.277-287, 2009. 
LUDWIG M. G.; VANEK M.; GUERINI D.; GASSER J. A.; JONES C. E.; JUNKER U.; HOFSTETTER H.; WOLF R. M.; SEUWEN K. Proton-sensing G-protein-coupled receptors. Nature. v.425, n.6953, p.93-98, 2003.

MAGEN I.; CHESSELET M. F. Genetic mouse models of Parkinson's disease The state of the art. Prog Brain Res., v.184, p.53-87, 2010.

MALHOTRA S. K.; SHNITKA T. K.; ELBRINK J. Reactive astrocytes--a review. Cytobios. v.61, n.246-247, p.133-160, 1990.

MARAGAKIS N. J.; ROTHSTEIN J. D. Mechanisms of Disease: astrocytes in neurodegenerative disease. Nat Clin Pract Neurol. v.2, n.12, p.679-689, 2006.

MARTENS E. K. A.; LEWIS S. J.; Pathology of behavior in PD: What is known and what is not? J Neurol Sci., v.15, n.374, p.9-16, 2017.

MCDOWELL K.; CHESSELET M. F. Animal models of the non-motor features of Parkinson's disease. Neurobiol Dis, v.46, n.3, p.597-606, 2012.

MCGEER P. L.; MCGEER E. G. Glial reactions in Parkinson's disease. Mov Disord., v.15, n.23, p. 474-483, 2008.

MEHANNA R.; JANKOVIC J. Respiratory problems in neurologic movement disorders. Parkinsonism Relat Disord, v.16, n.10, p.628-638, 2010.

MELO L M.; BARBOSA E. R.; CARAMELLI P. Declínio cognitivo e demência associados à doença de Parkinson: características clínicas e tratamento. Rev. Psiq. Clín., v.34, n.4, p.176-183, 2007.

MENKES H. A.; DUBOIS A. B. Subtraction of cardiopneumatic pulsations from body plethysmograph records. J Appl Physiol., v.27, n.6, p.910-911, 1969.

MIDDELDORP J.; HOL E. M. GFAP in health and disease. Prog Neurobiol., v.93, n.3, p.421-443, 2011.

MIRZA B.; HADBERG H.; THOMSEN P.; MOOS T. The absence of reactive astrocytosis is indicative of a unique inflammatory process in Parkinson's disease. Neuroscience, v.95, n.2, p. 425-432, 2000.

MITCHELL R. A.; LOESCHCKE H. H.; MASSION W. H.; SEVERINGHAUS J. W. Respiratory responses mediated through superficial chemosensitive areas on the medulla.J Appl Physiol. v.96, p.523-533,1963.

MONTGOMERY D. L. Astrocytes: form, functions, and roles in disease. Vet Pathol. v.31, n.2, p.145-167, 1994.

MOREIRA T. S.; TAKAKURA A. C.; CZEISLER C.; OTERO J. J. Respiratory and autonomic dysfunction in congenital central hypoventilation syndrome. J Neurophysiol., v.116, n.2, p.742-752, 2016.

MOREIRA T. S.; WENKER I. C.; SOBRINHO C. R.; BARNA B. F.; TAKAKURA A. C.; MULKEY D. K. Independent purinergic mechanisms of central and peripheral chemoreception in the rostral ventrolateral medulla. J Physiol. v.593, n.5, p.10671074, 2015. 
MOTA B.; HERCULANO-HOUZEL S. All brains are made of this: a fundamental building block of brain matter with matching neuronal and glial masses. Front Neuroanat. v.8, art. 127, 2014.

MULKEY D. K.; ROSIN D.L.; WEST G.; TAKAKURA A. C.; MOREIRA T.S.; BAYLISS D. A.; GUYENET P. G. Serotonergic neurons activate chemosensitive retrotrapezoid nucleus neurons by a pH-independent mechanism. J Neurosci. v.27, n.51, p.1412814138, 2007.

MULKEY D. K.; STORNETTA R. L.; WESTON M. C.; SIMMONS J. R.; PARKER A.; BAYLISS D. A.; GUYENET P. G. Respiratory control by ventral surface chemoreceptor neurons in rats. Nat Neurosci. v.7, p.1360-1369, 2004.

MURAKAMI N.; YOKOMIZO T.; OKUNO T.; SHIMIZU T. G2A is a proton-sensing Gprotein-coupled receptor antagonized by lysophosphatidylcholine. J Biol Chem. v. 279, n.41, p.42484-42491, 2004.

NASHEF L.; WALKER F.; ALLEN P.; SANDER J. W.; SHORVON S. D.; FISH D. R. Apnoea and bradycardia during epilepticseizures: relation to sudden death inepilepsy. J Neurol Neurosurg Psychiatry., v.60, n.3, p.297-300, 1996.

NATTIE E. CO2, brainstem chemoreceptors and breathing. Prog Neurobiol., v.59, n.4, p.299-331, 1999.

NATTIE E.E.; LI A. Substance P-saporin lesion of neurons with NK1 receptors in one chemoreceptor site in rats decreases ventilation and chemosensitivity. J Physiol. v.544 (Pt 2), p.603-616, 2002.

NEUMANN H. Control of glial immune function by neurons. Glia, v.36, n.2, p.191199, 2001.

NIEMEYER M. I.; CID L. P.; PEÑA-MÜNZENMAYER G.; SEPÚLVEDA F. V. Separate gating mechanisms mediate the regulation of K2P potassium channel TASK-2 by intra- and extracellular pH. J Biol Chem., v. 285, n.22, p.16467-16475, 2010.

NIMMERJAHN A.; KIRCHHOFF F.; HELMCHEN F. Resting microglial cells are highly dynamic surveillants of brain parenchyma in vivo. Science., v.308, n. 5726, pag. 1314-1318, 2005.

NOGUÉS M. A.; RONCORONI A. J.; BENARROCH E. Breathing control in neurological diseases. Clin Auton Res, v.12, n.6, p.440-449, 2002.

OBESO J. A.; RODRÍGUEZ-OROZ M. C.; RODRÍGUEZ M.; LANCIEGO J. L.; ARTIEDA J.; GONZALO N.; OLANOW C. W.; Pathophysiology of the basal ganglia in Parkinson's disease. Trends Neurosci., v.23, 10 Suppl, p.S8-19, 2000.

OHSAWA K.; IMAI Y.; SASAKI Y.; KOHSAKA S. Microglia/macrophage-specific protein Iba1 binds to fimbrin and enhances its actin-bundling activity. J Neurochem., v.88, n.4, p.844-856, 2004.

PALMERI R.; BUONO V. L.; CORALLO F.; FOTI M.; LORENZO G.; BRAMANTI P.; MARINO S. Nonmotor Symptoms in Parkinson Disease: A Descriptive Review on 
Social Cognition Ability. Journal of Geriatric Psychiatry and Neurology. v. 30, n.2, p. 109-121, 2017.

PAXINOS G, WATSON C. The rat brain in stereotaxic coordinates. Academic Press, New York, 1998.

PEKNY M.; LEVEEN P.; PEKNA M.; ELIASSON C.; BERTHOLD C. H.; WESTERMARK B.; BETSHOLTZ C. Mice lacking glial fibrillary acidic protein display astrocytes devoid of intermediate filaments but develop and reproduce normally. EMBO J. v.14, n.8, p.1590-1598, 1995.

PEKNY M.; PEKNA M. Astrocyte Reactivity and Reactive Astrogliosis: Costs and Benefits. Physiological Reviews. v.94, n.4, p. 1077-1098, 2014.

PRENDERGAST C. T.; ANDERTON S.M. Immune cell entry to central nervous system-current understanding and prospective therapeutic targets. Endocr Metab Immune Disord Drug Targets, v.9, n.4, p.315-327, 2009.

PRZEDBORSKI S.; LEVIVIER M.; JIANG H.; FERREIRA M.; JACKSON-LEWIS V.; DONALDSON D.; TOGASAKI D. M. Dose-dependent lesions of the dopaminergic nigrostriatal pathway induced by intrastriatal injection of 6-hydroxydopamine. Neuroscience, v.67, n.3, p.631-647, 1995.

PURISAI M. G.; MCCORMACK A. L.; CUMINE S.; LI J.; ISLA M. Z.; DI MONTE D. A. Microglial activation as a priming event leading to paraquat-induced dopaminergic cell degeneration. Neurobiol Dis, v.25, n.2, p.392-400, 2007.

QUINLAN R. A.; BRENNER M.; GOLDMAN J. E.; MESSING A. GFAP and its role in Alexander disease. Exp Cell Res., v.313, n.10, p.2077-2087, 2007.

RADU C. G.; NIJAGAL A.; MCLAUGHLIN J.; WANG L.; WITTE O. N. Differential proton sensitivity of related $G$ protein-coupled receptors $T$ cell death-associated gene 8 and G2A expressed in immune cells. Proc Natl Acad Sci U S A., v.102, n.5, p.1632-1637, 2005.

RAJPUT A. H. Levodopa prolongs life expectancy and is non-toxic to substantia nigra. Parkinsonism Relat Disord. v.8, n.2, p.95-100, 2001.

RAPPOLD P. M.; TIEU K. Astrocytes and therapeutics for Parkinson's disease. Neurotherapeutics. v.7, n.4, p.413-423, 2010.

RICHTER D. W. Generation and maintenance of the respiratory rhythm. J Exp Biol. v. 100, p.93-107, 1982.

RICHTER D. W.; SPYER K. M. Studying rhythmogenesis of breathing: comparison of in vivo and in vitro models. Trends Neurosci. v.4, n.8, p.464-472, 2001.

ROSIN D. L.; CHANG D. A.; GUYENET P. G. Afferent and efferent connections of the rat retrotrapezoid nucleus. J Comp Neurol. v.499, n.1, p.64-89, 2006.

SASAKI Y.; OHSAWA K.; KANAZAWA H.; KOHSAKA S.; IMAI Y. Iba1 is an actincross-linking protein in macrophages/microglia. Biochem Biophys Res Commun., v.286, n.2, p.292-297, 2001. 
SAWADA M.; IMAMURA K.; NAGATSU T. Role of cytokines in inflammatory process in Parkinson's disease. J Neural Transm Suppl., v.70, p.373-381, 2006.

SCHIESS M. C.; BARNES J. L.; ELLMORE T. M.; POINDEXTER B. J.; DINH K.; BICK R. J. CSF from Parkinson disease patients differentially affects cultured microglia and astrocytes. BMC Neurosci. v.11, n.151, p. 1-9, 2010.

SCHREIHOFER A. M; GUYENET P. G. Identification of C1 presympathetic neurons in rat rostral ventrolateral medulla by juxtacellular labeling in vivo. J Comp Neurol, v.387, n.4, p.524-536, 1997.

SCHULZ J. B.; FALKENBURGER B. H. Neuronal pathology in Parkinson's disease. Cell Tissue Res. v.318, n.1, p.135-147, 2004.

SCHWARTING R. K.; HUSTON J. P. Unilateral 6-hydroxydopamine lesions of mesostriatal dopamine neurons and their physiological sequelae. Prog Neurobiol, v.49, n.3, p.215-266, 1996.

SCHWARTZ M.; ZIV Y. Immunity to self and self-maintenance: a unified theory of brain pathologies. Trends Immunol, v.29, n.5, p.211-219, 2008.

SECCOMBE L. M.; GIDDINGS H. L.; ROGERS P. G.; CORBETT A. J.; HAYES M. W.; PETERS M. J.; VEITCH E. M. Abnormal ventilatory control in Parkinson's disease--further evidence for non-motor dysfunction. Respir Physiol Neurobiol., v.179, n.2-3, p.300-304, 2011.

SEIDL, S. E.; POTASHKIN, J. A. The promise of neuroprotective agents in Parkinson's disease. Front Neurol, v.2, n.68, p.1-19, 2011.

SHILL H.; STACY M. Respiratory function in Parkinson's disease. Clin Neurosci. v.5, n.2, p.131-135, 1998.

SHIMADA A.; UEMURA T.; YAMAMURA Y.; KOJIMA S.; MORITA T.; UMEMURA T. Localization of metallothionein-I and -II in hypertrophic astrocytes in brain lesions of dogs. J Vet Med Sci. v.60, n.3, p. 351-358, 1998.

SILVESTRELLI G.; LANARI A.; DROGHETTI A. Ventilatory disorders. Front Neurol Neurosci. v.30, p.90-93, 2012.

SMEYNE M.; JIAO Y.; SHEPHERD K. R.; SMEYNE R. J. Glia cell number modulates sensitivity to MPTP in mice. Glia, v.52, n.2, p.144-152, 2005.

SMITH J. C.; ABDALA A. P.; BORGMANN A.; RYBAK I. A.; PATON J. F. Brainstem respiratory networks: building blocks and microcircuits. Trends Neurosci. v.36, n.3, p.152-162, 2013.

SMITH J. C.; ABDALA A. P.; KOIZUMI H.; RYBAK I. A.; PATON J. F. Spatial and functional architecture of the mammalian brain stem respiratory network: a hierarchy of three oscillatory mechanisms. J Neurophysiol. v.98, n.6, p.3370-3387, 2007.

SMITH J. C.; ABDALA A. P.; RYBAK I. A.; PATON J. F. Structural and functional architecture of respiratory networks in the mammalian brainstem. Philos Trans $\mathbf{R}$ Soc Lond B Biol Sci. v. 364,n.1529, p.2577-2587, 2009. 
SMITH J. C.; ABDALA A. P; BORGMANN A.; RYBAK I.A.; PATON J. F. Brainstem respiratory networks: building blocks and microcircuits. Trends Neurosci., v. 36, n. 3, p. 152-162, 2013.

SMITH J. C.; ELLENBERGER H. H.; BALLANYI K.; RICHTER D. W.; FELDMAN J. L. Pre-Bötzinger complex: a brainstem region that may generate respiratory rhythm in mammals. Science, v.254, n.5032, p. 726-729, 1991.

SOBRINHO C. R.; WENKER I. C.; POSS E. M.; TAKAKURA A. C.; MOREIRA T. S.; MULKEY D. K. Purinergic signalling contributes to chemoreception in the retrotrapezoid nucleus but not the nucleus of the solitary tract or medullary raphe. $\mathbf{J}$ Physiol. v.592, n.6, p.1309-1323, 2014.

SOFRONIEW M. V.; VINTERS H. V. Astrocytes: biology and pathology. Acta Neuropathol., v.119, n.1, p.7-35 2010.

SOFRONIEW M.V. Molecular dissection of reactive astrogliosis and glial scar formation. Trends Neurosci., v. 32, n.12, p. 638-647, 2009.

SOUZA, C. F. M.; ALMEIDA, H. C. P.; SOUSA, J. B.; COSTA, P. H.; SILVEIRA, Y. S. S.; BEZERRA, J. C. L. A Doença de Parkinson e o Processo de Envelhecimento Motor: Uma Revisão de Literatura. Rev Neurocienc., v.19, n.4, p.718-723, 2011.

SPILLANTINI M.G.; CROWTHER R. A.; JAKES R.; CAIRNS N. J.; LANTOS P.L.; GOEDERT M. Filamentous alpha-synuclein inclusions link multiple system atrophy with Parkinson's disease and dementia with Lewy bodies. Neurosci Lett., v.251, n.3, p.205-208, 1998.

STEIDL, E. M. S.; ZIEGLER, J. R.; FERREIRA, F. V. Doença de Parkinson: Revisão bibliográfica. Disc. Scientia, v.8, n.1, p.115-129, 2007.

STORNETTA R. L.; ROSIN D. L.; WANG H.; SEVIGNY C. P.; WESTON M. C.; GUYENET P. G. A group of glutamatergic interneurons expressing high levels of both neurokinin-1 receptors and somatostatin identifies the region of the preBötzinger complex. J Comp Neurol., v. 455, n.4, p.499-512, 2003.

STORNETTA, R. L. et al. Expression of Phox2b by brainstem neurons involved in chemosensory integration in the adult rat. J. Neurosci., v. 26, n. 40, p. 10305-10314, 2006.

SUBRAMANIAN, H. H.; CHOW C. M.; BALNAVE R. J. Identification of Different Types of Respiratory Neurones in the Dorsal Brainstem Nucleus Tractus Solitarius of the Rat. Brain Res. v.1141, p.119-132, 2007.

SUKHORUKOVA E. G.; KRUZHEVSKIĬ D. É.; ALEKSEEVA O. S. Glial fibrillary acidic protein: the component of intermediate filaments in the vertebrate brain astrocytes. Zh Evol Biokhim Fiziol., v.51, n.1, p.3-10, 2015.

TADAIESKY M. T.; DOMBROWSKI P. A.; FIGUEIREDO C. P.; CARGNINFERREIRA E.; DA CUNHA C.; TAKAHASHI R. N. Emotional, cognitive and neurochemical alterations in a premotor stage model of Parkinson's disease. Neuroscience. v.156, n.4, p.830-840, 2008. 
TAKAKURA A. C.; BARNA B. F.; CRUZ J. C.; COLOMBARI E.; MOREIRA T. S.Phox2b-expressing retrotrapezoid neurons and the integration of central and peripheral chemosensory control of breathing in conscious rats.. Exp. Physiol., v. 99, n. 3, p. 571-585, 2014.

TAKAKURA A. C.; COLOMBARI E.; MENANI J. V.; MOREIRA T. S. Ventrolateral medulla mechanisms involved in cardiorespiratory responses to central chemoreceptor activation in rats. Am. J. Physiol. Regul. Integr. Comp. Physiol., v. 300, n. 2, p. 501-510, 2011.

TAKAKURA A. C.; MOREIRA T. S.; COLOMBARI E.; WEST G. H.; STORNETTA R. L.; GUYENET P. G. Peripheral chemoreceptor inputs to retrotrapezoid nucleus (RTN) $\mathrm{CO}_{2}$-sensitive neurons in rats. J Physiol. v.15, n.572 (Pt 2), p.503-523, 2006.

TAKAKURA A. C.; MOREIRA T. S.; WEST G. H.; GWILT J. M.; COLOMBARI E.; STORNETTA R.; GUYENET P. G. GABAergic pump cells of solitary tract nucleus innervate retrotrapezoid nucleus chemoreceptors. J. Neurophysiol., v. 98, n. 1, p. 374-381, 2007.

TAKAKURA, A. C.; MOREIRA T. S.; STORNETTA R. L.; WEST G. H.; GWILT J. M.; GUYENET P. G. Selective Lesion of Retrotrapezoid Phox2b-Expressing Neurons Raises the Apnoeic Threshold in Rats. J Physiol. v.586, n. 12, p.2975-2991, 2008.

TAKAKURA, A. C.; MOREIRA, T. S. Contribution of excitatory amino acid receptors of the retrotrapezoid nucleus to the sympathetic chemoreflex in rats. Exp. Physiol., v. 96, n. 10, p. 989-999, 2011.

TAN W.; PAGLIARDINI S.; YANG P.; JANCZEWSKI W. A.; FELDMAN J. L. Projections of preBötzinger complex neurons in adult rats. J Comp Neurol., v.518, n.10, p.1862-1878, 2010.

TANG F.; LANE S.; KORSAK A.; PATON J. F.; GOURINE A. V.; KASPAROV S.; TESCHEMACHER A. G. Lactate-mediated glia-neuronal signalling in the mammalian brain. Nat Commun., v. 5, n.3284, 2014.

TANNER C. M.; KAMEL F.; ROSS G. W.; HOPPIN J. A.; GOLDMAN S. M.; KORELL M.; MARRAS C.; BHUDHIKANOK G. S.; KASTEN M.; CHADE A. R.; COMYNS K.; RICHARDS M. B.; MENG C.; PRIESTLEY B.; FERNANDEZ H. H.; CAMBI F.; UMBACH D. M.; BLAIR A.; SANDLER D. P.; LANGSTON J. W. Rotenone, paraquat, and Parkinson's disease. Environ Health Perspect., v.119, n.6, p.866-872, 2011.

TESCHEMACHER A. G.; GOURINE A. V.; KASPAROV S. A Role for Astrocytes in Sensing the Brain Microenvironment and Neuro-Metabolic Integration. Neurochem Res. v.40, n.12, p.2386-2393, 2015.

TILLERSON J. L.; COHEN A. D.; CAUDLE W. M.; ZIGMOND M. J.; SCHALLERT T.; MILLER G. W. Forced nonuse in unilateral parkinsonian rats exacerbates injury. $\mathbf{J}$ Neurosci, v.22, n.15, P.6790-6799, 2002.

TOTOLA L. T.; TAKAKURA A. C.; OLIVEIRA J. A.; GARCIA-CAIRASCO N.; MOREIRA T. S. Impaired central respiratory chemoreflex in an experimental genetic model of epilepsy. J Physiol., v. 595, n.3, p.983-999, 2017. 
TRETIAKOFF C. Contribution à l'étude de l'anatomie pathologique du locus niger de Soemmering avec quelques déductions realtives à la pathogénie de troubles du tônus musculaire et la maladie de Parkinson. Thése de Médecine, Paris, 1919.

TROUTH C. O.; LOESCHCKE H. H.; BERNDT J. Topography of the respiratory responses to electrical stimulation in the medulla oblongata. Pflugers Arch. v.339, p.153-170,1973.

TUFEKCI K.U.; MEUWISSEN R.; GENC S.; GENC K. Inflammation in Parkinson's disease. Adv Protein Chem Struct Biol., v.88, p.69-132, 2012.

TUPPY M.; BARNA B. F.; ALVES-DOS-SANTOS L.; BRITTO L. R.; CHIAVEGATTO S.; MOREIRA T. S.; TAKAKURA A. C. Respiratory deficits in a rat model of Parkinson's disease. Neuroscience, v.297, p.194-204, 2015.

TZELEPIS G. E.; MCCOOL F. D.; FRIEDMAN J. H.; HOPPIN F. G. JR. Respiratory muscle dysfunction in Parkinson's disease. Am Rev Respir Dis. v.138, n.2, p.266$271,1988$.

WALLIMANN, T.; TOKARSKA-SCHLATTNER, M.; SCHLATTNER, U. The creatine kinase system and pleiotropic effects of creatine. Amino Acids., v.40, n.5, p.12711296, 2011.

WANG A.; COSTELLO S.; COCKBURN M, ZHANG X.; BRONSTEIN J.; RITZ B. Parkinson's disease risk from ambient exposure to pesticides. Eur $\mathbf{J}$ Epidemiol., v.26, n.7, p. 547-555, 2011.

WANG S.; BENAMER N.; ZANELLA S.; KUMAR N. N.; SHI Y.; BÉVENGUT M.; PENTON D.; GUYENET P. G.; LESAGE F.; GESTREAU C.; BARHANIN J.; BAYLISS D. A. TASK-2 channels contribute to $\mathrm{pH}$ sensitivity of retrotrapezoid nucleus chemoreceptor neurons. J Neurosci., v.33, n.41, p.16033-16044, 2013.

WERMUTH L.; STENAGER E. N.; STENAGER E.; BOLDSEN J. Mortality in patients with Parkinson's disease. Acta Neurol Scand., v.92, n.1, p.55-58, 1995.

WORLD HEALTH ORGANIZATION (WHO). Neurological disorders affect millions globally: WHO report. 2007. Disponível em: < http://www.who.int/mediacentre/news/releases/2007/pr04/en/ >. Acesso em: 19 mai. 2015.

YOKOYAMA H.; UCHIDA H.; KUROIWA H.; KASAHARA J.; ARAKI T. Role of glial cells in neurotoxin-induced animal models of Parkinson's disease. Neurol Sci, v.2, n.1,p.1-7, 2011.

ZHU C.; VOURC'H P.; FERNAGUT P. O.; FLEMING S. M.; LACAN S.; DICARLO C. D.; SEAMAN R. L.; CHESSELET M. F. Variable effects of chronic subcutaneous administration of rotenone on striatal histology. J Comp Neurol., v.478, n.4, p.41826, 2004.

ZUCH C. L.; NORDSTROEM V. K.; BRIEDRICK L. A.; HOERNIG G. R.; GRANHOLM A. C.; BICKFORD P. C. Time course of degenerative alterations in nigral dopaminergic neurons following a 6-hydroxydopamine lesion. J Comp Neurol., v. 427, n.3, p.440-454, 2000. 